Cochrane Database of Systematic Reviews

\title{
Inhaled corticosteroids versus sodium cromoglycate in children and adults with asthma (Review)
}

Guevara JP, Ducharme FM, Keren R, Nihtianova S, Zorc J

Guevara JP, Ducharme FM, Keren R, Nihtianova S, Zorc J.

Inhaled corticosteroids versus sodium cromoglycate in children and adults with asthma.

Cochrane Database of Systematic Reviews 2006, Issue 2. Art. No.: CD003558.

DOI: 10.1002/14651858.CD003558.pub2.

www.cochranelibrary.com

Inhaled corticosteroids versus sodium cromoglycate in children and adults with asthma (Review) 
TABLE OF CONTENTS

HEADER

ABSTRACT

PLAIN LANGUAGE SUMMARY

1

BACKGROUND

OBJECTIVES

METHODS

RESULTS

DISCUSSION

AUTHORS' CONCLUSIONS

ACKNOWLEDGEMENTS

\section{REFERENCES}

\section{CHARACTERISTICS OF STUDIES}

DATA AND ANALYSES

Analysis 1.1. Comparison 1 Inhaled Corticosteroids vs Cromolyn for Children, Outcome 1 Exacerbations (mean number per patient per year).

Analysis 1.2. Comparison 1 Inhaled Corticosteroids vs Cromolyn for Children, Outcome 2 Exacerbations (\%).

Analysis 1.3. Comparison 1 Inhaled Corticosteroids vs Cromolyn for Children, Outcome 3 FEV1(GIV).

Analysis 1.4. Comparison 1 Inhaled Corticosteroids vs Cromolyn for Children, Outcome 4 PEF(GIV).

Analysis 1.5. Comparison 1 Inhaled Corticosteroids vs Cromolyn for Children, Outcome 5 School Absence (mean days per patient per year).

Analysis 1.6. Comparison 1 Inhaled Corticosteroids vs Cromolyn for Children, Outcome 6 Nights Disturbed by Asthma (mean nights per patient per year).

Analysis 1.7. Comparison 1 Inhaled Corticosteroids vs Cromolyn for Children, Outcome 7 Asthma Symtom Score(GIV). .......... Analysis 1.8. Comparison 1 Inhaled Corticosteroids vs Cromolyn for Children, Outcome 8 Asthma Free Days (mean days per patient).

Analysis 1.9. Comparison 1 Inhaled Corticosteroids vs Cromolyn for Children, Outcome 9 Rescue Bronchodilator Use(GIV). .... Analysis 1.10. Comparison 1 Inhaled Corticosteroids vs Cromolyn for Children, Outcome 10 Rescue Bronchodilator Use(\%). ... Analysis 1.11. Comparison 1 Inhaled Corticosteroids vs Cromolyn for Children, Outcome 11 General Practitioner Visits (mean visits per patient per year).

Analysis 1.12. Comparison 1 Inhaled Corticosteroids vs Cromolyn for Children, Outcome 12 Emergency Department Visits (mean visits per patient per year).

Analysis 1.13. Comparison 1 Inhaled Corticosteroids vs Cromolyn for Children, Outcome 13 Hospitalizations (mean hospitalizations per patient per year).

Analysis 1.14. Comparison 1 Inhaled Corticosteroids vs Cromolyn for Children, Outcome 14 Hospitalizations (\%). .................. Analysis 1.15. Comparison 1 Inhaled Corticosteroids vs Cromolyn for Children, Outcome 15 Growth (mean cm per patient per year).

Analysis 1.16. Comparison 1 Inhaled Corticosteroids vs Cromolyn for Children, Outcome 16 Oropharyngeal Side Effects (\%). ... Analysis 1.17. Comparison 1 Inhaled Corticosteroids vs Cromolyn for Children, Outcome 17 Adrenal Suppession (mean nmol urinary cortisol per patient per day).

Analysis 1.18. Comparison 1 Inhaled Corticosteroids vs Cromolyn for Children, Outcome 18 Total Adverse Events (\%). ............ Analysis 1.19. Comparison 1 Inhaled Corticosteroids vs Cromolyn for Children, Outcome 19 Quality of life (mean score per patient per year).

Analysis 2.1. Comparison 2 Inhaled Corticosteroids vs Cromolyn for Children by Asthma Severity, Outcome 1 FEV1(GIV). ........ Analysis 2.2. Comparison 2 Inhaled Corticosteroids vs Cromolyn for Children by Asthma Severity, Outcome 2 PEF(GIV). ......... Analysis 3.1. Comparison 3 Inhalded Corticosteroids vs Cromolyn for Children by BDP-equivalent Steroid Dosage, Outcome 1 FEV1 (GIV).

Analysis 3.2. Comparison 3 Inhalded Corticosteroids vs Cromolyn for Children by BDP-equivalent Steroid Dosage, Outcome 2 PEF(GIV).

Analysis 4.1. Comparison 4 Inhaled Corticosteroids vs Cromolyn for Children by Study Quality, Outcome 1 FEV1(GIV).

Analysis 4.2. Comparison 4 Inhaled Corticosteroids vs Cromolyn for Children by Study Quality, Outcome 2 PEF(GIV). .............. Analysis 5.1. Comparison 5 Inhaled Corticosteroids vs Cromolyn for Children by Cromolyn Dosage, Outcome 1 FEV1(GIV). ..... Analysis 5.2. Comparison 5 Inhaled Corticosteroids vs Cromolyn for Children by Cromolyn Dosage, Outcome 2 PEF(GIV). ....... 
Analysis 6.1. Comparison 6 Inhaled Corticosteroids vs Cromolyn for Adults, Outcome 1 Exacerbations (mean number per patient per 6 months).

Analysis 6.2. Comparison 6 Inhaled Corticosteroids vs Cromolyn for Adults, Outcome 2 Exacerbations (\%).

Analysis 6.3. Comparison 6 Inhaled Corticosteroids vs Cromolyn for Adults, Outcome 3 FEV(GIV).

Analysis 6.4. Comparison 6 Inhaled Corticosteroids vs Cromolyn for Adults, Outcome 4 PEF(GIV).

Analysis 6.5. Comparison 6 Inhaled Corticosteroids vs Cromolyn for Adults, Outcome 5 Asthma Symptom Score(GIV).

Analysis 6.6. Comparison 6 Inhaled Corticosteroids vs Cromolyn for Adults, Outcome 6 Rescue Bronchodilator Use (GIV). ......

Analysis 6.7. Comparison 6 Inhaled Corticosteroids vs Cromolyn for Adults, Outcome 7 Oropharyngeal Side Effects (\%). ........

Analysis 6.8. Comparison 6 Inhaled Corticosteroids vs Cromolyn for Adults, Outcome 8 Total Adverse Events (\%).

Analysis 7.1. Comparison 7 Inhaled Corticosteroids vs Cromolyn for Adults by Asthma Severity, Outcome 1 FEV1(GIV).

Analysis 7.2. Comparison 7 Inhaled Corticosteroids vs Cromolyn for Adults by Asthma Severity, Outcome 2 PEF(GIV).

Analysis 8.1. Comparison 8 Inhaled Corticosteroids vs Cromolyn for Adults by Study Quality, Outcome 1 FEV1(GIV).

Analysis 8.2. Comparison 8 Inhaled Corticosteroids vs Cromolyn for Adults by Study Quality, Outcome 2 PEF(GIV).

Analysis 9.1. Comparison 9 Inhaled Corticosteroids vs Cromolyn for Adults by Cromolyn Dosage, Outcome 1 FEV1(GIV).

Analysis 9.2. Comparison 9 Inhaled Corticosteroids vs Cromolyn for Adults by Cromolyn Dosage, Outcome 2 PEF(GIV). ADDITIONAL TABLES

WHAT'S NEW

HISTORY

CONTRIBUTIONS OF AUTHORS

DECLARATIONS OF INTEREST

INDEX TERMS 
[Intervention Review]

\section{Inhaled corticosteroids versus sodium cromoglycate in children and adults with asthma}

James P Guevara1 ${ }^{1}$, Francine M Ducharme², Ron Keren ${ }^{3}$, Snejana Nihtianova ${ }^{4}$, Joseph Zorc ${ }^{5}$

1Department of Pediatrics, University of Pennsylvania School of Medicine, Philadelphia, PA, USA. 2Research Centre, CHU Sainte-Justine, Montreal, Canada. ${ }^{3}$ Department of Pediatrics, The Children's Hospital of Philadelphia, Philadelphia, USA. ${ }^{4}$ Pediatrics, The Children's Hospital of Philadelphia, Philadelphia, PA, USA. 5Divisions of Pediatric Emergency Medicine, Department of Pediatrics, Children's Hospital of Philadelphia, Philadelphia, USA

Contact address: James P Guevara, Department of Pediatrics, University of Pennsylvania School of Medicine, The Children's Hospital of Philadelphia, 34th and Civic Center Blvd, Philadelphia, PA, 19104, USA. guevara@email.chop.edu.

Editorial group: Cochrane Airways Group

Publication status and date: Edited (no change to conclusions), published in Issue 3, 2009.

Citation: Guevara JP, Ducharme FM, Keren R, Nihtianova S, Zorc J. Inhaled corticosteroids versus sodium cromoglycate in children and adults with asthma. Cochrane Database of Systematic Reviews 2006, Issue 2. Art. No.: CD003558. DOI: 10.1002/14651858.CD003558.pub2.

Copyright $\odot 2009$ The Cochrane Collaboration. Published by John Wiley \& Sons, Ltd.

\section{A B S T R A C T}

\section{Background}

Inhaled corticosteroids (ICS) and sodium cromoglycate (SCG) have become established as effective controller medications for children and adults with asthma, but their relative efficacy is not clear.

\section{Objectives}

To compare the relative effectiveness and adverse effects of ICS and SCG among children and adults with chronic asthma.

\section{Search methods}

Systematic search of the Cochrane Airways Group's special register of controlled trials (to Feb. 2004), hand searches of the reference lists of included trials and relevant review papers, and written requests for identification of additional trials from pharmaceutical manufacturers.

\section{Selection criteria}

Randomized controlled trials comparing the effect of ICS with SCG in children and adults with chronic asthma.

\section{Data collection and analysis}

All studies were assessed independently for eligibility by three review authors. Disagreements were settled by consensus. Trial authors were contacted to supply missing data or to verify methods. Eligible studies were abstracted and fixed-and random-effects models were implemented to pool studies. Separate analyses were conducted for paediatric and adult studies. Subgroup analyses and meta-regression models were fit to explore heterogeneity of lung function outcomes by type of RCT, category of ICS or SCG dosage, asthma severity of participants, and study quality on outcomes.

\section{Main results}

Of 67 identified studies, 17 trials involving 1279 children and eight trials involving 321 adults with asthma were eligible. Thirteen (76\%) of the paediatric studies and six (75\%) of the adult studies were judged to be high quality. Among children, ICS were associated with a higher final mean forced expiratory volume in 1 second [FEV1] (weighted mean difference [WMD] 0.07 litres, 95\% confidence interval [Cl] 0.02 to 0.11 ) and higher mean final peak expiratory flow rate [PEF] (WMD 17.3 litres/minute, 95\% $\mathrm{Cl} 11.3$ to 23.3) than SCG. In addition, ICS were associated with fewer exacerbations (WMD -1.18 exacerbations per year, $95 \% \mathrm{Cl}-2.15$ to -0.21 ), lower asthma symptom scores, and less rescue bronchodilator use than SCG. There were no group differences in the proportion of children with adverse effects. Among 
adults, ICS were similarly associated with a higher mean final FEV1 (WMD 0.21 litres, $95 \% \mathrm{CI} 0.13$ to 0.28 ) and a higher final endpoint PEF (WMD 28.2 litres/minute, $95 \% \mathrm{Cl} 18.7$ to 37.6 ) than SCG. ICS were also associated with fewer exacerbations (WMD -3.30 exacerbations per year, $95 \% \mathrm{Cl}-5.62$ to -0.98$)$, lower asthma symptom scores among cross-over trials but not parallel trials, and less rescue bronchodilator use than SCG. There were no differences in the proportion of adults with adverse effects. In subgroup analyses involving lung function measures, paediatric and adult studies judged to be of high quality had results consistent with the overall results. Lung function measures in children were higher in studies with medium BDP-equivalent steroid dosages than low BDP-equivalent dosages, while adult studies could not be compared by steroid dosage since they all incorporated similar dosages. There were no significant differences in lung function by the asthma severity of participants for adult or child studies.

\section{Authors' conclusions}

ICS were superior to SCG on measures of lung function and asthma control for both adults and children with chronic asthma. There were few studies reporting on quality of life and health care utilization, which limited our ability to adequately evaluate the relative effects of these medications on a broader range of outcomes. Although there were no differences in adverse effects between ICS and SCG, most trials were short and may not have been of sufficient duration to identify long-term effects. Our results support recent consensus statements in the U.S. and elsewhere that favour the use of ICS over SCG for control of persistent asthma.

\section{PLAIN LANGUAGE SUMMARY}

\section{Inhaled corticosteroids versus sodium cromoglycate in children and adults with asthma}

Inhaled corticosteroids (ICS) and sodium cromoglycate (SCG) have been advocated as medications to control persistent asthma symptoms among children and adults, yet information on which class of drugs is superior has been conflicting. This study pooled randomized controlled trials that directly compared the effects of ICS to SCG on measures of lung function, asthma control, and health care use. Results suggest that ICS were superior to SCG on measures of lung function and morbidity. The results were consistent among children and adults. There were no differences in adverse effects between ICS and SCG, although inconsistent reporting and insufficient long-term monitoring prevents firm conclusions on safety from being drawn. 


\section{B A C K G R O U N D}

Inhaled corticosteroids (ICS) and sodium cromoglycate (SCG) have been advocated for the treatment of persistent asthma in children and adults. ICS have been shown to be effective at improving lung function and reducing chronic asthma symptoms (Adams 2004a; Adams 2004b; Adams 2004c). Adverse effects of ICS remain a controversial subject. Effects on short-term growth in children have been reported, although long- term growth does not appear to be affected (Pedersen 2001). In addition, there have been concerns about important but subtle effects on bone architecture and metabolism(Crowley 1998; Baraldi 1994). The safety of SCG has been well established, but the effectiveness of SCG in controlling asthma symptoms may be limited (Van der Wouden 2004).This latter concern may have contributed to a decline in the use of SCG and an increase in the use of ICS since the early 1990's (Helms 2000). Recent clinical guidelines published by the World Health Organization (GINA 2003), National Heart Lung and Blood Institute in the US (NAEPP 1997), the Canadian Asthma Consensus Group (Canada 1999; Lemiere 2004), and the British Thoracic Society (BTS 2003) have generally favoured the use of inhaled steroids as first line therapy for the treatment of persistent asthma. SCG has been considered by these authoritative groups as an alternative drug, particularly when concerns about adverse effects of ICS have been raised. Studies directly comparing the efficacy ICS and SCG have produced mixed results. For this reason, we conducted a systematic review and meta-analysis of studies that directly compared ICS with SCG for the treatment of persistent asthma in children and adults. The findings from this study can be used to guide the selection of medications to control persistent asthma symptoms.

\section{O B J E C T IVES}

The objective of this review was to compare the relative effectiveness and adverse effects of ICS and SCG in children and adults with persistent asthma.

\section{METHOD S}

\section{Criteria for considering studies for this review}

\section{Types of studies}

We considered randomized controlled trials that used either parallel group or crossover designs with a washout period of one week or more between therapies as eligible for inclusion

\section{Types of participants}

We considered all trials enrolling children, adolescents, and adults as potentially eligible for inclusion, provided that children and adolescents were examined separately from adults. All patients had to have a diagnosis of chronic asthma, ranging from intermittent asthma to severe persistent asthma. We considered studies eligible if they based the diagnosis of asthma on physician opinion or objective criteria related to symptoms, airway reversibility or bronchial hyper-responsiveness. Studies that delivered interventions to patients at community/primary care sites, hospital outpatient clinics, emergency rooms, and inpatient settings were included. We excluded studies if they enrolled participants with pulmonary diagnoses other than asthma and did not report on participants with asthma separately.

\section{Types of interventions}

We only considered studies that reported on direct head-to-head comparisons of ICS with SCG. We considered studies without regard to the type of delivery devices used in the trials, including metered dose inhalers (MDI), MDI with spacer/chamber, drypowder inhalers (DPI), or wet nebulisers. We only considered studies with an intervention period of four weeks or longer in order to ascertain a minimum duration for asthma control. We excluded studies employing medication co-interventions (e.g. theophylline or montelukast), but we considered studies that incorporated rescue short acting inhaled or oral beta agonists and rescue systemic steroids.

\section{Types of outcome measures}

\section{Primary outcomes}

The primary outcome measure was asthma exacerbations, defined as the number or proportion of subjects with episodes of asthma, asthma attacks, or episodes requiring the use of systemic steroid bursts.

\section{Secondary outcomes}

1. Measures of lung function: Forced Expiratory Volume in 1 second (FEV1), Peak Expiratory Flow rate (PEF).

2. Measures of asthma control: days of school or work absence, days of restricted activity, nights disturbed by asthma, asthma symptom scores, asthma-free days, rescue bronchodilator use, quality of life.

3. Measures of health care utilization: general practitioner visits, emergency department visits, hospitalizations.

4. Measures of adverse effects: growth rate, oropharyngeal side effects, adrenal suppression, osteopenia, total adverse events.

Outcomes were measured as dichotomous and continuous where possible, e.g. the proportion with exacerbations and the mean exacerbations per treatment group. For continuous measures, we only included final scores and not change scores, since change scores were not routinely reported. We determined the asthma severity of participants in each study by individual study report, examination of mean FEV1 or PEF baseline measurements $>80 \%$ predicted as mild, $60-80 \%$ predicted as moderate, $<60 \%$ predicted as severe), or reported chronicity of mean baseline asthma symptoms (ATS 1991; NAEPP 1997). We categorized asthma severity as "mild-moderate" or "moderate-severe" depending on whether patients with severe asthma were included. We categorized asthma severity as "unclear" if asthma severity was not reported and could not be deduced from examination of study baseline lung function measurements or reported chronicity of asthma symptoms.

\section{Search methods for identification of studies}

\section{Electronic searches}

We identified studies from the Cochrane Airways Group's register of controlled trials. The Airways Group's databases were comprised of references from MEDLINE (1966-Feb 2004), EMBASE (1980-Feb 2004), CINAHL (1982-Feb 2004), and hand-searched airways-related journals. Controlled trials were identified and exported into a separate register. The following search terms were used to identify relevant randomized controlled trials: 
steroid ${ }^{\star}$ OR glucocorticoid ${ }^{\star}$ OR corticosteroid ${ }^{\star}$ OR beclomethasone OR budesonide OR fluticasone OR triamcinolone OR flunisolide OR becotide OR becloforte OR pulmicort OR flixotide AND cromolyn sodium OR dscg OR cromoglycate OR cromone OR intal

\section{Searching other resources}

The bibliographies of included studies identified from the electronic search and relevant review articles were hand-searched to identify additional trials. In addition, corresponding authors of included studies and pharmaceutical manufacturers of ICS and SCG were contacted to identify additional trials. We considered both published and unpublished studies for inclusion.

\section{Data collection and analysis}

\section{Selection of studies}

We screened the title and abstract of each citation identified through the search strategy for eligibility. We obtained the full text of each study determined to be possibly eligible, and we had studies translated into English if necessary. We assessed each article independently for study eligibility (JG, RK, JZ). Disagreement was settled by consensus. Information on randomization methods, blinding or masking, setting, participants (age, sex, ethnicity/race, and asthma severity), intervention duration, medications (agent, dose, method of delivery, co-intervention medications, length of treatment), follow-up procedures and withdrawals, and outcomes were abstracted onto pre-printed data collection forms. To obtain or verify information on reported outcomes and methods, we contacted all corresponding authors by mail or e-mail. We then entered all information into Review Manager 4.2 prior to analysis.

\section{Data extraction and management}

We estimated study-specific effect sizes using final endpoint values for each outcome of interest with corresponding 95\% confidence intervals $(\mathrm{Cl})$. For continuous outcomes, we used the weighted mean difference (WMD) or the standardized weighted mean difference (SMD) if outcomes across studies were reported in different units. For dichotomous outcomes, we used the relative risk (RR). In order to achieve a common interpretable metric across studies reporting on lung function outcomes, we converted average $\%$ predicted FEV1 and PEF measures to absolute values of FEV1 (litres) and PEF (litres/minute) using polynomial models derived from spirometric reference values (Hankinson 1999). We selected the models for male Caucasian subjects $<20$ years of age, since all included studies reported a majority of enrolled patients as being white and male. There were few differences in lung function measures if models for white female subjects $<20$ years of age were used. We used the average age and height of participants in each study to derive the expected values of FEV1 and PEF. If height was not reported, we used the median height for boys for a given age from population reference values. We then multiplied the $\%$ predicted FEV1 and PEF (\% predicted FEV1 SD and PEF SD) reported in these trials by the expected values of FEV1 and PEF to arrive at the absolute estimates (absolute SDs). Since twoperiod cross-over studies may not report appropriate variance measures from paired analyses, we imputed paired standard errors from unpaired standard errors (Elbourne 2002). If the correlation between treatment periods in cross-over trials was not reported, we assumed that the correlation was 0.50 (Follmann 1992).
When two or more trials reported results for an outcome, we pooled effect sizes using both fixed-effects (Hasselblad 1995) and randomeffects (DerSimonian 1986) models, since there is little agreement on which model is preferable. For consistency, we reported effect sizes from the fixed-effects model in the text. Where effect sizes differed statistically, we also reported effect sizes from the randomeffects model. Data from both treatment periods in cross-over trials were pooled with data from parallel group trials if data were reported in absolute values in order to estimate a common effect across all studies and to improve efficiency. Data from cross-over and parallel studies were pooled separately using SMD if data were reported in different units, since methods to reliably pool data from parallel and cross-over trials using SMD were not available. We made separate comparisons for children/adolescents and adults.

\section{Assessment of risk of bias in included studies}

Two authors (JG, SN) assessed the methodological quality of included trials independently. Inter-rater agreement was assessed using the kappa statistic and any disagreement was resolved by consensus. The primary measure of quality was a 5-point scale that evaluated the reported quality of randomization $(0$ if not randomized, 1 if reported randomized, 2 if randomized and method appropriate), blinding ( 0 if not blinded, 1 if reported blinded, 2 if blinded and method appropriate), and description of withdrawals and dropouts ( 0 if not described and 1 if appropriately described) [Jadad 1996]. A score of 3-5 was considered suggestive of high quality, while a score of 1-2 was suggestive of low quality. We also evaluated the quality of allocation concealment using the Cochrane approach [Clarke 1999]:

\section{Grade A: adequate concealment}

Grade B: uncertain concealment

Grade C: clearly inadequate concealment

\section{Assessment of heterogeneity}

We tested for heterogeneity using the 12 Test (Higgins 2003). This test assesses the percentage of total variability that is due to between-study heterogeneity rather than chance. We categorized heterogeneity as low (I2: $25-50 \%)$, moderate (I2: $51-75 \%)$, or high $(12>75 \%)$. To detect biases in the publication and identification of trials, funnel plot asymmetry was determined for outcomes with at least three contributing studies by regressing the standard normal deviate on the precision (Egger 1997).

\section{Data synthesis}

We undertook preplanned subgroup analyses for lung function comparisons: FEV1 and PEF. We performed subgroup comparisons by stratifying studies on key characteristics separately for children/ adolescents and adults in order to estimate the magnitude of their effects on outcomes and to explore heterogeneity. We were primarily interested in whether outcomes varied across trials with respect to the asthma severity of participants, beclomethasone (BDP)-equivalent ICS dosage category, study quality, and the type of trial. We also performed a post-hoc subgroup analysis to investigate if differences in outcomes were evident between studies with optimal SCG dosages (20 mg QID) and studies with sub-optimal dosages (<80 mg per day) (Van der Wouden 2004). 


\section{Subgroup analysis and investigation of heterogeneity}

We tested for statistical significance among subgroups by partitioning the overall heterogeneity into within and between group differences (Deeks 2001). We considered between group differences of $\mathrm{P}<0.1$ as indicative of significant group differences in outcomes. We stratified these comparisons by:

a) Asthma severity (mild/moderate versus moderate/severe versus unclear)

b) BDP Steroid-equivalent dosage (medium versus low)

c) Study quality (low versus high Jadad score)

d) Type of trial (parallel-group versus cross-over)

e) SCG Dosage (optimal versus sub-optimal)

We consulted inhaled steroid dosage equivalence charts to determine BDP-equivalence (GINA 2003). BDP-equivalent dosages of 200-400 mcg per day were considered low dose, while BDPequivalent dosages of $401-800 \mathrm{mcg}$ per day were considered medium dose. We stratified on type of trial to assess for the presence of carry-over effects or other biases in cross-over trials (Curtin 2002a; Curtin 2002b).

To assess the independent effect of key characteristics, we developed meta-regression models (Berlin 1994). We fit separate models for children and adults for FEV1 and PEF outcomes. We regressed effect sizes on the following characteristics: asthma severity, BDP-equivalent ICS dosage category, type of trial, and study quality. We explored for co linearity of characteristics using correlation matrices and found moderate correlation $(r>0.65)$ involving type of trial and most other variables. For this reason, we dropped type of trial from all models. For some models (adult outcomes), we dropped ICS dosage category, because there was no variability among the trials for these measures. We performed the main meta-analysis using RevMan Analysis 1.0, but we conducted the funnel plot asymmetry and meta-regression using Stata version 8.

\section{RESULTS}

\section{Description of studies}

\section{Results of the search}

Our search identified 672 titles and abstracts of potentially eligible studies. After review of the titles and abstracts from the literature search and bibliographies, we considered 89 trials as possibly eligible for inclusion. We examined the full text of these studies and excluded 55 for the following reasons: not randomized controlled trials ( $N=26)$, interventions shorter than four weeks $(N=6)$, subjects without asthma $(\mathrm{N}=2)$, and comparisons other than SCG versus ICS $(\mathrm{N}=21)$. Six studies are awaiting assessment, since they were published in abstract form and we have been unable to locate a full-text form (published or unpublished). Three studies were found to be duplicate publications. Therefore, a total 25 individual trials were selected for inclusion. Of these, 17 trials included children and adolescents (1279 subjects), while eight trials included adults (321 subjects). The paediatric and adult studies are reported separately.

\section{Included studies}

\section{Pediatric Studies}

Ten (59\%) of the paediatric trials used parallel group design (Andersson 2001; Cserhati 2000; Edmunds 1994; Giorgi 1998;
Kraemer 1987; Kraemer 1993; Leflein 2002; Price 1995; Price 1997; Shapiro 1991) and the remainder were crossover trials (DeBaets 1998; Francis 1984; Kuzemko 1974; Hiller 1975; Mitchell 1976; Ng 1977; Riedler 1991). The mean age of participants across the studies was 8.8 years $(S D \pm 2.5)$. The average duration of the intervention was 17.5 weeks $(S D \pm 17.1)$. The paediatric trials varied in size (mean 75, range 11 - 335 participants), severity of asthma among participants (two with moderate-to-severe asthma [Hiller 1975; Ng 1977], 12 with mild-to-moderate asthma [Andersson 2001; Cserhati 2000; Edmunds 1994; Giorgi 1998; Kraemer 1987; Kraemer 1993; Leflein 2002; Mitchell 1976; Price 1995; Price 1997; Shapiro 1991; Riedler 1991], and three with unclear severity [DeBaets 1998; Francis 1984; Kuzemko 1974)]), and the proportion of participants with complete follow-up (range $75-100 \%$ ). Eight of the paediatric trials included preschool age children (ages two to five years), thirteen of the trials included school-age children (ages six to 12 years), and eleven of the trials included adolescents (ages 13 years and above). No trials included children under age two years. We were unable to stratify studies on age, because included trials did not report outcomes separately by age group.

Regarding the intervention, seven studies incorporated low BDP-equivalent ICS dosages (DeBaets 1998 ( beclomethasone $300 \mathrm{mcg}$ ); Kraemer 1993 (beclomethasone $150 \mathrm{mcg}$ to 300 mcg); Kuzemko 1974 (betamethasone 400 mcg); Mitchell 1976 (beclomethasone $200 \mathrm{mcg}$ to $400 \mathrm{mcg}$ ); Price 1995 (fluticasone $100 \mathrm{mcg}$ ); Price 1997 (fluticasone $100 \mathrm{mcg}$ ); Shapiro 1991 (triamcinolone $600 \mathrm{mcg}$ )), while ten used medium BDP-equivalent ICS dosages (Andersson 2001 (budesonide $400 \mathrm{mcg}$ ); Cserhati 2000 (budesonide $400 \mathrm{mcg}$ ); Edmunds 1994 (budesonide $800 \mathrm{mcg}$ ); Francis 1984 (beclomethasone $400 \mathrm{mcg}$ );Giorgi 1998 (flunisolide 1200 mcg); Hiller 1975 (betamethasone 800 mcg; Kraemer 1987 (beclomethasone $300 \mathrm{mcg}$ to $600 \mathrm{mcg}$ ); Leflein 2002 (budesonide $500 \mathrm{mcg}$ ); Ng 1977 (betamethasone $800 \mathrm{mcg}$ ); Riedler 1991 (beclomethasone $600 \mathrm{mcg}$ )). There was heterogeneity with respect to the specific ICS agent employed: six with beclomethasone (DeBaets 1998; Francis 1984; Kraemer 1987; Kraemer 1993; Mitchell 1976; Riedler 1991), four with budesonide (Andersson 2001; Cserhati 2000; Edmunds 1994; Leflein 2002), three with betamethasone (Hiller 1975; Kuzemko 1974; Ng 1977), three with fluticasone (Giorgi 1998; Price 1995; Price 1997), and 1 with triamcinolone (Shapiro 1991). The dosage of SCG varied from 30 $\mathrm{mg}$ to $160 \mathrm{mg}$ daily. Nine studies used optimal doses of at least $80 \mathrm{mg}$ per day (20 mg QID) of SCG (Cserhati 2000; Edmunds 1994; Francis 1984; Hiller 1975; Leflein 2002; Mitchell 1976; Ng 1977; Price 1995; Price 1997), while eight studies incorporated sub-optimal dosing strategies (Andersson 2001; DeBaets 1998; Giorgi 1998; Kraemer 1987; Kraemer 1993; Kuzemko 1974; Shapiro 1991; Riedler 1991). Eight studies used metered-dose inhalers (Andersson 2001; Cserhati 2000; Francis 1984; Hiller 1975; Kraemer 1993; Ng 1977; Shapiro 1991; Riedler 1991), four studies used dry powder inhalers (Edmunds 1994; Kraemer 1987; Price 1995; Price 1997), two studies used wet nebulizers (Giorgi 1998; Leflein 2002), and three studies did not report on the delivery devices used (DeBaets 1998; Kuzemko 1974; Mitchell 1976). Among the cross-over trials, the wash-out period varied from two to three weeks.

\section{Adult Studies}

Among the adult trials, four (50\%) used parallel group designs (Faurschou 1994; Hoshino 1998; Orefice 1992; Lindqvist 2003), and the remainder were crossover trials (Couch 1977; Dawood 1977; Molema 1989; Svendsen 1987). The mean age was 35.5 
years (SD \pm 8.0 ) across the studies. The average duration of the intervention was 11.5 weeks $( \pm 7.0)$. The adult trials also varied in size (mean 40, range 12-80 participants), severity of asthma among participants (two with moderate-severe asthma [Couch 1977; Molema 1989], four with mild-moderate asthma [Dawood 1977; Faurschou 1994; Hoshino 1998; Orefice 1992], and two with unclear severity [Svendsen 1987; Lindqvist 2003]), and the proportion of participants with complete follow-up (range 70 $100 \%)$.

Regarding the intervention, all 7 adult studies used low BDP-equivalent ICS dosages(Couch 1977 (betamethasone 800 mcg); Dawood 1977 (betamethasone 800 mcg); Faurschou 1994 (beclomethasone $400 \mathrm{mcg}$ ); Hoshino 1998 (beclomethasone $400 \mathrm{mcg}$ ); Molema 1989 (budesonide $400 \mathrm{mcg}$ ); Orefice 1992 (beclomethasone $150 \mathrm{mcg}$ ); Svendsen 1987 (beclomethasone 400 $\mathrm{mcg}$ ), while 1 used medium BDP-equivalent ICS dosages Lindqvist 2003 (fluticasone $500 \mathrm{mcg}$ ). Similar to the pediatric studies, there was heterogeneity in the specific ICS agents used: four with beclomethasone (Faurschou 1994; Hoshino 1998; Orefice 1992; Svendsen 1987), two with betamethasone (Couch 1977; Dawood 1977), 1 with fluticasone (Lindqvist 2003), and 1 with budesonide (Molema 1989). The SCG dosage also varied from $8 \mathrm{mg}$ daily to 80 $\mathrm{mg}$ daily, however only two adult studies used optimal dosages of $80 \mathrm{mg}$ or more a day (Couch 1977; Dawood 1977). Five studies incorporated metered-dose inhalers (Couch 1977; Faurschou 1994; Molema 1989; Orefice 1992; Svendsen 1987), 1 used dry powder inhalers (Lindqvist 2003), while the remaining two did not specify the type of delivery device (Dawood 1977; Hoshino 1998). Among the cross-over trials, the wash-out period varied from two to three weeks.

\section{Author verification}

We attempted to contact corresponding authors of all adult and paediatric studies in order to verify allocation concealment procedures and to obtain missing data. We used both e-mail and post when e-mail addresses were unavailable. We received responses from 17 authors (68\%) regarding clarification of study design and missing data(Andersson 2001; Kraemer 1987; Kraemer 1993; Molema 1989; DeBaets 1998; Shapiro 1991; Cserhati 2000; Mitchell 1976; Orefice 1992; Price 1995; Price 1997; Leflein 2002; Hoshino 1998; DeBaets 1998; Dawood 1977; Francis 1984; Lindqvist 2003).

\section{Excluded studies}

See Characteristics of excluded studies.

\section{Risk of bias in included studies}

The methodological quality of the studies varied. Of the 17 pediatric studies, eight (47\%) were felt to have adequate allocation concealment (Andersson 2001; Cserhati 2000; DeBaets 1998; Francis 1984; Kraemer 1987; Mitchell 1976; Price 1995; Price 1997), but for the other nine studies it was not possible to determine the method of concealment based on published results (Edmunds 1994; Giorgi 1998; Hiller 1975; Kraemer 1993; Kuzemko 1974; Leflein 2002; Ng 1977; Shapiro 1991; Riedler 1991). Thirteen (76\%) of the studies were judged to be high quality (Jadad Score $>2$ ) (Andersson 2001; Cserhati 2000; DeBaets 1998; Francis 1984; Hiller 1975; Kraemer 1987; Kuzemko 1974; Leflein 2002; Mitchell 1976; Ng 1977; Price 1995; Price 1997; Shapiro 1991). Of the eight adults studies, only four (50\%) were felt to have adequate allocation concealment (Dawood 1977; Hoshino 1998; Molema 1989; Lindqvist 2003), while in the remaining four the adequacy of concealment was unclear. Six (75\%) of the adult studies were judged to be high quality (Jadad Score > 2) (Couch 1977; Dawood 1977; Faurschou 1994; Molema 1989; Svendsen 1987; Lindqvist 2003). The level of agreement between authors for allocation concealment was perfect (Kappa $=1.0)$, while the level of agreement for Jadad score was good (Kappa $=0.75)$.

\section{Effects of interventions}

Results are presented separately for children and adults.

OUTCOMES: Inhaled corticosteroids versus cromolyn for children ( $\mathrm{N}=17$ Trials)

1) Measures of asthma control for children (12 trials)

Proportion with exacerbations $(\mathrm{N}=2)$

Mean number of exacerbations per patient per year $(\mathrm{N}=1)$

Mean number of days of school absence per patient per year $(\mathrm{N}=1)$

Mean number of asthma free days per patient per year $(\mathrm{N}=2)$

Mean number of nights disturbed by asthma per patient per year $(\mathrm{N}=1)$

Asthma symptoms score $(\mathrm{N}=9)$

Proportion with rescue bronchodilator use $(\mathrm{N}=2)$

Rescue bronchodilator use per patient $(\mathrm{N}=6)$

Days of restricted activity per patient $(\mathrm{N}=0)$

Health-related quality of life per patient per year $(\mathrm{N}=1)$

2) Measures of lung function for children (15 trials)

Forced expiratory volume in 1 second $(F E V 1)(N=10)$

Peak expiratory flow rate (PEF) $(\mathrm{N}=10)$

3) Measures of health care utilization for children ( 2 trials)

Mean number of general practitioner visits per patient per year $(\mathrm{N}=2)$

Proportion with emergency department visits $(\mathrm{N}=0)$

Mean number of emergency department visits per patient per year $(\mathrm{N}=2)$

Proportion with hospitalizations $(\mathrm{N}=1)$

Mean number of hospitalizations per patient per year $(\mathrm{N}=1)$

4) Measures of adverse effects for children (9 trials)

Mean growth per person ( $\mathrm{cm} /$ year) $(\mathrm{N}=1)$

Proportion with oropharyngeal side effects $(\mathrm{N}=2)$

Mean adrenal suppression per patient per year $(\mathrm{N}=1)$

Proportion with total adverse events $(\mathrm{N}=6)$

Osteopenia per patient $(\mathrm{N}=0)$

\section{Measures of asthma control (paediatric studies)}

Twelve trials involving 1043 patients reported data comparing inhaled steroids to cromolyn on measures of asthma control. Only one study reported on the main outcome, asthma exacerbations. In that study, ICS were associated with fewer exacerbations ( $\mathrm{N}=1$ trial, WMD -1.18 exacerbations per patient per year, $95 \% \mathrm{Cl}-2.15$ to -0.21 ) than SCG. ICS were associated with lower asthma symptom scores than SCG in both parallel group trials $(\mathrm{N}=6, \mathrm{SMD}-0.39,95 \% \mathrm{Cl}-0.54$ to -0.24 ) and cross-over trials ( $\mathrm{N}=3, \mathrm{SMD}-0.38,95 \% \mathrm{Cl}-0.71$ to -0.05 ). Similarly, ICS were associated with less rescue bronchodilator usage than SCG in both parallel group $(\mathrm{N}=5, \mathrm{SMD}-0.24,95 \% \mathrm{Cl}$ -0.42 to -0.07$)$ and cross-over trials $(\mathrm{N}=1, \mathrm{SMD}=-0.64,95 \% \mathrm{Cl}-1.28$ to 0.00 ). Tests of between group variability were not significant $(P>0.10)$, suggesting that parallel group and cross-over studies were 
reporting similar estimates of asthma symptoms score and rescue bronchodilator use. There were no group differences in asthma-free days ( $\mathrm{N}=2$, WMD 0.69 days per patient per year, $95 \% \mathrm{Cl}-0.33$ to 1.71 ), days of school absence ( $\mathrm{N}=1$, WMD 0.27 days per patient per year, $95 \% \mathrm{Cl}-3.33$ to 3.87 ), nights disturbed by asthma ( $\mathrm{N}=1$, WMD -2.56 nights per patient per year, $95 \% \mathrm{Cl}-8.81$ to 3.69 ), or quality of life score ( $\mathrm{N}=1$, WMD -0.10 mean scores, $95 \% \mathrm{Cl}-2.27$ to 2.07 ). There was modest statistical heterogeneity among the trials pooled for asthma symptom scores $(12=36.5 \%)$ but none among trials pooled for rescue bronchodilator use ( $12=0 \%)$. Results from random-effects models were consistent with those from fixed-effects models for all outcomes. No evidence for publication bias was found for asthma symptom scores (intercept $0.2,90 \%$ confidence interval -2.0 to 2.4) or rescue bronchodilator use (intercept $0.6,90 \%$ confidence interval -3.6 to 4.7 ). No trials reported on days of restricted activity.

\section{Measures of Lung function (paediatric studies)}

Fifteen trials involving 813 children reported data comparing inhaled steroids to cromolyn on measures of lung function. ICS were associated with a higher mean final FEV1 ( $\mathrm{N}=10$ trials, WMD 0.07 litres, $95 \% \mathrm{Cl} 0.02$ to 0.11 ) and higher final endpoint PEF (N=10, WMD 17.3 litres/minute, $95 \% \mathrm{Cl} 11.3$ to 23.3) than SCG. Tests of between group variability were not significant $(P>0.10)$, suggesting that parallel group and cross-over studies were reporting similar final endpoint estimates of FEV1 and PEF. There was no statistical heterogeneity among trials reporting on FEV1 $(I 2=0 \%)$, but there was moderate heterogeneity among trials reporting on PEF $(12=57.9 \%)$. The pooled estimates obtained by the random-effects model were consistent with those from the fixed-effects models. There was no evidence of publication bias for FEV1 (intercept $0.7,90 \%$ confidence interval -0.2 to 1.6 ), but there was possible publication bias involving PEF (intercept 1.7, $90 \%$ confidence interval 0.6 to 2.9 ).

\section{Measures of Health care utilization (paediatric studies)}

Two trials involving 467 children reported data comparing inhaled steroids to cromolyn on measures of health care utilization. No group differences between ICS and SCG were found for emergency department visits $(\mathrm{N}=2$ trials, WMD - 0.03 visits per patient per year, $95 \%,-0.13$ to 0.06 ), hospitalizations ( $N=1$, WMD 0.02 hospitalizations per patient per year, $95 \% \mathrm{Cl}-0.05$ to 0.09 ), or general practitioner visits $(\mathrm{N}=2$, WMD -0.36 visits per patient per year, $95 \% \mathrm{Cl}-0.91$ to 0.19 ). There was no heterogeneity among trials pooled for emergency department visits or general practitioner visits, and fixed- and random-effects models were consistent in their findings. Because only two studies reported utilization outcomes, we did not estimate funnel plot asymmetry or perform meta-regression.

\section{Measures of Adverse effect (paediatric studies)}

Six trials involving 150 children reported data comparing inhaled steroids to cromolyn on adverse effects. There were no group difference between ICS and SCG in the proportion of patients with any adverse effect ( $\mathrm{N}=6$ trials, $\mathrm{RR} 1.02,95 \% \mathrm{Cl} 0.72$ to 1.45$)$, proportion with oropharyngeal effects $(\mathrm{N}=2$, RR $1.26,95 \% \mathrm{Cl} 0.25$ to 6.48 ), growth ( $\mathrm{N}=1, \mathrm{WMD}-0.50 \mathrm{~cm}$ per patient per year, $95 \%$ $\mathrm{Cl}-1.03$ to 0.03 ) or adrenal suppression ( $\mathrm{N}=1$, WMD $-5.40 \mathrm{nmol}$ urinary cortisol per patient per day, $95 \% \mathrm{Cl}-41.14$ to 30.34 ). There was no heterogeneity among the trials pooled for oropharyngeal effects $(12=0 \%)$, but there was modest heterogeneity among trials pooled for total adverse events $(12=47.0 \%)$. Estimates obtained from random-effects models were consistent with those from fixedeffects models. We did not estimate funnel plot asymmetry or perform meta-regression for any measure of adverse effects due to the limited number of contributing studies. No trials reported data on osteopenia.

\section{SUBGROUP ANALYSES: \\ OUTCOMES: INHALED CORTICOSTEROIDS VERSUS CROMOLYN FOR CHILDREN STRATIFIED BY ASTHMA SEVERITY}

We stratified lung function outcomes by the asthma severity of each study's participants. The two trials that enrolled subjects with moderate-severe asthma had a higher final estimate of PEF in favour of ICS (WMD liters/minute 58.2 versus 19.5, chisquare $=12.2(2 \mathrm{df}), \mathrm{P}<0.025)$ than the six trials that had subjects with mild-moderate asthma. Comparisons of differences in FEV1 by asthma severity could not be made, since none of the trials reporting on this outcome included severe asthmatics. In metaregression models, asthma severity was not associated with PEF (coefficient 16.3, $\mathrm{P}=0.33$ ) after controlling for ICS dosage and Jadad Score (Table 1; Table 2).

\section{OUTCOMES: INHALED CORTICOSTEROIDS VERSUS CROMOLYN FOR CHILDREN STRATIFIED BY STEROID DOSAGE}

We stratified lung function outcomes by BDP-equivalent dosage categories. The five trials utilizing medium ICS dosages had a higher final estimate of FEV1 favouring ICS (WMD liters 0.18 versus 0.06 , chi-square $=2.82(1 \mathrm{df}), \mathrm{P}<0.10$ ) than the five trials utilizing low ICS dosages. Similarly, the five trials using medium ICS dosages had a higher final estimate of PEF favouring ICS (WMD liters/minute 48.0 versus 12.0 , Chi-square $=17.45$ ( $1 \mathrm{df}), \mathrm{P}<0.001$ ) than the four trials using low ICS dosages. In meta-regression models, ICS dose was associated with FEV1 (coefficient $0.16, \mathrm{P}=0.07$ ) and PEF (coefficient 28.2, $P=0.01$ ) after controlling for asthma severity and Jadad Score, suggesting that ICS given at a medium dosage is associated with greater improvement in lung function than ICS given at a low dosage (Table 1; Table 2).

\section{OUTCOMES: INHALED CORTICOSTEROIDS VERSUS CROMOLYN FOR CHILDREN STRATIFIED BY STUDY QUALITY}

We stratified lung function outcomes by study quality (Jadad Score $=3$ versus $<3$ ). The six trials with high quality scores demonstrated similar final estimates of FEV1 (WMD liters 0.07 versus 0.09 , Chisquare $=0.11(1 \mathrm{df}), \mathrm{P}>0.75)$ as the 4 trials with low quality scores. Similarly, the eight trials with high quality scores demonstrated similar final estimates of PEF (WMD liters/minute 22.9 versus 48.0, Chi-square $=0.19(1 \mathrm{df}), P>0.50)$ as the one trial with a low quality score. In meta-regression models, study quality was not associated with FEV1 (coefficient 0.06, $\mathrm{P}=0.44$ ) or PEF (coefficient -6.1, $\mathrm{P}=0.93$ ) after controlling for asthma severity and ICS dose. (Table 1 ; Table 2 ).

\section{OUTCOMES: INHALED CORTICOSTEROIDS VERSUS CROMOLYN FOR CHILDREN STRATIFIED BY CROMOLYN DOSAGE (post hOC analyses)}

We performed a post hoc analysis by stratifying lung function outcomes by the dosage of SCG (optimal (greater than $80 \mathrm{mg}$ ) versus suboptimal(less than $80 \mathrm{mg}$ )). The four trials with optimal and the six trials with suboptimal SCG dosages had similar final estimates of FEV1 favouring ICS (WMD liters 0.07 versus 0.04 , chisquare $=0.3$ (1df), $P>0.50$ ). However, the 7 trials with optimal SCG dosages had a higher final estimate of PEF in favor of ICS (WMD 
liters $/$ minute 23.8 versus 11.0 , Chi-square $=4.62(1 \mathrm{df}), \mathrm{P}<0.10)$ than the two trials with suboptimal SCG dosages. We did not include cromolyn dosage in meta-regression models(Table 1; Table 2).

\section{ADULT STUDIES}

OUTCOMES: Inhaled corticosteroids versus cromolyn for adults $(\mathrm{N}=8$ Trials $)$

1) Measures of asthma control for adults (5 trials)

Proportion with exacerbations $(\mathrm{N}=1)$

Mean number of exacerbations per patient per year $(\mathrm{N}=1)$

Days of work absence per patient $(\mathrm{N}=0)$

Asthma free days per patient $(\mathrm{N}=0)$

Nights disturbed by asthma per patient $(\mathrm{N}=0)$

Asthma symptom scores $(\mathrm{N}=4)$

Proportion with rescue bronchodilator use $(\mathrm{N}=0)$

Rescue bronchodilator use $(\mathrm{N}=3)$

Days of restricted activity per patient $(\mathrm{N}=0)$

2) Measures of lung function (8 trials)

Forced expiratory volume in 1 second (FEV1) $(\mathrm{N}=7)$

Peak expiratory flow rate $(\mathrm{PEF})(\mathrm{N}=5)$

3) Measures of health care utilization for adults ( 0 trials)

Mean number of general practitioner visits per patient $(\mathrm{N}=0)$

Mean number of emergency department visits per patient $(\mathrm{N}=0)$

Proportion with hospitalization $(\mathrm{N}=0)$

Mean number of hospitalizations per patient $(\mathrm{N}=0)$

4) Measures of adverse Effects for adults (2 trials)

Proportion with oropharyngeal side effects $(\mathrm{N}=1)$

Mean adrenal suppression per patient $(\mathrm{N}=0)$

Proportion with total adverse effects $(\mathrm{N}=2)$

Osteopenia per patient $(\mathrm{N}=0)$

\section{Measures of asthma control (adult studies)}

Five trials involving 155 adults reported data comparing inhaled steroids to cromolyn on measures of asthma control. Only one study reported on the main outcome, asthma exacerbations. In this study, ICS were associated with fewer exacerbations ( $\mathrm{N}=1$ trial, WMD -3.30 exacerbations per patient per six months, $95 \% \mathrm{Cl}-5.62$ to -0.98$)$ and a reduced risk of exacerbations $(\mathrm{N}=1, \mathrm{RR} 0.22,95 \% \mathrm{Cl}$ 0.06 to 0.82 ) compared with SCG. ICS were associated with lower asthma symptom scores among cross-over trials $(\mathrm{N}=3$, SMD -0.58 , $95 \% \mathrm{Cl}-0.96$ to -0.20 ) but not among parallel group trials ( $\mathrm{N}=1, \mathrm{SMD}$ $0.32,95 \% \mathrm{Cl}-0.91$ to 1.55 ). Variability between the single parallel group study and the three cross-over trials was not significant (Chisquare $=1.86(1 \mathrm{df}), \mathrm{P}>0.10)$. ICS were associated with less rescue bronchodilator use among cross-over trials ( $N=3, S M D-0.52,95 \% \mathrm{Cl}$ -0.90 to -0.14 ) than SCG. There was modest heterogeneity among trials reporting asthma symptom scores $(12=44.5 \%)$ and rescue bronchodilator use $(12=46.0 \%)$. The pooled estimates obtained from random-effects models were consistent with those from fixedeffect models. One additional study, which could not be pooled due to absent point estimates, reported that both ICS and SCG demonstrated similar reductions in asthma symptom scores and rescue bronchodilator use. No evidence of publication bias was found for asthma symptom scores (intercept 1.7, 90\% confidence interval -11.5 to 14.9 ) or rescue bronchodilator use (intercept -1.8, $90 \%$ confidence interval -54.5 to 50.9 ). No trials reported data on measures of days of work absence, asthma free days, nights disturbed by asthma, proportion with rescue bronchodilator use, or days of restricted activity.

\section{Measures of Lung Function (adult studies)}

Eight trials involving 321 adults reported data on measures of lung function. Inhaled steroids were associated with a higher final mean FEV1 ( $\mathrm{N}=7$ trials, WMD 0.21 litres, $95 \% \mathrm{Cl} 0.13$ to 0.28 ) and a higher final mean PEF ( $N=5$, WMD 28.2 litres/minute, $95 \% \mathrm{Cl}$ 18.7 to 37.6$)$ than SCG. The four studies employing crossover designs were associated with a higher mean final estimate of FEV1 (WMD liters 0.25 versus -0.05 , Chi-square $=8.33(2 \mathrm{df}), P<0.005$ ) than the three trials with parallel design. However, the four cross-over studies and the single parallel study had similar final estimates of PEF (WMD 28.8 versus -17.2 , chi-square $=1.20(1 \mathrm{df}), \mathrm{P}>0.25$ ). There was moderate heterogeneity for FEV $1(12=65.1 \%)$ but modest heterogeneity for PEF $(12=27.7 \%)$. The pooled estimates obtained by the random-effects model were consistent with the fixed effect model. One additional trial that could not be pooled due to absent point estimates reported that ICS were associated with an increase in FEV1 by 0.31 litres and an increase in PEF by 75 litres/minute, while SCG had no change on either lung function measure. No evidence of publication bias was found for FEV1 (intercept -1.6, 90\% confidence interval -4.2 to 1.0 ) or PEF (intercept $0.9,90 \%$ confidence interval -1.5 to 3.4$)$.

\section{Measures of Health care utilization (adult studies)}

None of the included trials reported data on measures of health care utilization.

\section{Measures of Adverse effects (adult studies)}

Two trials involving 99 patients reported data comparing inhaled steroids to cromolyn on measures of adverse effects. We found no difference between ICS and SCG in the proportion with any adverse effects ( $\mathrm{N}=2$ trials, $\mathrm{RR} 1.04,95 \% \mathrm{Cl} 0.37$ to 2.91 ) or the proportion with oropharyngeal effects ( $\mathrm{N}=1, \mathrm{RR} 2.00,95 \% \mathrm{Cl} 0.39$ to 10.13 ). There was no heterogeneity among the two trials reporting on any adverse effects $(12=0 \%)$. None of the trials reported data on measures of adrenal suppression or osteopenia.

\section{SUBGROUP ANALYSES:}

\section{OUTCOMES: INHALED CORTICOSTEROIDS VERSUS CROMOLYN FOR ADULTS STRATIFIED BY ASTHMA SEVERITY}

We stratified lung function outcomes by asthma severity. The two trials that enrolled subjects with moderate-severe asthma had a greater estimate of FEV1 (WMD liters 0.32 versus 0.15 , Chisquare $=5.65(2 \mathrm{df}), \mathrm{P}<0.10)$ than the four trials with mild-moderate asthma subjects. The two trials with moderate-severe asthma severity and the two trials with mild-moderate asthma severity had similar estimates of PEF (WMD liters/minute 23.5 versus 35.8 , chi-square $=3.78(2 \mathrm{df}), \mathrm{P}>0.10)$. In meta-regression models, asthma severity was marginally associated with FEV1 (coefficient 0.16 , $\mathrm{P}=0.06$ ) but not with PEF (coefficient $-15.5, \mathrm{P}=0.18$ ) after controlling for Jadad score (Table 3; Table 4).

\section{OUTCOMES: INHALED CORTICOSTEROIDS VERSUS CROMOLYN FOR ADULTS STRATIFIED BY STEROID DOSAGE}

Because all adult studies reported low dosage, this comparison could not be performed, and steroid dosage could not be controlled for in meta-regression models. 


\section{OUTCOMES: INHALED CORTICOSTEROIDS VERSUS CROMOLYN FOR ADULTS STRATIFIED BY STUDY QUALITY}

We next stratified lung function outcomes by study quality (Jadad Score $=3$ versus $<3$ ).The five studies with high quality were associated with a greater estimate of FEV1 (WMD liters 0.23 versus -0.01 , chi-square $=4.36(1 \mathrm{df}), \mathrm{P}<0.05$ ) than two studies of low quality. The four studies of high quality were similarly associated with a greater estimate of PEF (WMD liters/minute 28.8 versus -17.2, chi-square $=1.20(1 \mathrm{df}), \mathrm{P}=0.10$ ) than the single study of low quality. The estimates for FEV1 and PEF among high quality studies were all similar to the overall pooled estimates. In meta-regression models, study quality was not associated with FEV1 (coefficient $0.19, \mathrm{P}=0.12$ ) or $\mathrm{PEF}$ (coefficient 56.2, $\mathrm{P}=0.68$ ) after adjusting for asthma severity (Table 3; Table 4)

\section{OUTCOMES: INHALED CORTICOSTEROIDS VERSUS CROMOLYN FOR ADULTS STRATIFIED BY CROMOLYN DOSAGE (pOst hOC analyses)}

We performed a post hoc analysis by stratifying lung function outcomes by cromolyn dosage (optimal versus sub-optimal). The two trials that used optimal cromolyn dosages had greater estimates of FEV1 (WMD liters 0.26 versus 0.07 , chisquare $=5.39(1 \mathrm{df}), P<0.05)$ than the five studies that used suboptimal cromolyn dosages. The two studies that used optimal cromolyn dosages and the three studies that used sub-optimal cromolyn dosages had similar estimates of PEF (WMD liters/minute 41.6 versus 23.8 , chi-square $=2.56(1 \mathrm{df}), \mathrm{P}>0.10$ ) (Table 3 ; Table 4 )

\section{DISCUSSION}

In this systematic review of 17 paediatric and eight adult randomized controlled trials comparing ICS to SCG for the treatment of chronic asthma, the use of ICS was associated with fewer asthma exacerbations than SCG. However, only single studies reported on this outcome among paediatric and adult studies. For other outcomes, ICS were associated with better lung function, fewer asthma symptoms and less use of rescue bronchodilators than SCG. The results were consistent among adult and child studies and were similar for estimates pooled by either fixedor random-effects models. ICS were not different than SCG on measures of health care utilization in the few paediatric trials reporting this outcome; no adult studies reported on health care use. There were no group differences in adverse effects between ICS and SCG, but the types of adverse effects were reported inconsistently across studies. For example, growth delay, a major concern among children using ICS, was rarely assessed.

Subgroup analyses were conducted to explore heterogeneity in results with respect to patient and study factors. With only one trial reporting the main outcome for both paediatric and adult studies, subgroup analyses on exacerbations could not be performed. Therefore, we conducted these analyses on lung function outcomes, FEV1 and PEF, for which we had sufficient numbers of contributing studies. Asthma severity did not modify the superiority of ICS over SCG for lung function outcomes. However, the superiority of ICS over SCG was modified by ICS dosage for paediatric studies but could not be assessed for adult studies which were all of similar dosages. Here, lung function improved to a greater degree among studies utilizing moderate ICS dosages than among studies with low ICS dosages. This result was independent of the study quality and asthma severity of participants. There was little heterogeneity in lung function by SCG dosage, except for FEV1 measures among adults (in which all ICS doses were low dose) and PEF measures in children. In these paradoxical cases, the superiority of ICS was magnified in studies using optimal doses of SCG than in studies with suboptimal SCG, suggesting that the superiority of ICS is independent of SCG dosage and may be modified by other factors. Finally, there was no heterogeneity of lung function measures by study quality, suggesting a robust finding.

The results of this review suggest that there were few differences in adverse effects between ICS in mild to moderate doses and SCG. This was true whether we examined all adverse effects reported by trials or specific adverse effects such as growth, oropharyngeal effects, or adrenal suppression. However, adverse effects in these trials were reported inconsistently, and most trials were shortterm. This may have limited our ability to identify adverse effects, particularly those such as growth retardation which require more prolonged monitoring. In this latter instance, only one paediatric study monitored growth for at least one year, and results did not show any difference in growth between ICS and SCG.

To our knowledge, this is the first systematic review comparing the effects of cromolyn to the gold standard, inhaled steroids. The study had a number of strengths. First, this study benefited from the large number of eligible studies ( $\mathrm{N}=25$ ), which provided sufficient statistical power to identify clear group differences in measures of lung function and asthma control. The large number of contributing studies also allowed us to explore more adequately possible variables affecting heterogeneity in results. Second, this study benefited from a fairly exhaustive search method that allowed us to identify a large number of eligible trials, irrespective of language of publication, and to limit any possible publication bias. In fact, we found evidence for publication bias in only one of several outcomes involving children and adults. In addition, correspondence with authors permitted the verification of methods and data for $68 \%$ of included trials, adding credibility to the results. Finally, this study benefited from the robustness of findings across outcomes and subgroup analyses. Indeed, study findings were relatively consistent whether study authors employed parallel group or crossover designs.

There are a few limitations to discuss. A major limitation of this review was the under-reporting of health care utilization and adverse effects among eligible studies. With only two trials reporting health care use in paediatrics and no trials in adults, there is insufficient data to clarify if ICS reduces health care utilization compared to SCG. It is also not clear whether there are differences in adverse effects between the medications given the inconsistent measurement and insufficient long-term monitoring present in these studies. This limited our ability to draw firm conclusions on the relative safety of ICS compared to SCG, particularly with regards to growth in children. In addition, a number of studies failed to adequately report on study methods such as allocation concealment procedures. This limited our ability somewhat to adequately explore subgroup comparisons based on study quality. Using another measure of study quality, the Jadad Score, results among higher quality studies were consistent with results of lower quality studies. Next, our analysis lacked adequate methods to combine data from parallel and cross-over studies when outcomes were reported in different units. Results, however, among parallel group and cross-over trials for these outcomes were similar. Finally, 
continuous outcomes were only reported as final values, rather than changes from baseline. Final values are less sensitive than changes measured from baseline; results nonetheless consistently favoured ICS highlighting the robustness of findings.

The findings from this review appear generalisable to a large spectrum of children and adults with persistent asthma. Included studies enrolled children, adolescents, and adults with mild to severe asthma. We are unable to recommend ICS over SCG for infants (<two years old) or elderly adults ( $>65$ years old), since studies included in this review did not enroll subjects in these age categories. Yet, the findings from this review are consistent with recent systematic reviews, which suggest a strong benefit of ICS (Adams 2004a; Adams 2004b; Adams 2004c) over placebo and question the benefit of SCG over placebo (Van der Wouden 2004).

\section{AUTHORS' CONCLUSIONS}

\section{Implications for practice}

1. The results from this systematic review suggest that ICS are superior to SCG on measures of asthma control including asthma exacerbations, asthma symptoms, and the need for rescue bronchodilators.

2. The results also suggest that ICS are superior to SCG on measures of lung function among both adults and children.

3. There is insufficient evidence to suggest that ICS are different from SCG on measures of health care utilization such as physician visits, emergency department visits, and hospitalizations.

4. There is insufficient evidence to conclude that there are differences in adverse effects between ICS and SCG. Adverse effects were reported inconsistently, and most trials were too short to adequately measure the impact of these drugs on long-term effects.

5. The results suggest that the superiority of ICS over SCG may be independent of asthma severity, since results were generally similar among those with milder and more severe asthma. The results also suggest that the superiority of ICS over SCG may depend on the dosage of inhaled steroid, since results in favour of ICS were generally stronger among studies with moderate doses than among those with low doses.

6. The results suggest that both low-dose and medium-dose ICS are superior to SCG, but medium -dose ICS may result in greater differences in lung function in children than low-dose.

\section{Implications for research}

This systematic review examined paediatric and adult studies separately. The results in favour of ICS were consistent across both types of studies and across a range of subgroup analyses. These data suggest that future studies comparing ICS to SCG for lung function and asthma control outcomes may not be warranted. If future trials are considered, we would suggest addressing the following gaps in knowledge:

1. There were few paediatric studies and no adult studies reporting on physician visits, emergency department visits, and hospitalizations. Future studies may be considered to investigate the difference between ICS and SCG on health care utilization.

2. A single paediatric study included in this review reported on health-related quality of life. As patient-centred outcomes are being recognized increasingly as important, future studies may be considered to evaluate the relative effects of these drugs on quality of life.

3. The types of inhaled corticosteroids and delivery devices were too heterogeneous to allow for adequate comparisons. Future studies may choose to investigate if the types of ICS and associated delivery devices affect the group differences between ICS and SCG, using direct comparisons.

4. We were unable to pool data from parallel and cross-over studies when outcomes were reported in different units. This limited our statistical power and ability to explore heterogeneity for these outcomes. Methods should be considered for development that will allow standardization and pooling of measures and their variances when they are derived from parallel and cross-over studies designs. 5. For many studies, we were unable to determine the adequacy of allocation concealment or the method of randomization and blinding. Future studies should more fully report their methods.

6. Few studies reported on changes in outcomes from baseline. Future studies may wish to include measures of change in addition to final values when reporting outcomes.

\section{ACK N O WLEDGEMENTS}

We would like to thank the Cochrane Airways Group including Dr. Francine M. Ducharme who assisted in the development of the protocol, Karen Blackhall who ran the literature searches, Toby Lasserson who assisted in the translation of foreign language publications, and Dr. Christopher Cates who assisted in the technical aspects of data analysis. 


\section{R E F E R E N C E S}

\section{References to studies included in this review}

Andersson 2001 \{published data only\}

Andersson F, Kjellman M, Forsberg G, Moller C, Arheden L. Comparison of the cost-effectiveness of budesonide and sodium cromoglycate in the management of childhood asthma in everyday clinical practice. Annals of Allergy Asthma and Immunology 2001;86(5):537-544.

Couch 1977 \{published data only\}

* Couch AHC, Sutton PH, Walker SR. A 12-month double blind clinical comparison of betamethasone valerate and sodium chromoglycate in the treatment of asthma.. The Practitioner 1977;219(1313):751-4.

\section{Cserhati 2000 \{published data only\}}

Cserhati E, Spicak V. The efficacy of budesonide and disodiumcromoglycate therapy in children with mild and moderate persistent bronchial asthma. International Review of Allergology and Clinical Immunology 2000;6(3):91-98.

\section{Dawood 1977 \{published data only\}}

Dawood AG, Hendry AT, Walker SR. The combined use of betamethasone valerate and sodium cromoglycate in the treatment of asthma. Clinical Allergy 1977;7(2):161-165.

\section{DeBaets 1998 \{published data only\}}

De Baets F, Van Daele S, Franckx H, Vinaimont F. Inhaled steroids compared with disodium cromoglycate in preschool children with episodic viral wheeze. Pediatric Pulmonology 1998;25(6):361-366

\section{Edmunds 1994 \{published data only\}}

Edmunds AT, Goldberg RS, Duper B, Devichand P, Follows RMA. A comparison of budesonide 800 micrograms and 400 micrograms daily via Turbohaler with disodium cromoglycate via Spinhaler for asthma prophylaxis in children. British Journal of Clinical Research 1994;5:11-23.

\section{Faurschou 1994 \{published data only\}}

Faurschou P, Bing J, Edman G, Engel A-M. Comparison between sodium cromoglycate (MDI: metered dose inhaler) and beclomethasone dipropionate (MDI) in treatment of adult patients with mild to moderate bronchial asthma. Allergy 1994;49:659-663.

\section{Francis 1984 \{published data only\}}

Francis RS, McEnery G. Disodium cromoglycate compared with beclomethasone dipropionate in juvenile asthma. Clinical Allergy 1984;14(6):537-540.

\section{Giorgi 1998 \{published data only\}}

Giorgi PL, Oggiano N, Kantar A, Coppa GV, Ricciotti R, Arena F, Bernardi F, Colombo ML, Fano M, D'Arcais AF, Guarnaccia S, La Rosa M, Marcucci F, Panasci G, Sensi L, Spinello M, Biraghi M. Bone metabolism in children with asthma treated with nebulized flunisolide: a multicenter Italian study. Current Therapeutics Research 1998;59(12):896-908.
Hiller 1975 \{published data only\}

Hiller EJ, Milner AD. Betamethasone 17 valerate aerosol and disodium cromoglycate in severe childhood asthma. British Journal of Diseases of the Chest 1975;69(2):103-106.

Hoshino 1998 \{published data only\}

Hoshino M, Nakamura Y, Sim JJ, Tomioka H. A comparative study of the effects of ketotifen, disodium cromoglycate, and beclomethasone dipropionate on bronchial mucosa and asthma symptoms in patients with atopic asthma. Respiratory Medicine 1998;92(7):942-950.

\section{Kraemer 1987 \{published data only\}}

Kraemer R, Sennhauser F. Inhaleted beclometasone and cromoglycate on bronchial hyperreactivity in asthmatic children. Atemw-Lundenkrkh 1986;12(3):110-123.

* Kraemer R, Sennhauser F, Reinhardt M. Effects of regular inhalation of beclomethasone dipropionate and sodium cromoglycate on bronchial hyperreactivity in asthmatic children. Acta Paediatrica Scandinavica 1987;76(1):119-123.

Kraemer 1993 \{published data only\}

Kraemer R, Modelska K, Casaulta Aebischer CC, Schoni MH. Comparison of different inhalation schedules to control childhood asthma. Agents Actions Supplement 1993;40:211-221.

\section{Kuzemko 1974 \{published data only\}}

Kuzemko JA, Bedford S, Wilson L, Walker SR. A comparison of betamethasone valerate aerosol and sodium cromoglycate in children with reversible airways obstruction.. Postgraduate Medical Journal 1974;219(50(suppl.)):53-9.

Leflein 2002 \{published data only\}

* Leflein JG, Szefler SJ, Murphy KR, Fitzpatrick S, CruzRivera M, Miller CJ, Smith JA. Nebulized budesonide inhalation suspension compared with cromolyn sodium nebulizer solution for asthma in young children: results of a randomized outcomes trial. Pediatrics 2002;109(5):866-872.

Murphy K, Fitzpatrick S, Cruz-Rivera M, Miller, C, Parasuraman B. Effects of Budesonide Inhalation Suspension Compared With Cromolyn Sodium Nebulizer Solution on Health Status and Caregiver Quality of Life in Childhood Asthma.. Pediatrics 2003;112(3):e212-e219.

\section{Lindqvist 2003 \{published data only\}}

* Lindqvist Ari, Karjalainen Eeva-Maija, Laitinen, Lauri A, Kava Tuomo, Altraja Alan, Pulkkinen Markku, Halme Maija, Laitinen Annika. Salmeterol resolves airway obstruction but does not possess anti-eosinophil efficacy in newly diagnosed asthma: A randomized, double-blind, parallel group biopsy study comparing the effects of salmeterol, fluticasone propionate, and disodium cromoglycate. Journal of Allergy and Clinical Immunology 2003;112:23-8.

\section{Mitchell 1976 \{published data only\}}

Mitchell I, Paterson IC, Cameron SJ, Grant IW. [Treatment of childhood asthma with sodium cromoglycate and 
beclomethasone dipropionate aerosol singly and in combination]. British Medical Journal 1976;2(6033):457-458.

\section{Molema 1989 \{published data only\}}

Molema J, Van Herwaarden CLA, Folgering HThM. Effects of long-term treatment with inhaled cromoglycate and budesonide on bronchial hyperresponsiveness in patients with allergic asthma. European Respiratory Journal 1989;2(4):308-316.

\section{Ng 1977 \{published data only\}}

$\mathrm{Ng} \mathrm{SH}$, Dash CH, Savage SJ. Betamethasone valerata compared with sodium cromoglycate in asthmatic children.. Postgraduate Medical Journal 1977;53(620):315-20.

\section{Orefice 1992 \{published data only\}}

Orefice U, Struzzo P, Dorigo R, Peratoner A. Long-term treatment with sodium cromoglycate, nedocromil sodium and beclomethasone dipropionate reduces bronchial hyperresponsiveness in asthmatic subjects. Respiration 1992;59(2):97-101.

\section{Price 1995 \{published data only\}}

Booth PC, Wells NEJ, Morrison AK. A comparison of the cost effectiveness of alternative prophylactic therapies in childhood asthma.. PharmacoEconomics 1996;10(3):262-268.

* Price JF, Weller PH. Comparison of fluticasone propionate and sodium cromoglycate for the treatment of childhood asthma (an open parallel group study). Respiratory Medicine 1995;89(5):363-368

\section{Price 1997 \{published data only\}}

Price JF, Russell G, Hindmarsh PC, Weller P, Heaf DP, Williams J. Growth during one year of treatment with fluticasone propionate or sodium cromoglycate in children with asthma. Pediatric Pulmonology 1997;24(3):178-186.

\section{Riedler 1991 \{published data only\}}

Riedler J Brandauer M. Long-tearm effect of inhaled corticosteroid and cromoglycate on the bronchial responsiveness in children with asthma. [Langzeiteinfluss von topischem Steroid and Cromoglykat auf den Verlauf der bronchialen Hyperreaktivitat beim Asthma bronchial des Kindes.]. Atemwegs-Und Lunderkrankheiten 1991;17(9):453-7.

\section{Shapiro 1991 \{published data only\}}

Shapiro GG, Sharpe M, DeRouen TA, Pierson WE, Furukawa CT, Virant FS, Bierman CW. Cromolyn versus triamcinolone acetonide for youngsters with moderate asthma. Journal of Allergy and Clinical Immunology 1991;88:742-8.

\section{Svendsen 1987 \{published data only\}}

Svendsen UG, Frolund L, Madsen F, Nielsen NH, HolsteinRathlou N-H, Weeke B. [A comparison of the effects of sodium cromoglycate and beclomethasone dipropionate on pulmonary function and bronchial hyperreactivity in subjects with asthma]. Journal Allergy Clinical Immunology 1987;80(1):68-74.

\section{References to studies excluded from this review}

Adelroth 1998 \{published data only\}

Adelroth E, Barnes NC, Chung KF, Davies RJ, Poulter LW. Drug trials. European Respiratory Journal 1998;11(suppl. 26):36S-38S.

\section{Agertoft 1994 \{published data only\}}

Agertoft L, Pederson S. Effects of long-term treatment with an inhaled corticosteroid on growth and pulmonary function in asthmatic children. Respiratory Medicine 1994;88:373-381.

Anonymous 1975 \{published data only\}

Bronchial asthma and its treatment with disodium cromoglycate.. Acta Allergologica 1995;30(supp):123-7.

Anonymous 1996 \{published data only\}

Anonymous. Asthma Programme in Finland 1994-2004: Report of a working group. Clinical Experimental Allergy 1996;26(suppl. 1):1-24.

Anonymous 1997 \{published data only\}

Drug therapy for asthma in children. Geneesmiddelenbulletin 1997;31(3):27-34

\section{Arner 1971 \{published data only\}}

Arner B, Berg B, Bertler A, Johansson SGO. Steroid sparing effect of disodium cromoglycate in chronic bronchial asthma. Acta Allergologica 1971;26(5):383-399.

Balzano 2002 \{published data only\}

Balzano G, Fuschillo S, Gaudiosi C. Leukotriene receptor antagonists in the treatment of asthma: an update. Allergy 2002;57(Suppl 72):16-19.

\section{Baxter Jones 2000 \{published data only\}}

* Baxter Jiones. Early asthma prophylaxis, natural history, skeletal development and economy(EASE): A pilot randomised control trial. Health Technology Assessment 2000;4(28):1-77.

Bisgaard 2004 \{published data only\}

Bisgaard H, Allen D, Milanowski J, Kalev I, Willits L, Davies P. Twelve-Month Safety and Efficacy of Inhaled Fluticasone Propionate in Children Aged 1 to 3 Years with Recurrent Wheezing. Pediatrics 2004;113:87-94.

Brown 1973 \{published data only\}

Brown HM, Storey G. Beclomethasone dipropionate steroid aerosol in treatment of perennial allergic. British Medical Journal 1973;3(872):161-4.

\section{Capristo 1994 \{published data only\}} Capristo AF, Miraglia del Giudice Jr M, Alfaro C, Maiello N. Corticosteroid-sparing effect of chromoglycate sodium and nedocromil. Mediators Inflammation 1994;3(suppl.):S25-S30.

\section{Carlsen 1996 \{published data only\}}

Carlsen K-H, Larsson K. The efficacy of inhaled disodium cromoglycate and glucocorticoids. Clinical Experimental Allergy 1996;26(4):8-17. 


\section{Carter 2002 \{published data only\}}

Carter E. Fluticasone vs Placebo in Toddlers With Asthma: Good Science or Questionable Ethics?. The Cardiopulmonary and Critical Care Journal 2002;122(6):2267-2268.

\section{Chuchalin 2002 \{published data only\}}

Chuchalin A.G, Kremer H.-J, Metzenauer P, O'Keefe E, Hermann R. Clinical Equivalence Trial on Budesonide Delivered either by the Novolizer Multidose Dry Powder Inhaler or the Turbuhaler in Asthmatic Patients. Respiration 2002;69:502-508.

\section{Cockcroft 1987 \{published data only\}}

Cockcroft DW, Murdock KY. Comparative effects of inhaled salbutamol, sodium cromoglycate, and beclomethasone dipropionate on allergen-induced early asthmatic responses, late asthmatic responses, and increased bronchial responsiveness to histamine. Journal of Allergy and Clinical Immunology 1987;79(5):734-740.

\section{Comis 1993 \{published data only\}}

Comis A, Valletta EA, Sette L, Andreoli A, Boner AL. Comparison of nedocromil sodium and sodium cromoglycate administered by pressurized aerosol, with and without a spacer device in exercise-induced asthma in children. European Respiratory Journal 1993;6(4):523-526.

\section{Del Bufalo 1993 \{published data only\}}

Del Bufalo C, Fasano L, Fabbri M, Quarta CC, Gunella G. Efficacy and tolerability of nedocromil sodium versus placebo in chronic reversible obstructive airways disease. Journal of Investigative Allergology and Clinical Immunology 1993;3:136-141.

\section{Donahue 1997 \{published data only\}}

Donahue JG, Weiss ST, Livingston JM, Goetsch MA, Greineder DK, Platt R. Inhaled steroids and the risk of hospitalization for asthma. Journal of American Medical Association 1997;277(11):887-891.

\section{Dubus 2003 \{published data only\}}

Dubus Jean Christophe, Anhoj J. A Review of once-daily delivery of anti-asthmatic drugs in children. Journal of Pediatric Allergy and Immunology 2003;14(1):4.

\section{Friday 1973 \{published data only\}}

Friday GA, Facktor MA, Bernstein RA, Fireman P. Cromolyn therapy for severe asthma in children. Journal of Pediatrics 1973;83(2):299-304

\section{Gordon 2003 \{published data only\}}

Gordon J.R, Swystun V.A, Li F, Zhang X, Davis B.E, Hull P, Cockcroft D.W. Regular salbutamol use increases CXCL8 responses in asthma: relationship to the eosinophil response. European Respiratory Journal 2003;22:118-126.

\section{Higgs 1996 \{published data only\}}

Higgs CMB, Lazlo G. Influence of treatment with beclomethasone, cromoglycate and theophylline on perception of bronchoconstriction in patients with bronchial asthma. Clinical Science 90(3):227-234.
Holgate 1997 \{published data only\}

Holgate ST, Frew AJ. Choosing therapy for childhood asthma. New England Journal of Medicine 1997;337(23):1690-2.

Kannisto S 2000 \{published data only\}

Kannisto S, Korppi M, Remes K, Voutilainen R. Adrenal suppression, evaluated by a low dose adrenocorticotropin test, and growth in asthmatic children treated with inhaled steroids. Journal of Clinical Endocrinology and Metabolism 2000;85:652-7.

Kanter 1997 \{published data only\}

* Kanter J. Inhaled fluticasone propionate in the treatment of asthma.. Advances in Therapy 1997;14(1):1-7.

Khurana 1977 \{published data only\}

Khurana S, Hyde JS. Cromolyn sodium, five to six years later. Annals of Allergy 1977;39(2):94-98.

\section{Kidner 1968 \{published data only\}}

Kidner PH, Meisner P, Pride NB, Pearson RS. Disodium cromoglycate in the treatment of bronchial asthma. Lancet 1968;2 (7569):655-657.

\section{Kurokawa 1970 \{published data only\}}

Kurokawa D. Single-blind trial of disodium cromoglycate (Intal) for the treatment of bronchial asthma. Arerugi 1970;19(1):45-60.

\section{Lindquist 2001 \{published data only\}}

Lindqvist AE, Karjalainen EM, Laitinen LA, Kava T, Altraja A, Pulkkinen M, Halme M, Laitinen A. Salmeterol (sim), fluticasone propionate $(\mathrm{fp})$ or disodium cromoglycate $(\mathrm{dscg})$ in the treatment of newly diagnosed asthma. Annual Thoracic Society 97th International Conference.

\section{Mapp 1987 \{published data only\}}

Mapp C, Boschetto P, Dal Vecchio L, Crescioli S, De Marzo N, Paleari D, Fabbri LM. Protective effect of antiasthma drugs on late asthmatic reactions and increased airway responsiveness induced by toluene diisocyanate in sensitized subjects. American Review of Respiratory Disease 1987;136:1403-1407.

Martinati 1996 \{published data only\}

Martinati LC, Bertoldo F, Gasperi E, Micelli S, Boner AL. Effect on cortical and trabecular bone mass of different antiinflammatory treatments in preadolescent children with chronic asthma. American Journal of Respiratory and Critical Care Medicine 1996;153:232-236.

Martinati 1998 \{published data only\}

Martinati LC, Bertoldo F, Gasperi E, Fortunati P, Lo Cascio V, Boner AL. Longitudinal evaluation of bone mass in asthmatic children treated with inhaled beclomethasone dipropionate or cromolyn sodium. Allergy 1998;53:705-708.

Mathison 1971 \{published data only\}

Mathison DA, Condemi JJ, Lovejoy FW, Vaughan JH. Cromolyn treatment of asthma. Journal of American Medical Assosiation 1971;216(9):1454-1458. 
Meyer 2003 \{published data only\}

Meyer K.A, Aruino Jean Marie, Santanello N.C, Knorr Barbara, Bisgaard $\mathrm{H}$. Response to montelukast among subgroups of children aged 2 to 14 years with asthma. Journal of Allergy and Clinical Immunology 2003;111:757-62.

Muijsers 2002 \{published data only\}

Muijsers R, Noble S. Spotlight on Montelukast in Asthma in Children 2 to 14 years of age. American Journal of Respiratory Medicine 2002, (3):225-228.

\section{Nikander 2003 \{published data only\}}

Nikander K, Arheden L, Denyer J, Cobos N. Parents' adherence with nebulizer treatment of their children when using an adaptive aerosol delivery (AAD) system. Journal of Aerosol Medicine-Deposition Clearance \& Effects in the Lung 2003;16(3):273-281.

\section{Pauwels 2003 \{published data only\}}

Pauwels R.A, Pederson S, Busse W.W, Tan W.C, Chen Y, Ohlsson S.V, Lamm C, O'Byrne P.M. Early intervention with budesonide in mild persistent asthma: a randomised, doubleblind trial. The Lancet 2003;361(9363):1071-1076.

Pelikan 1988a \{published data only\}

Pelikan Z, Pelikan-Filipek M, Schoemaker MC, Berger MPF. Effects of disodium cromoglycate and beclomethasone dipropionate on the asthmatic response to allergen challenge I. Immediate response (IAR). Annals of Allergy 1988;60:211-216.

Pelikan 1988b \{published data only\}

Pelikan Z, Pelikan-Filipek M, Remeijer L. Effects of disodium cromoglycate and beclomethasone dipropionate on the asthmatic response to allergen challenge II. Late response (LAR). Annals of Allergy 1988;60:217-225.

\section{Pepys 1974 \{published data only\}}

Pepys J, Davies RJ, Breslin ABX, Hendrick DJ, Hutchcroft BJ. The effects of inhaled beclomethasone dipropionate (Becotide) and sodium cromoglycate on asthmatic reactions to provocation tests. Clinical Allergy 1974;4:13-24.

\section{Petersen 1996 \{published data only\}}

Petersen W, Karup-Pedersen F, Friis B, Howitz P, Nielsen F, Stromquist L-H. Sodium cromoglycate as a replacement for inhaled corticosteroids in mild-to-moderate childhood asthma. Allergy 1996;51:870-875.

\section{Pichaipat 1995 \{published data only\}}

Pichaipat V, Nerntong T, Tongpenyai Y, Sriprapachiranont C. The protective effect of inhaled terbutaline, sodium cromoglycate and budesonide on exercise-induced asthma in children. Journal of the Medical Association Thailand 1995;78(10):505-508.

\section{Reijonen 1996 \{published data only\}}

Reijonen T, Korppi M, Kuikka L, Remes K. Anti-inflammatory therapy reduces wheezing after bronchiolitis. Archives of Pediatrics Adolescent Medicine 1996;150:512-517.

\section{Reijonen 1998 \{published data only\}}

Reijonen T, Korppi M. One-year follow-up of young children hospitalized for wheezing: the influence of early antiinflammatory therapy and risk factors for subsequent wheezing and asthma. Pediatric Pulmonology 1998;26:113-119.

Rubinfeld 1985 \{published data only\}

Rubinfeld A, Czarny D, Ruffin R, Pain M, Bowes G, Alpers J, Nana A. Multicentre trial of nedocromil sodium in chronic asthma [abstract]. Australian and New Zealand Journal of Medicine Supplament 1985;15(4):494.

Ruffin 1987 \{published data only\}

* Ruffin RE, Alpers JH, Pain MC, Rubinfeld AR, Czarny D, Bowes $\mathrm{G}$. The efficacy of nedocromil sodium (Tilade) in asthma. Australian and New Zealand Journal of Medicine 1987;17(6):557-61.

\section{Sarsfield 1977 \{published data only\}}

Sarsfield JK, Sugden E. A comparative study of betamethasone valerate aerosol and sodium cromoglycate in children with severe asthma.. Practitioner 1977;218(1303):128-32.

Shore 1971 \{published data only\}

Shore SC. A clinical trial of disodium cromoglycate (Lomudal) in asthmatic children. South African Medical Journal 1971;45(6):141-143.

Sidelnikov 1985 \{published data only\}

Sidelnikov VM, Pashun TV, Pomytkina LR. Comparative evaluation of the effectiveness of different methods of prophylactic treatment for children with bronchial asthma [Sravnitel'naia orsenka effektivnosti razlichnykh metodov profilakticheskogo lecheniia detei s bronkhial'noi astmoi]. Pediatriia 1985;4:34-6.

\section{Sin Hyung 1998 \{published data only\}}

Sin Hyung $L$, et al. The protective effect of inhaled heparin, cromolyn, budesonide, and furesomide on exercise-induced asthma. Tubercular Respiratory Disease 1998;45(6):1188-1198.

\section{Toogood 1981 \{published data only\}}

Toogood JH, Jennings B, Lefcoe NM. A clinical trial of combined cromolyn/beclomethasone treatment for chronic asthma. Journal of Allergy Clinical Immunology 1981;67(4):317-324.

\section{Volovitz 2003 \{published data only\}}

Volovitz B, Nussinovitch M. Effect of High Starting Dose of Budesonide Inhalation Suspension on Serum Cortisol Concentration in Young Children with Recurrent Wheezing Episodes. Journal of Asthma 2003;40(6):625-629.

\section{Von Berg 2002 \{published data only\}}

Von Berg, A. Albrecht B, Darlath W, Vo H W Berdel D. Intraindividual, randomised, double-blind comparison between sodium cromoglycate and reproterol to assess the protective effect of the single drugs and their combination in children with exercise-induced asthma. Allergologie 2002;11:557-564. 
Wuthrich 1982 \{published data only\}

Wuthrich B, Chen-Walden H. Evaluation of FCB, BDP, and DSCG in allergen inhalation challenge test. International Journal of Clinical Pharmacology, Therapy, and Toxicology 1982;20(12):595-599.

\section{Zeiger 1991 \{published data only\}}

Zeiger RS, Heller S, Mellon MH, Wald J, Falkoff R, Schatz M. Facilitated referral to asthma specialist reduces relapses in asthma emergency room visits. Journal of Allergy and Clinical Immunology June 1991;87:1160-8.

\section{References to studies awaiting assessment}

Mendelson 2000 \{published data only\}

* Mendelson L, Welch M, Murphy K, Walton-Bowen K, Fitzpatrick S, Smith J, Cruz-Rivera M. Greater efficacy of budesonide inhalation suspension compared to cromolyn sodium over 52 weeks in young children with persistent asthma. American Journal of Respiratory and Critical Care Medicine 2000;161(Supplement 3):A36.

\section{Paralija 1998 \{published data only\}}

Paralija B, Dizarevic Z, Zutic H, Mehic B, Cukic V. Comparative study of the effects of fluticasone propionate and sodium cromoglycate in newly detected asthma cases. European Respiratory Journal 1998;12((Suppl 29):73s):552.

\section{Turpeinen 2000 \{published data only\}}

Turpeinen M. Helsinki early intervention childhood asthma (HEICA) astudy: inhaled budesonide halved the number of asthma exacerbations compared with inhaled disodium cromoglycate during 18 months of treatment. European Respiratory Journal 2000;16((Supplement 31)):311s.

\section{Von Berg 02 \{published data only\}}

Von Berg, A. Gappa M. Steinkamp G. Fluticasone for the treatment of symptomatic bronchial asthma in children treated with sodium cromogylate- a prospective randomised trial. Euroren Journal of Medical Research 2002;7(6):267-64.

\section{Zielen 2000 \{published data only\}}

Zielen S, Jarisch A Reichenbach J Ortland C Hofmann D. Budesonide nebulizing suspension is more effective than cromoglycate in early childhood asthma. American Journal of Respiratory and Critical Care Medicine 2000;161((Suppl 3)):A36.

\section{Zubovic 2003 \{published data only\}}

Zubovic I, Rozmanic V, Ahel V, Banac S. Assessment of treatment by measuring the level of eosinophyluic cation protein (ECP) in the serum of children with asthma. Ser. Paediatria Croatica 2003;47(3):145-148.

\section{Additional references}

\section{Adams 2004a}

Adams N, Bestall J, Jones PW. Budesonide for chronic asthma in children and adults.. The Cochrane Library 2004, Issue 4.

\section{Adams 2004b}

Adams N, Bestall J, Jones PW. Inhaled fluticasone propionate for chronic asthma. The Cochrane Library 2004, Issue 4.

\section{Adams 2004c}

Adams NP, Bestall JB, Jones PW. Inhaled beclomethasone versus placebo for chronic asthma. The Cochrane Library 2004, Issue 4.

\section{Altman 1998}

Altman DG. Confidence intervals for the number needed to treat. British Medical Journal 1998;317:1309-1312.

\section{ATS 1991}

American Thoracic Society. Lung function testing: selection of reference values and interpretative strategies. American Journal of Respiratory and Critical Care Medicine 1991;144:1202-1218.

\section{Baraldi 1994}

Baraldi E, Bollini MC, De Marchi A, Zacchello F. Effect of beclomethasone dipropionate on bone mineral content assessed by $\mathrm{x}$-ray densitometry in asthmatic children: a longitudinal evaluation. European Respiratory Journal 1994;7:710-714.

\section{Berlin 1994}

Berlin J, Antman E. Advantages and limitations of meta-analytic regressions of clinical trials data. Online Journal for Current Clinical Trials 1994 June 4;Doc No 134.

\section{BGAM 1997}

BGAM. The british guidelines on asthma management: 1995 review and position statement. Thorax 1997;52:21.

\section{BTS 2003}

British Thoracic Society, Scottish Intercollegiate Guidelines Network. British guidelines on the management of asthma. Thorax Aug. 2003;58(8):735.

\section{Canada 1999}

Canadian Asthma Consensus Group. Canadian Asthma Consensus Report. Canadian Medical Association Journal 1999;161(suppl)(11):S1-S5.

\section{Carlsen 1996}

Carlsen K-H, Larsson K. The efficacy of inhaled disodium cromoglycate and glucocorticoids. Clinical Experimental Allergy 1996;26:8-17.

\section{Clarke 1999}

Clarke M, Oxman A. The cochrane reviewers' handbook 4.0. 4th Edition. Oxford: The Cochrane Collaboration, 1999.

\section{Crowley 1998}

Crowley S, Trivedi P, Risteli L, et al. Collagen metabolism and growth in prepubertal children with asthma treated with inhaled steroids. Journal of Pediatrics 1998;132:409-413. 


\section{Curtin 2002a}

François Curtin, Douglas G. Altman, Diana Elbourne. Metaanalysis combining parallel and cross-over clinical trials. I: Continuous outcomes. Statistics in Medicine 2002;21:2131-2144.

\section{Curtin 2002b}

François Curtin, Diana Elbourne, Douglas G. Altman. Metaanalysis combining parallel and cross-over clinical trials. II: Binary outcomes. Statistics in Medicine 2002;21:2145-2159.

\section{Deeks 2001}

Deeks JJ, Altman DG, Bradburn MJ. Statistical methods for examining heterogeneity and combining results from several studies in meta-analysis. In: Egger M, Davey Smith G, Altman DG editor(s). Systematic reviews in health care: meta-analysis in context. second. 2001:285-312.

\section{DerSimonian 1986}

DerSimonian R, Laird N. Meta-analysis in clinical trials. Controled Clinical Trials 1986;7:177-188.

\section{Egger 1997}

Egger M, Smith G, Schneider M, Minder C. Bias in meta-analysis detected by a simple graphical test. British Medical Journal 1997;315:629-634.

\section{Elbourne 2002}

Diana R Elbourne, Douglas G Altman, Julian PT Higgins, Francois Cutrin, Helen V Worthington, Andy Vail. Meta-analyses involving cross-over trials: methodological issues. International Journal of Epidemiology 2002;31:140-149.

\section{Follmann 1992}

Dean Follmann, Paul Elliott, Il Suh, Jeffrey Cutler. Variance Imputation for Overviews of Clinical Trials with Continuous Response. Journal of Clinical Epidemiology 1992;45(7):769-773.

\section{GINA 2003}

Global Initiatives for Asthma (GINA). Global Strategy for Asthma Management and Prevention.. NIH publication No. 02-3659, Issued. Bethesda, MD: US Department of Health and Human Services, Public Health Service, National Heart, Lung, and Blood Institute, 1995(updated 2003).

\section{Hankinson 1999}

John L Hankinson, John R. Odencrantz, Kathleen B. Fedan. Spirometric Reference Value from a Sample of the General U. S. Population. American Journal of Crit Care Medicine 1999;159:179-187.

\section{Hasselblad 1995}

Hasselblad V, Hedges L. Meta-analysis of screening and diagnostic tests. Psychological Bulletin 1995;117:167-178.

\section{Helms 2000}

Helms PJ. Inhaled disodium cromoglycate as maintenance therapy for childhood asthma: time to consign to history?. Thorax 2000;55:886.

\section{Higgins 2003}

Julian P T Higgins, Simon G Thompson, Jonathan J Deeks, Douglas $G$ Altman. Measuring inconsistency in meta-analyses Measuring inconsistency in meta-analyses. British Medical Journal Sep. 2003;327:557-60.

\section{Jadad 1996}

Jadad AR, Moore A, Carroll D, Jenkinson C, Reynolds DJM, Gavaghan DJ, McQuay HJ. Assessing the quality of reports of randomized clinical trials: is blinding necessary?. Controled Clinical Trials 1996;17:1-12.

\section{Kanter 1997}

Kanter L. Inhaled fluticasone propionate in the treatment of asthma. Advances in Therapy 1997;14(1):1-7.

\section{Kuczmarski 2000}

Kuczmarski RJ, Ogden CL, Grummer-Strawn LM, Flegal KM, Guo SS, Wei R, Mei Z, Curtin LR, Roche AF, Johnson CL. CDC Growth Charts: United States. Advance Data from Vital and Health Statistics. Hyattsville, Maryland: National Center for Health Statistics, 2000; Vol. No. 314.

\section{Lemiere 2004}

Lemiere C, Bai T, Balter M, Bayliff C, Becker A, Boulet LP, Bowie D, Cartier A, Cave A, Chapman K, Cowie R, Coyle S, Cockcroft D, Ducharme FM, Ernst P, Finlayson S, FitzGerald JM, Hargreave FE, Hogg D, Kaplan A, Kim H, Kelm C, O'Byrne P, Sears M, Markham AW. Adult Asthma Consensus Guidelines Update 2003.. Can Respiratory Journal 2004, May 11;Suppl A:9A-18A.

\section{NAEPP 1997}

National Asthma Education and Prevention Program (NAEP). Expert panel report 2: clinical practice guidelines. Guidelines for the diagnosis and managment of asthma. NIH Publication No. 98-4051. Rockville, MD: US Department of Health and Human Services, Public Health Service, National Heart, Lung, and Blood Institute, 1997.

\section{Pedersen 2001}

Pedersen S. Do inhaled corticosteroids inhibit growth in children?. American Journal of Respiratory and Critical Care Medicine 2001;164:521-535.

\section{Petitti 1994}

Petitti DB. Meta-analysis, decision analysis, and costeffectiveness analysis: methods for quantitative synthesis in medicine. New York: Oxford University Press, 1994.

\section{Powell 2005}

Powell H, Gibson PG. High dose versus low dose inhaled corticosteroid as inital starting dose for sthma in adults and children. Cochrane Database of Systematic Reviews 2005, Issue 1.

\section{Steyerberg 1999}

Steyerberg EW, Eijkemans MJ, Habbema JD. Stepwise selection in small data sets: a simulation study of bias in logistic regression analysis. Journal of Clinical Epidemiology 1999;52:935-42. 


\section{Van der Wouden 2004}

Van der Wouden JC, Tasche MJA, Bernsen RMD, Uijen JHJM, de Jongste JC, Ducharme FM. Inhaled sodium cromoglycate for asthma in children. The Cochrane Library 2004, Issue 4.

\section{CHARACTERISTICS OF STUDIES}

Characteristics of included studies [ordered by study ID]

\section{Andersson 2001}

Methods

RCT: parallel group design.

Blinding: none.

One of inclusion criteria was a positive clinical response to budesonide.

Participants
* Indicates the major publication for the study

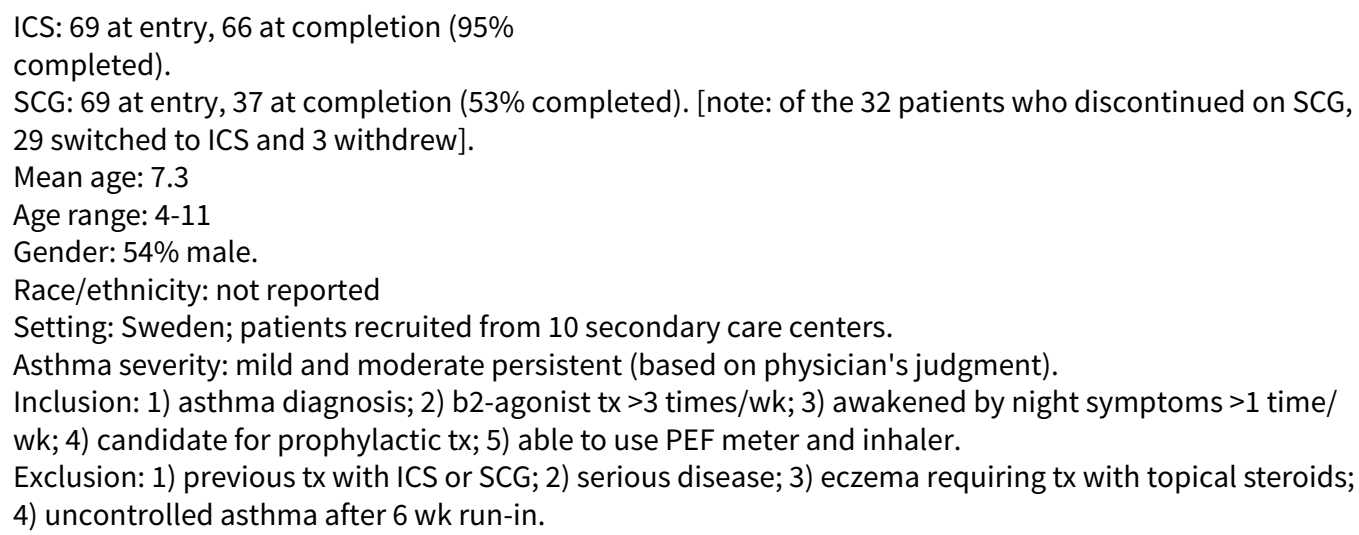

Interventions

After a 4 wk run-in period on budesonide, subjects with well-controlled asthma were randomized to 12 months of budesonide vs SCG. If asthma was poorly controlled, run-in period was extended for 2 more weeks. No placebo used. Subjects could receive terbutaline as rescue medication.

Duration: 52 weeks.

Dose: $200 \mathrm{mcg}$ (ICS); $20 \mathrm{mg}$ (SCG).

Daily dose: $400 \mathrm{mcg}$ (ICS) Medium dose; $60 \mathrm{mg}$ (SCG).

Doses/day: 2 (ICS); 3 (SCG).

Cumulative dose: 146000 mcg (ICS); 21840 mg (SCG).

Delivery device: MDI (ICS); DPI, with switch to MDI allowed (SCG).

$\begin{array}{ll}\text { Outcomes } & \text { morning PEF, asthma exacerbations, school absences, symptom-free days, nights disturbed by asthma, } \\ \text { symptom score, rescue medication use, physician visits, ER visits, hospitalizations, house calls, tele- } \\ \text { phone contacts, discontinuations. }\end{array}$
phone contacts, discontinuations.

$\begin{array}{ll}\text { Notes } & \text { Jadad Quality Score: } 3 \\ & \text { Possible selection bias (baseline differences), performance/detection bias (open label trial) }\end{array}$

\section{Risk of bias}

\begin{tabular}{lll}
\hline Bias & Authors' judgement & Support for judgement \\
\hline Allocation concealment? & Low risk & A - Adequate \\
\hline
\end{tabular}

\section{Couch 1977}

$\begin{array}{ll}\text { Methods } & \text { RCT: cross-over design } \\ & \text { Blinding: double }\end{array}$


Couch 1977 (Continued)

Participants

ICS/SCG: 12 at entry, 12 at completion (100\% completed).

Mean age: 50

Age range: $30-68$

Gender: $58 \%$ male

Setting: Norfolk, UK; clinical setting not reported.

Asthma severity: moderate and severe persisitent (based on inclusion criterion of $\mathrm{FEV} 1<70 \%$ pred, and mean $\mathrm{FEV} 1=30 \%$ pred)

Inclusion: 1) adult patients maintained on bronchodilators; 2) FEV1<70\% pred; 3) $15 \%$ increase in FEV1

$\mathrm{w} /$ salbutamol; 4) sufficiently incapacitated to require short courses of oral corticosteroids.

Exclusion: none.

Interventions

After a 1 wk run-in period with decreasing daily regimen of oral betamethasone + placebo inhaler + placebo spin capsules, patients were randomized to betamethasone valerate or SCG. Double dummy placebos were used to maintain double-blind nature. After 6 mos, patients were changed to alternative treatment. Salbutamol and betamethasone tablets were used when necessary as rescue medication.

Duration: 26 wks

Dose: $200 \mathrm{mcg}$ (ICS); $20 \mathrm{mg}$ (SCG).

Daily dose: $800 \mathrm{mcg}$ (ICS) Low dose; $80 \mathrm{mg}$ (SCG).

Doses/day: 4

Cumulative dose: $146000 \mathrm{mcg}$ (ICS); $14560 \mathrm{mg}$ (SCG).

Delivery device:MDI (ICS); DPI (SCG)

Outcomes $\quad$ FEV1, mean daily PEFR, courses of oral corticosteroids, mean monthly symptom scores, mean daily
dose of salbutamol

Notes Jadad Quality Score: 3

Possible bias:none

\section{Risk of bias}

\begin{tabular}{lll}
\hline Bias & Authors' judgement & Support for judgement \\
\hline Allocation concealment? & Unclear risk & B - Unclear \\
\hline
\end{tabular}

Cserhati 2000

$\begin{array}{ll}\text { Methods } & \text { RCT: parallel group design. } \\ & \text { Blinding: none. }\end{array}$

Participants ICS: 69 at entry, 68 at completion (99\%completed).

SCG: 64 at entry, 61at completion (95\%completed).

Mean age: 10.7

Age range: 6-16.

Gender: $60 \%$ male.

Race/ethnicity: not reported

Setting: 8 Hungarian and 9 Czech pediatric institutions.

Asthma severity: mild and moderate persistent (based on WHO classification).

Inclusion: 1) age 6-16 yrs; 2) FEV1>60\%; 3) symptoms of at least mild persistent asthma after run-in; 4) increased $\mathrm{FEV} 1>12 \%$ with terbutaline.

Exclusion: 1) steroid therapy within 4 weeks; 2) ketotifen within 1 mo; 3) astemisol within 2 mos; 4) short-life antihistamines / long-life beta-mimetics within 3 days; 5) allergy to drugs used in study; 6) serious illness; 7) airway infection within 2 weeks; 8) awaiting surgery.

Interventions

After a 4 wk run-in period on SCG (20 mg qid), subjects with persisting asthmatic symptoms were randomized to 12 weeks of budesonide or a higher dosage of SCG. Subjects could receive terbutaline as rescue medication.

Duration: 12 weeks. 
Cserhati 2000 (Continued)

Dose: $200 \mathrm{mcg}$ (ICS); $40 \mathrm{mg}$ (SCG).

Daily dose: $400 \mathrm{mcg}$ (ICS) Medium dose; $160 \mathrm{mg}$ (SCG).

Doses/day: 2 (ICS); 4 (SCG).

Cumulative dose: $33600 \mathrm{mcg}$ (ICS); $13440 \mathrm{mg}$ (SCG).

Delivery method: MDI.

Outcomes

FEV1, morning/evening PEF, FVC, FEF 25-75\%, symptom-free days, $\dagger$ rescue medication use, $\dagger^{\star}$ day/night symptoms

\begin{tabular}{ll}
\hline Notes & Jadad Quality Score: 3 \\
& Possible bias: none apparent
\end{tabular}

\section{Risk of bias}

\begin{tabular}{lll}
\hline Bias & Authors' judgement & Support for judgement \\
\hline Allocation concealment? & Low risk & A - Adequate \\
\hline
\end{tabular}

\section{Dawood 1977}

\begin{tabular}{|c|c|}
\hline Methods & $\begin{array}{l}\text { RCT: cross-over design. } \\
\text { Blinding: double. }\end{array}$ \\
\hline Participants & $\begin{array}{l}\text { ICS/SCG: } 25 \text { at entry, } 22 \text { at completion ( } 88 \% \text { completed). } \\
\text { Mean age: } 35 . \\
\text { Age range: } 16-63 \\
\text { Gender: } 40 \% \text { male. } \\
\text { Race/ethnicity: not reported } \\
\text { Setting: Hampshire, England; clinical setting not reported. } \\
\text { Asthma severity: moderate persistent (lung function }<70 \% \text { predicted) } \\
\text { Inclusion: 1) lung function }<70 \% \text { predicted; } 2 \text { ) increased FEV1>15\% with bronchodilator. } \\
\text { Exclusion: } 1 \text { ) failure to attend follow-up clinic. }\end{array}$ \\
\hline Interventions & $\begin{array}{l}\text { Subjects were randomized to } 4 \text { weeks of betamethasone valerate, sodium cromoglycate, or both drugs. } \\
\text { This was followed by } 4 \text { wk periods on each of the other } 2 \text { treatments. Rescue medication with bron- } \\
\text { chodilators was allowed. } \\
\text { Duration: } 4 \text { weeks. } \\
\text { Dose: } 200 \mathrm{mcg} \text { (ICS); } 20 \mathrm{mg} \text { (SCG). } \\
\text { Daily dose: } 800 \mathrm{mcg} \text { (ICS)Low dose; } 80 \mathrm{mg} \text { (SCG). } \\
\text { Doses/day: } 4 \\
\text { Cumulative dose: } 22400 \mathrm{mcg} \\
\text { (ICS); } 2240 \mathrm{mg} \text { (SCG). } \\
\text { Delivery device: not reported }\end{array}$ \\
\hline
\end{tabular}

\begin{tabular}{|c|c|c|}
\hline Outcomes & \multicolumn{2}{|c|}{ FEV1, PEFR, rescue medication, symptom score } \\
\hline Notes & \multicolumn{2}{|l|}{$\begin{array}{l}\text { Jadad Quality Score: } 5 \\
\text { Possible bias:none }\end{array}$} \\
\hline \multicolumn{3}{|l|}{ Risk of bias } \\
\hline Bias & Authors' judgement & Support for judgement \\
\hline Allocation concealment? & Low risk & A - Adequate \\
\hline
\end{tabular}


DeBaets 1998

\begin{tabular}{ll} 
Methods & RCT: cross-over design. \\
& Blinding: double. \\
\hline Participants & ICS/SCG:15 at entry, 13 at completion (87\% completed). \\
& Mean age: 4.7 \\
& Age range: $3.6-5.5$ \\
& Gender: $53 \%$ male. \\
& Race/ethnicity: not reported \\
& Setting: Asthma center "De Hann Belgium". \\
& Asthma severity: unclear (episodic virally induced wheezing). \\
Inclusion: 1 )Specific airway resistance and peak flow variability w/in $10 \%$ on 3 consecutive measure- \\
ments. \\
Exclusion: 1 ) atopy, determined by skin prick and/or RAST test.
\end{tabular}

Interventions

After a 2 wk run-in period, patients were randomized to DSCG or BDP for 2 mos. After a washout period of 2 weeks, treatment was switched from SCG to BDP or vice versa for 2 more months. Regular aerosol therapy with fenoterol $1 \mathrm{mg}$ and ipratropium bromide $250 \mathrm{ug}$ in $2 \mathrm{ml}$ saline was given 3 times daily. Duration: 8 weeks

Dose: $100 \mathrm{mcg}$ (ICS); $10 \mathrm{mg}$ (SCG).

Doses/day: 3 Daily dose $300 \mathrm{mcg}$ (ICS) Low dose: $30 \mathrm{mg}$ (SCG)

Cumulative dose: $16800 \mathrm{mcg}$ (ICS); $1680 \mathrm{mg}$ (SCG).

Delivery method: not reported

\begin{tabular}{ll}
\hline Outcomes & ${ }^{*}$ morning peak flow, symptom periods, withdrawals. \\
\hline Notes & $\begin{array}{l}\text { Jadad Quality Score } 4 \\
\text { Possible bias:none }\end{array}$ \\
\hline
\end{tabular}

\section{Risk of bias}

\begin{tabular}{lll}
\hline Bias & Authors' judgement & Support for judgement \\
\hline Allocation concealment? & Low risk & A-Adequate \\
\hline
\end{tabular}

Edmunds 1994

$\begin{array}{ll}\text { Methods } & \text { RCT: parallel group design. } \\ & \text { Blinding: none. }\end{array}$

Participants ICS: 35 at entry, 34 at completion ( $97 \%$ completed).

SCG: 29 at entry, 26 at completion ( $90 \%$ completed).

Mean age: 10.2

Age range: 6-16.

Gender: $67 \%$ male.

Race/ethnicity: not reported

Setting: 10 out-patient clinics and 9 general practices around the UK.

Asthma severity: mild to moderate persistent (based on average FEV1).

Inclusion: 1) age 6-16 yrs; 2) history of asthma and documented response to b-agonist; 2) currently receiving b-agonist and DSCG but still experiencing symptoms; 3 ) competent with peak-flow meter.

Exclusion: 1) glucocorticosteroids by any route within previous month. or DSCG. After first four weeks of treatment, dosage was maintained or halved at discretion of doctor. Patients were allowed to use inhaled b2-agonist for symptomatic relief. Other asthma medications (eg oral bronchodilators) were permitted at a constant dose. 
Duration: 8 weeks

Dose: $400 \mathrm{mcg}$ (ICS); $40 \mathrm{mg}$

(SCG). Dose could be reduced to $200 \mathrm{mcg}$ (ICS) or $20 \mathrm{mg}$ (SCG) after first 4 weeks at discretion of investi-

gator.

Doses/day: 2

(ICS) ; 4 (SCG); Daily dose 800 mcg (ICS) Medium dose; 160 mg(SCG)

Cumulative dose: $44800 \mathrm{mg}$

(ICS); $8960 \mathrm{mg}$

(SCG). If dosage is not reduced after 4 weeks.

Delivery device: DPI.

Outcomes FEV1, diary card am/pm PEF, clinic visit am/pm PEF, "overall" asthma severity, b2-agonist use,
withdrawals, sore throat.

Notes Jadad Quality

Score: 2

Possible selection bias (differences in baseline characteristics).

\section{Risk of bias}

\begin{tabular}{lll}
\hline Bias & Authors' judgement & Support for judgement \\
\hline Allocation concealment? & Unclear risk & B - Unclear \\
\hline
\end{tabular}

\section{Faurschou 1994}

$\begin{array}{ll}\text { Methods } & \text { RCT: parallel group design. } \\ & \text { Blinding: double. }\end{array}$

\section{Participants}

ICS: 18 at entry, 16 at completion,(89\% completed)

SCG: 19 at entry, 17 at completion,(89\% completed).

Mean age: 44.0

Age range: not reported

Gender: $35 \%$ male.

Race/ethnicity: not reported.

Setting: Hellerup, Denmark; clinical setting not reported.

Asthma severity: mild and moderate persistent

Inclusion: 1) >18 and <65 years old; 2) bronchial asthma >6 mo; 3) symptomatic despite tx with inhaled bronchodilators only; 4) diary card score $>10$ for $>7$ days of run-in period; 5) increased FEV1 $>15 \%$ with salbutamol or $>20 \%$ PEFR variability in $1 \mathrm{wk}$.

Exclusion: none.

$\begin{array}{ll}\text { Interventions } & \text { After a } 2 \text { wk run-in, subjects were randomized to } 8 \\ \text { dipropionate. Appropriate placebos were given to } \\ \text { ication. } \\ \text { Duration: } 8 \text { weeks. } \\ \text { Dose: } 100 \mathrm{mcg} \text { (ICS); } 10 \mathrm{mg} \text { (SCG). } \\ \text { Daily dose: } 400 \mathrm{mcg} \text { (ICS) Low dose; } 40 \mathrm{mg} \text { (SCG). } \\ \text { Doses/day: } 4 . \\ \text { Cumulative dose: } 22400 \mathrm{mcg} \text { (ICS); } 2240 \mathrm{mg} \text { (SCG). } \\ \text { Delivery device: MDI. }\end{array}$

\section{Outcomes}

FEV1, morning/evening PEFR, symptom scores, additional bronchodilator medication, withdrawals, physician/patient preferences.

Notes Jadad Quality Score: 5


Faurschou 1994 (Continued)

Possible selection bias (baseline differences in proportion of males)

\section{Risk of bias}

\begin{tabular}{lll}
\hline Bias & Authors' judgement & Support for judgement \\
\hline Allocation concealment? & Unclear risk & B - Unclear \\
\hline
\end{tabular}

\section{Francis 1984}

\begin{tabular}{ll}
\hline Methods & RCT: cross-over design. \\
& Blinding: double \\
\hline Participants & ICS/SCG:24 at entry, \\
& 24 at completion \\
$(100 \%$ completed). & Mean age: 12 \\
& Age range: $4-16$ \\
& Gender: $58 \%$ male. \\
& Race/ethnicity: \\
& not reported. \\
& Setting: London, \\
& U.K.; clinical setting: Children's chest clinic in general inner city hospital. \\
& Asthma severity: \\
& unclear. \\
Inclusion: 1$)$ perennial asthma; 2)ability to use spinhaler, \\
pressurized aerosol and peakflow meter; 3) cooperation of child and parents; 4)inadequate response to \\
pre-referral medication. \\
Exclusion: 1 )poor diary-keeping; 2) misreading of PEF meter.
\end{tabular}

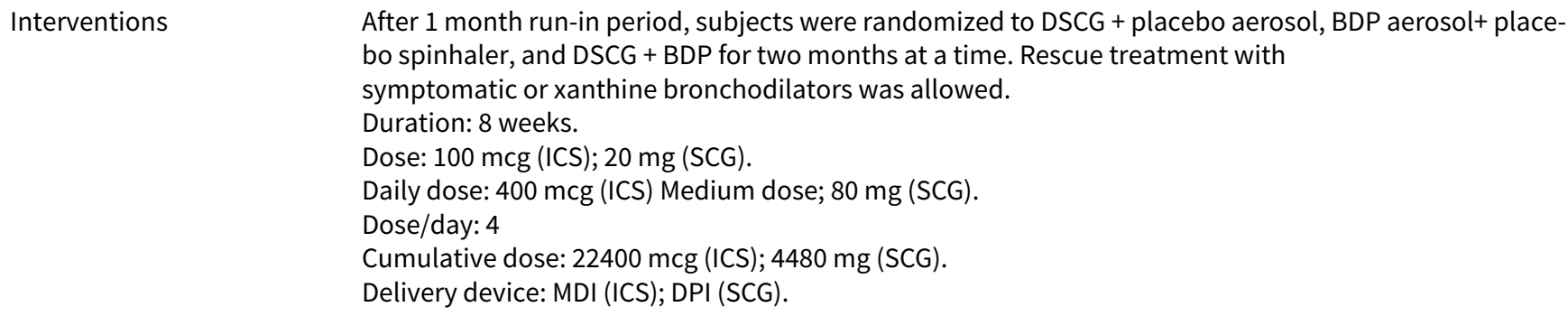

\section{Outcomes} 0800/1800 PEF, wheezing grade A days (\%), wheezing grade $\mathrm{C}$ or D days (\%), days with added bronchodilator (\%)

\begin{tabular}{ll}
\hline Notes & Jadad Quality \\
& Score: 4 \\
& Possible bias:none \\
\hline
\end{tabular}

\section{Risk of bias}

\begin{tabular}{lll}
\hline Bias & Authors' judgement & Support for judgement \\
\hline Allocation concealment? & Low risk & A - Adequate \\
\hline
\end{tabular}


Giorgi 1998

$\begin{array}{ll}\text { Methods } & \text { RCT: parallel group design. } \\ & \text { Blinding: none. }\end{array}$

Blinding: none.

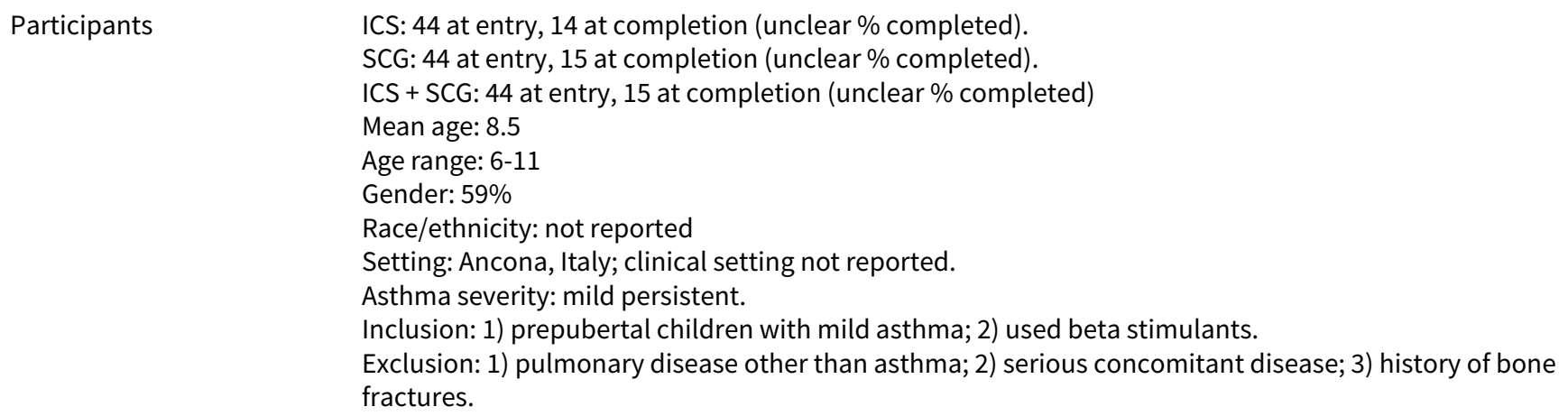

Participants

ICS: 44 at entry, 14 at completion (unclear $\%$ completed).

SCG: 44 at entry, 15 at completion (unclear $\%$ completed).

ICS + SCG: 44 at entry, 15 at completion (unclear $\%$ completed)

Mean age: 8.5

Age range: $6-11$

Gender: 59\%

Race/ethnicity: not reported

Setting: Ancona, Italy; clinical setting not reported.

Asthma severity: mild persistent.

Inclusion: 1) prepubertal children with mild asthma; 2) used beta stimulants.

Exclusion: 1) pulmonary disease other than asthma; 2) serious concomitant disease; 3) history of bone fractures.

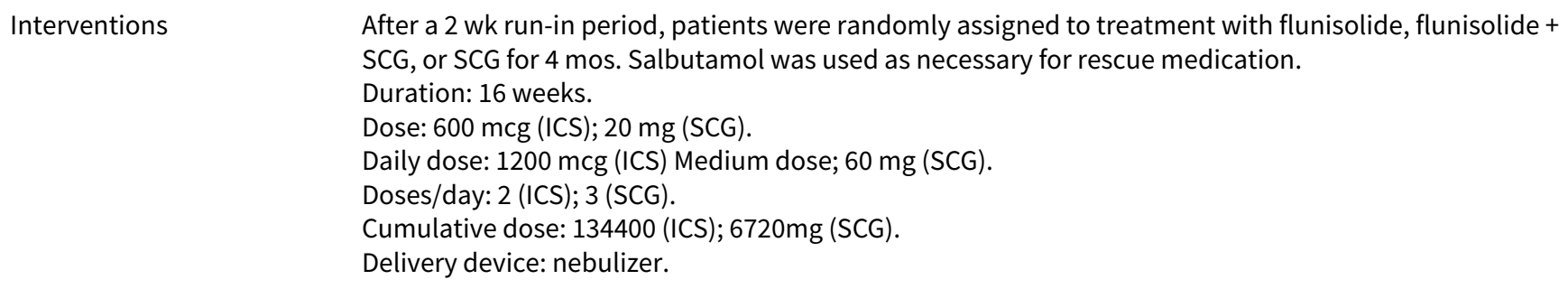

Outcomes $\quad$ FEV1, rescue medication, markers of bone formation(I collagen telopeptide, procollagen type I carboxyterminal propeptide,osteocalcin, and bone alkaline phosphate.

$\begin{array}{ll}\text { Notes } & \text { Jadad Quality Score: } 1 \\ & \text { Possible selection bias (baseline differences in \% males) and detection bias (open label trial). }\end{array}$

\section{Risk of bias}

\begin{tabular}{lll}
\hline Bias & Authors' judgement & Support for judgement \\
\hline Allocation concealment? & Unclear risk & B - Unclear \\
\hline
\end{tabular}

Hiller 1975

$\begin{array}{ll}\text { Methods } & \text { RCT: cross-over design. } \\ & \text { Blinding: double } \\ \text { One of inclusion criteria was that patients were inadequately controlled on SCG. }\end{array}$

ICS/SCG: 11 at entry, 11 at completion (100\% completed).
Mean age: 11.6
Age range: $9-13$
Gender: $80 \%$ male.
Race/ethnicity: not reported
Setting: Nottingham, UK; clinical setting :not reported
Asthma severity: moderate and severe persistent(based on average FEV1 Group D of McNichol and
William's classification.)
Inclusion: 1 ) chronic perennial asthma poorly controlled on DSCG and bronchodilator therapy; 2 ) not
taking systemic corticosteroids; 3) able to use inhaler and PF meter; 4) parent/child cooperation.
Exclusion: none stated.


Hiller 1975 (Continued)

Interventions
For a 4 month period, patients were assigned to 1 month on each of the following 4 treatments in random order: placebo, DSCG, betamethasone valerate, and DSCG + betamethasone valerate. Bronchodilator drugs could be taken as required.

Duration: 4 weeks.

Dose: $200 \mathrm{mcg}$ (ICS); $20 \mathrm{mg}$ (SCG).

Daily dose: 800 mcg (ICS) Medium dose; 80 mg (SCG)

Doses/day: 4

Cumulative dose: $22400 \mathrm{mcg}$ (ICS); $2240 \mathrm{mg}$ (SCG).

Delivery device: MDI (ICS); DPI (SCG).

Outcomes FEV 0.75, clinical/home PEFR \%predicted, symptom scores.

$\begin{array}{ll}\text { Notes } & \text { Jadad Quality Score: } 4 \\ & \text { Possible selection bias (one inclusion criterion was a poor clinical response to SCG). }\end{array}$

\section{Risk of bias}

\begin{tabular}{lll}
\hline Bias & Authors' judgement & Support for judgement \\
\hline Allocation concealment? & Unclear risk & B - Unclear \\
\hline
\end{tabular}

\section{Hoshino 1998}

\begin{tabular}{ll}
\hline Methods & RCT: parallel group design. \\
& Blinding: none. \\
\hline Participants & ICS: 10 at entry, 10 at completion (100\% completed). \\
SCG: 9 at entry, 9 at completion (100\% completed). \\
Mean age: 28 \\
Age range: $16-50$ \\
Gender: $63 \%$ male. \\
Race/ethnicity: not reported. \\
Setting: Tokyo, Japan; clinical setting not reported. \\
Asthma severity: mild or moderate persistent. \\
Inclusion: 1 ) asthma diagnosis based on chest tightness, wheezing, coughing, or shortness of breath \\
and reversible airflow obstruction; 2 ) 2 or more positive skin tests and presence of aeroallergen-specific \\
IgE; 3 ) no inhaled or oral corticosteroids or any other anti-inflammatory drugs in previous 2 mos. \\
Exclusion: \\
1) smoking; 2 ) FEV1 < 50\% pred; 3 ) upper/lower respiratory tract disease in previous 2 weeks.
\end{tabular}

Interventions

Patients were randomly allocated to receive either ketotifen, DSCG, or BDP for 12 weeks of treatment. B2-agonists were used as necessary.

Duration: 12 weeks.

Dose: $100 \mathrm{mcg}$ (ICS); $2 \mathrm{mg}$ (SCG).

Daily dose: $400 \mathrm{mcg}$ (ICS) Low dose; $8 \mathrm{mg}$ (SCG).

Doses/day: 4

Cumulative dose: 33600 mcg (ICS); 672 mg (SCG).

Delivery device: not reported

\begin{tabular}{ll}
\hline Outcomes & $\begin{array}{l}\text { (change in) FEV1\% pred, (change in) PEF, *symptom score, cell counts (eosinophils, mast cells, and } \\
\text { cells). }\end{array}$ \\
\hline Notes & $\begin{array}{l}\text { Jadad Quality Score: } 2 \\
\text { Possible selection bias (PEF and FEV1 baseline measurements higher in BDP group) and perfor- } \\
\text { mance/detection bias (open label trial). }\end{array}$
\end{tabular}


Hoshino 1998 (Continued)

Risk of bias

\begin{tabular}{lll}
\hline Bias & Authors' judgement & Support for judgement \\
\hline Allocation concealment? & Low risk & A - Adequate \\
\hline
\end{tabular}

Kraemer 1987

$\begin{array}{ll}\text { Methods } & \text { RCT: parallel group design. } \\ \text { Blinding: double with respect to BDP; single with respect to SCG. }\end{array}$

ICS: 10 at entry, 7 at completion (70\% completed).
SCG: 10 at entry, 8 at completion (80\% completed).
Mean age: not reported.
Age range: $4-17$
Gender: $47 \%$ male.
Race/ethnicity: not reported.
Setting: Berne, Switzerland; clinical setting not reported.
Asthma severity: mild and moderate persistent (based on physician assessment and lung function
tests).
Inclusion: 1 ) history of wheezing; 2 ) elevated IgE-levels; 3) positive RAST to 1 or more perennial aller-
gens; 4) laboratory documentation of reversible airway obstruction.
Exclusion: 1 ) B2-agonists or xanthines within 12 hrs of lung function tests; 2 ) long-acting xanthines, an-
tihistamines, SCG or systemic steroid treatment.; 3) lack of cooperation; 4) respiratory tract infection.

Interventions

For an 8 wk treatment period, subjects were randomized to BDP, SCG, or placebo. Subjects in SCG group received salbutamol in $2 \mathrm{ml} \mathrm{SCG}$, and placebo Rotacaps; BDP group received salbutamol in $2 \mathrm{ml}$ saline, and BDP Rotacaps; placebo group received salbutamol in $2 \mathrm{ml}$ saline, and placebo Rotacaps. Duration: 8 weeks.

Dose: $100 \mathrm{mcg}$ if $<12$ yrs or $200 \mathrm{mcg}$ if $>12$ yrs (ICS); $20 \mathrm{mg}$ (SCG).

Daily dose: $300 \mathrm{mcg}$ if $<12$ yrs or $600 \mathrm{mcg}$ if $>12 \mathrm{yrs}$ (ICS) Medium dose; $60 \mathrm{mg}$ (SCG).

Doses/day: 3

Cumulative dose: $16800 \mathrm{mcg}$ if $<12$ yrs or $33600 \mathrm{mg}$ if $>12 \mathrm{yrs}$ (ICS); $3360 \mathrm{mg}$ (SCG). Delivery device: DPI (ICS); nebulizer (SCG).

Outcomes FEV1, change in FEV1, airway resistance (Raw), specific airway conductance (sGaw), hyperreactivity to carbachol (PD100).

Notes Jadad Quality Score: 5

Possible selection bias (baseline lung function differences), exclusion bias (large number of drop-outs), and detection bias (single-blinding may affect patient effort on lung function tests).

\section{Risk of bias}

\begin{tabular}{lll}
\hline Bias & Authors' judgement & Support for judgement \\
\hline Allocation concealment? & Low risk & A - Adequate \\
\hline
\end{tabular}

\section{Kraemer 1993}

$\begin{array}{ll}\text { Methods } & \text { RCT: parallel design. } \\ & \text { Blinding: double. }\end{array}$

Participants ICS: 16 at entry, 12 at completion ( $75 \%$ completed).


SCG: 16 at entry, 12 at completion ( $75 \%$ completed).

Mean age: not reported

Age range: $5.5-13.2$

Gender: $72 \%$ male

Race/ethnicity: not reported.

Setting: Berne, Switzerland; asthma center of the university children's hospital.

Asthma severity: mild and moderate persistent (based on baseline FEV1).

Inclusion: 1) history of wheezy attacks, elevated RAST; 2 ) abnormal lung function (TGV $>130 \%$, Raw $>130 \%$ pred, and/or MEF50 <80\% pred, along with PD65 <960 ug); 3) child and parent willingness to participate.

Exclusion: 1) xanthines, antihistamines, or systemic steroid treatment during 2 weeks before entry or during study; 2) drug use $<70 \%$ prescribed over study period; 3 ) drug intake could not be objectively measured due to loss of canisters; 4) symptoms and/or daily PF not registered on diary card.

Interventions

Patients were randomized to BDP + salbutamol, SCG + salbutamol, or salbutamol + placebo for 6 mos. Rescue medication was allowed when necessary.

Duration: 26 weeks.

Dose: $50 \mathrm{mcg}$ (ICS); $1 \mathrm{mg}$ (SCG). Doubled if patient>12 years old

Daily dose: $150 \mathrm{mcg}$ (ICS) Low dose; $3 \mathrm{mg}$ (SCG). Doubled if patient $>12$ years old.

Doses/day: 3

Cumulative dose: 27300 mcg (ICS) Low dose; 546 mg (SCG).Doubled if patients > 12 years old.

Delivery device: MDI

\begin{tabular}{|c|c|c|}
\hline Outcomes & \multicolumn{2}{|c|}{ (change in) *FEV1, morning PF, Raw, TGV, MEF50, diary card symptoms. } \\
\hline Notes & \multicolumn{2}{|c|}{$\begin{array}{l}\text { Jadad Quality Score: } 2 \\
\text { Possible exclusion bias ( } 25 \% \text { excluded from study) }\end{array}$} \\
\hline \multicolumn{3}{|l|}{ Risk of bias } \\
\hline Bias & Authors' judgement & Support for judgement \\
\hline Allocation concealment? & Unclear risk & B - Unclear \\
\hline
\end{tabular}

Kuzemko 1974

\begin{tabular}{ll} 
Methods & RCT: cross-over design. \\
& Blinding: double. \\
\hline Participants & ICS/SCG:40 at entry, 40 at completion (100\% completed). \\
Mean age: 9.9 \\
Age range: $7-15.8$ \\
Gender: $67.5 \%$ male \\
Race/ethnicity: not reported \\
Setting: Northants, UK; clinical setting not reported \\
Asthma severity: not reported \\
Inclusion: 1 ) asthmatic children attending hospital outpatient clinic; 2 ) SCG for $>3$ mo; 3) no steroids \\
courses within 3 mos. \\
Exclusion: none.
\end{tabular}

Interventions

For a 2 weeks run-in period, patients were given placebo betamethasone valerate + placebo SCG. They were then randomized to 4 weeks of BV + placebo SCG, or SCG + placebo BV. For a final 4 weeks, they were assigned the alternative treatment to that received in the first $4 \mathrm{wk}$ period. Bronchodilators were allowed as necessary.

Duration: 4 weeks.

Dose: $200 \mathrm{mcg}$ (ICS); $20 \mathrm{mg}$ (SCG).

Daily dose: $400 \mathrm{mcg}$ (ICS) Low dose ; $40 \mathrm{mg}$ (SCG). 
Kuzemko 1974 (Continued)

Doses/day: 2

Cumulative dose: 11200 mcg (ICS); 1120 mg (SCG).

Delivery device: not reported

Outcomes

Clinic FEV1, clinic/diary card PEF, total symptom score (night disturbance, wheeze, activity, cough, sputum), bronchodilator usage, and plasma cortisol.

\begin{tabular}{ll}
\hline Notes & Jadad Quality Score: 3 \\
& Possible bias:none
\end{tabular}

\section{Risk of bias}

Bias Authors' judgement Support for judgement

Allocation concealment? Unclear risk B - Unclear

Leflein 2002

Methods RCT: parallel group design.

Blinding: none.

Participants

ICS: 168 at entry, 154 at completion (92\%completed).

SCG: 167 at entry, 133 at completion (80\%completed).

Mean age: 4.3

Age range: $2-7$

Gender: $63.9 \%$ male.

Race/ethnicity: $80.6 \%$ white, $13.1 \%$ black, $2.1 \%$ asian, $4.2 \%$ other.

Setting: 36 sites in the US including medical centers, clinical research centers, and community prac-

tices.

Asthma severity: mild to moderate persistent

Inclusion: 1) persistent asthma treated with at least 1 long-term control medication; 2) asthma symptoms $>2$ x weekly within 6 months; 3 ) nocturnal asthma symptoms $>2 \times$ monthly; 4) at least 1 exacerbation requiring systemic corticosteroids within 6 mos or at least 2 within 9 mos; 5) use of at least 1 longterm asthma medication daily with periodic use of rescue med within 3 mos; 6) symptom scores $>2$ on $>7$ days of run-in; 7 ) rescue med use on $>5$ days of run-in.

Exlusion: 1) long-term or intermittent oral corticosteroid treatment within 12 weeks or 15 days respectively; 2) born prematurely; 3 ) history of severe / unstable asthma or ventilatory assistance; 4) hospitalized for airway obstruction within 30 days; 5) respiratory tract infection within 14 days; 6) concomitant lung disease or other significant medical condition.

After 2-3 weeks run-in period, patients were randomized to treatment with budesonide or cromolyn sodium for 52 weeks. After first 8 weeks, dosages could be adjusted at discretion of physician, but maximum and minimum dosages were specified. B2-agonist use was allowed throughout study, and systemic corticosteroids were allowed to treat exacerbations.

Duration: 52 weeks.

Dose: 500 or $250 \mathrm{mcg}$ (ICS); $20 \mathrm{mg}$ (SCG).

Daily Dose: $500 \mathrm{mcg}$ (ICS) Low dose; $80 \mathrm{mg}$ (SCG). After 8 weeks, doses could be titrated as follows: for ICS, $\max =1000 \mathrm{mcg}$ twice daily, $\min 200 \mathrm{mcg}$ once daily; for SCG, $20 \mathrm{mg}$ t.i.d. or q.i.d.

Doses/day: 1 (if $500 \mathrm{mcg}$ dose) or 2 (if $250 \mathrm{mcg}$ dose) (ICS); 4 (SCG).

Cumulative dose: $375000 \mathrm{mcg}$ (ICS):22960mg (SCG)

Delivery device: nebulizer.

\section{Outcomes}

asthma exacerbation rate, symptom scores, rescue medication use, time to first exacerbation, unscheduled physician visits, emergency dept visits, hospitalizations, withdrawals, quality of life 
Leflein 2002 (Continued)

Possible performance bias (lack of blinding may have allowed physician bias to impact dosage titration and/or decisions to treat exacerbations with systemic steroids)

\section{Risk of bias}

\begin{tabular}{lll}
\hline Bias & Authors' judgement & Support for judgement \\
\hline Allocation concealment? & Unclear risk & B - Unclear \\
\hline
\end{tabular}

Lindqvist 2003

\begin{tabular}{ll} 
Methods & RCT:parallel group design. \\
& Blinding:double \\
\hline Participants & 83 patients were enrolled, 80 were eligible, 78 completed, 1 excluded, 1 withdrawn. \\
Mean age: 36.5, age range: $18-60,10 \%$ male. \\
Race/ethnicity: \\
not reported. \\
Setting: Regions of Helsinki University Central Hospital and North Carelia Central Hospital in Finland. \\
Asthma Severity: no clear description of asthma severity, but based on baseline FEV1, appears to be \\
mild to moderate asthma severity. \\
Inclusion: FEV1 $60 \%-100 \%$ of National predicted value = moderate to severe bronchial hyperrespon- \\
siveness to histamine(PD15FEV1 0.4 MG) No smoking history for at least 2 years, no treatment with \\
long acting B2-antagonist or cromones for 4 weeks, no antihistamines for 2 weeks, no inhaled oral \\
steroids for the last 2 months. \\
Exclusion: Patients with respiratory tract infections or asthma exacerbation within 4 weeks of study, \\
patients with seasonal allergy were not studied during allergy season.
\end{tabular}

Interventions

After a 2-week run in period eligible patients were randomly assigned to receive inhaled salmeterol, fluticasone propionate, disodium cromoglycate, rescue medications were permitted.

Duration: 16 weeks

Dose: (ICS) $250 \mathrm{mcg}$ (SCG) 5mg, Daily Dose: (ICS) 500 mcg (scg) 20mg, Doses per Day: (ICS) 2 (SCG) 4, Cumulative: (ICS) $56000 \mathrm{mg}$ (SCG) $2240 \mathrm{mg}$

Delivery Device: (ICS) DPI, (SCG) MDI.

Outcomes

FEV1: PD15, PEF: PEFR, Other: FVC, histamine. Exacerbations: oral oxazepam, Asthma Severity: asthma symptom scores, Rescue Medication: bronchodilator, Other

\begin{tabular}{lll}
\hline Notes & $\begin{array}{l}\text { Jadad Quality Score:4 } \\
\text { No bias }\end{array}$ \\
\hline Risk of bias & \\
\hline Bias & Authors' judgement & Support for judgement \\
\hline Allocation concealment? & Unclear risk & B - Unclear \\
\hline
\end{tabular}

\section{Mitchell 1976}

\begin{tabular}{ll}
\hline Methods & $\begin{array}{l}\text { RCT: cross-over design. } \\
\text { Blinding: double. }\end{array}$ \\
\hline Participants & ICS/SCG: 14 at entry, 14 at completion (100\% completed). \\
& Mean age: 8.9
\end{tabular}


Mitchell 1976 (Continued)

Age range: 5.2-15

Gender: $79 \%$ male.

Race/ethnicity: not reported

Setting: Edinburgh, Scotland; outpatient clinic in University hospital.

Asthma severity: moderate persistent.

Inclusion: 1) recurrent attacks of wheeze and dyspnoea uncontrolled by bronchodilators; 2 ) has not re-

quired oral corticosteroids; 3 ) one positive skin test.

Exclusion: none.

Interventions

After a 2 wk run-in period during which patients received placebo SCG and placebo beclomethasone aerosol, patients were assigned to 12 weeks on each of three treatments (ICS, SCG, ICS + SCG) in random order.

Duration: 12 weeks.

Dose: $50 \mathrm{mcg}$ (ICS) Double if patient $>13$ years old ; $20 \mathrm{mg}$ (SCG).

Daily dose: $200 \mathrm{mcg}$ (ICS) Low dose; $80 \mathrm{mg}$ (SCG).

Doses/day: 4

Cumulative dose: $33600 \mathrm{mcg}$ (ICS) Double if patient> 13 years old ; $6720 \mathrm{mg}$ (SCG).

Delivery device: not reported

\begin{tabular}{ll}
\hline Outcomes & ${ }^{*}$ mean FEV1, diurnal/nocturnal wheezing \\
\hline Notes & Jadad Quality Score: 3 \\
& Possible bias:none \\
\hline
\end{tabular}

\section{Risk of bias}

\begin{tabular}{lll}
\hline Bias & Authors' judgement & Support for judgement \\
\hline Allocation concealment? & Low risk & A - Adequate \\
\hline
\end{tabular}

\section{Molema 1989}

$\begin{array}{ll}\text { Methods } & \text { RCT: cross-over design. } \\ & \text { Blinding: double. }\end{array}$

\section{Participants}

\section{ICS/SCG:31 at entry, 22 at completion (70\%completed).}

Mean Age: 27

Age Range: $15-47$

Gender: $61 \%$ male.

Race/ethnicity: not reported.

Setting: Dekkerswald, Netherlands; outpatient clinic.

Asthma severity: mild, moderate, and severe persistent (based on FEV1 at baseline).

Inclusion: 1) FEV1>50\% pred; 2) increased FEV1>15\% with B2-agonist; 3) PC20 <8; 4) + skin test to dust mites and 2 others.

Exclusion: 1) pregnant; 2) serious concomitant disease; 3) recent steroids; 4) recent airway infection; 5) unable to use PEF meter, MDI, or diary cards. 
Molema 1989 (Continued)

Outcomes
FEV1, exercise induced fall in FEV1, ${ }^{*}$ morning/ evening PEF, symptom scores ( ${ }^{*}$ dyspnoea, wheezing, cough, sputum), ${ }^{*}$ b2-agonist use, physician symptom score, withdrawals, hoarseness.

$\begin{array}{ll}\text { Notes } & \text { Jadad Quality Score: } 5 \\ & \text { Possible exclusion bias ( } 30 \% \text { withdrew from study) }\end{array}$

\section{Risk of bias}

\begin{tabular}{lll}
\hline Bias & Authors' judgement & Support for judgement \\
\hline Allocation concealment? & Low risk & A - Adequate \\
\hline
\end{tabular}

$\mathrm{Ng} 1977$

\begin{tabular}{ll}
\hline Methods & RCT: cross-over design \\
& Blinding: double \\
\hline Participants & ISC/SCG:20 at entry, 20 at completion (100\% completed). \\
& Mean age: 9.7 \\
& Age range: $6.7-13.7$ \\
& Setting: London, UK; clinical setting not reported. \\
& Asthma severity: severe and moderate persistent (based on mean PEF=52\% pred) \\
& Inclusion: 1 ) asthma inadequately controlled by bronchodilator therapy; 2 ) no regular systemic corti- \\
& Costeroids in previous 3 mo; 3) able to use inhaler, PF meter, and diary cards. \\
& Exclusion: none. \\
& After 2 wk run-in period on placebo, patients were randomly assigned to BV + placebo spincap or place- \\
& bo BV + SCG. At the end of 4 wks, the alternative therapy was given for a further 4 weeks. Salbutamol \\
& was used as necessary. \\
& Duration: 4 weeks \\
& Dose: 200 mcg (ICS); 20 mg (SCG). \\
& Daily dose: 800 mcg (ICS)Medium dose; 80 mg (SCG). \\
& Doses/day: 4 \\
& Cumulative dose: 22400 mcg (ICS); 2240 mg (SCG). \\
& Delivery device: MDI (ICS); DPI (SCG).
\end{tabular}

Outcomes Morning/evening PEFR, day/night symptom score, doses of bronchodilator, plasma cortisol levels.

\begin{tabular}{ll}
\hline Notes & Jadad Quality Score: 3 \\
& Possible bias:none
\end{tabular}

\section{Risk of bias}

\begin{tabular}{lll}
\hline Bias & Authors' judgement & Support for judgement \\
\hline Allocation concealment? & Unclear risk & B - Unclear \\
\hline
\end{tabular}

\section{Orefice 1992}

\begin{tabular}{ll}
\hline Methods & RCT: parallel group design \\
& Blinding: none.
\end{tabular}

\section{Participants}

ICS: 40 at entry, 40 at completion, (100\% completed) SCG: 39 at entry, 39 at completion, (100\% completed) 
Orefice 1992 (Continued)

Mean age: 34.6

Age range: $20-52$

Gender: 64\% male.

Race/ethnicity: not reported.

Setting: not reported.

Asthma severity: mild and moderate persistent (based on baseline FEV1>75\%).

Inclusion: none?

Exclusion: none?

Interventions

After a 2 wk run-in period, subjects were randomized to sodium cromoglycate, nedocromil sodium, beclomethasone dipropionate, or placebo. Subjects could receive B2-agonists or ipratropium bromide as rescue medication; if worsening of symptoms occurred, an oral corticosteroid was permitted.

Duration: 12 weeks.

Dose: $500 \mathrm{mcg}$ (ICS); $0.01 \mathrm{mg}$ (SCG).

Daily dose: $1500 \mathrm{mcg}$ (ICS) Low dose; $0.04 \mathrm{mg}$ (SCG).

Doses/day: 3 (ICS); 4 (SCG).

Cumulative dose: $126000 \mathrm{mcg}$ (ICS); $3.36 \mathrm{mg}$ (SCG).

Delivery device: MDI.

Outcomes $\quad$ FEV1, PD20, inhaled bronchodilator dose, symptom scores.

\begin{tabular}{ll}
\hline Notes & Jadad Quality Score: 1 \\
& Possible performance bias (lack of blinding may influence physician care) and detection bias (lack of \\
& blinding may influence physician's lung function measurements and patients' assessment of symp- \\
& toms, effort on lung function tests, etc).
\end{tabular}

\section{Risk of bias}

\begin{tabular}{lll}
\hline Bias & Authors' judgement & Support for judgement \\
\hline Allocation concealment? & Unclear risk & B - Unclear \\
\hline
\end{tabular}

\section{Price 1995}

\begin{tabular}{ll}
\hline Methods & RCT: parallel group. \\
& Blinding: none. \\
\hline Participants & ICS: 110 at entry, 99 at completion $(90 \%$ completed). \\
SCG: 115 at entry, 89 at completion $(77 \%$ competed). \\
Mean age: 8.2 \\
Age range: $4-12$. \\
Gender: $58 \%$ male. \\
Race/ethnicity: not reported. \\
Setting: London, UK; 62 general practices and 2 hospital centers. \\
Asthma severity: mild and moderate persistent \\
Inclusion: 1$)$ age $4-12 ; 2)$ not previously treated with SCG or ICS; 3 ) able to use peak flow meter; 4$)$ symp- \\
toms requiring 1 or $>1$ doses of salbutamol $>7$ days of run-in or PEFR $<80 \%$. \\
Exclusion: 1$)$ oral corticosteroids in previous 6 weeks; 2$)>3$ short courses of systemic corticosteroids in \\
previous 6 mo; 3 respiratory tract infection in previous 2 weeks.
\end{tabular}

Interventions

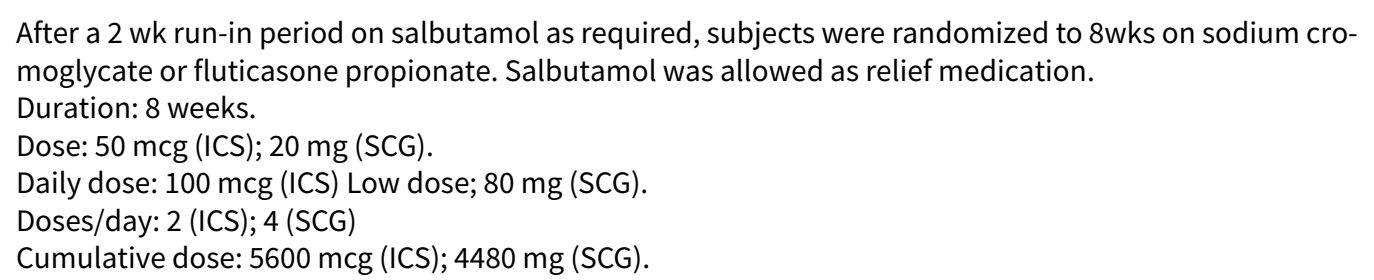


Price 1995 (Continued)

Delivery device: DPI.

Outcomes $\quad$ FEV1, morning/evening PEFR, symptom free days/nights, daytime/nighttime relief medication, withdrawals.

$\begin{array}{ll}\text { Notes } & \text { Jadad Quality Score: } 3 \\ \text { Possible Exclusion bias (difference in withdrawal rates) possible performance bias (difference in com- } \\ \text { pliance rates?)and detection bias }\end{array}$

\section{Risk of bias}

\begin{tabular}{lll}
\hline Bias & Authors' judgement & Support for judgement \\
\hline Allocation concealment? & Low risk & A - Adequate \\
\hline
\end{tabular}

\section{Price 1997}

\begin{tabular}{|c|c|}
\hline Methods & $\begin{array}{l}\text { 1)RCT: parallel group. } \\
\text { Blinding: none }\end{array}$ \\
\hline Participants & $\begin{array}{l}\text { ICS: } 52 \text { at entry, } 52 \text { at completion ( } 100 \% \text { completed). } \\
\text { SCG: } 71 \text { at entry, } 48 \text { at completion ( } 68 \% \text { completed). [note: } 22 \text { patients who started on SCG switched to } \\
\text { ICS, due to uncontrolled asthma; } 18 \text { of these patients completed]. } \\
\text { Mean age: } 6.2 \\
\text { Age range: } 4-10 \\
\text { Gender: } 61 \% \text { male. } \\
\text { Race/ethnicity: not reported. } \\
\text { Setting: London, UK; subjects from } 15 \text { UK centers. } \\
\text { Asthma severity: severe persistent (based on PEF at baseline). } \\
\text { Inclusion: } 1 \text { ) history of asthma with recurrent periods of wheeze/cough; } 2 \text { ) satisfactory inhaler and PF } \\
\text { meter technique. } \\
\text { Exclusion: } 1 \text { ) inhaled prophylactic therapy within } 1 \text { yr; } 2 \text { ) oral corticosteroids within } 3 \text { mos; } 3 \text { ) acute res- } \\
\text { piratory tract infection within } 2 \text { weeks; } 4 \text { ) concurrent disease or medication that might affect growth; } \\
\text { 5) secondary sex characteristics > Tanner/Whitehouse stage } 1 \text { of development; } 6 \text { ) uncontrolled asthma, } \\
\text { defined by: am PEF < } 80 \% \text {, symptoms }+ \text { salbutamol use on }>6 \text { of the last } 14 \text { days, or investigator/patient } \\
\text { felt asthma control was inadequate. }\end{array}$ \\
\hline
\end{tabular}

After a 2 wk run-in, subjects were randomized in 3:4 ratio to FP or SCG. After 8 weeks, those whose asthma was not adequately controlled were switched from SCG to FP or withdrawn. Subjects could receive salbutamol as rescue medication.

Duration: 52 weeks.

Dose: $50 \mathrm{mcg}$ (ICS); $20 \mathrm{mg}$ (SCG)

Daily dose: $100 \mathrm{mcg}$ (ICS) Low dose; $80 \mathrm{mg}$ (SCG).

Doses/day: 2 (ICS); 4 (SCG).

Cumulative dose: $36400 \mathrm{mg}$ (ICS); $29120 \mathrm{mg}$ (SCG).

Delivery method: DPI

\begin{tabular}{ll}
\hline Outcomes & Morning PEF, height velocity, urinary free cortisol, oral corticosteroid courses, withdrawals. \\
\hline Notes & $\begin{array}{l}\text { Jadad Quality Score: } 3 \\
\text { Possible selection bias (baseline differences in symptoms and relief med use), performance/detection } \\
\text { bias (open label trial), and exclusion bias (difference in rates of switching medication). }\end{array}$
\end{tabular}

\section{Risk of bias}


Price 1997 (Continued)
Allocation concealment?
Low risk
A - Adequate

Riedler 1991

\begin{tabular}{ll}
\hline Methods & $\begin{array}{l}\text { RCT: cross-over } \\
\text { design } \\
\text { Blinding:none }\end{array}$ \\
\hline Participants & ICS/SCG:21 at entry,19 at \\
Completion, \\
(90\% completed) \\
Mean age:not reported \\
Age range:7-15 \\
Gender:57\% \\
Race/ethnicity: not reported \\
Setting:One hospital clinic \\
Asthma severity:mild and moderate persistent (based on baseline FEV1) \\
Inclusion:1) Reversible,recurring airways obstruction.2)Raised IgE levels in response to one from:House \\
dust,animal epithelium,tree or grass.3)Available and able to take lung function test.4) At least one pos- \\
itive bronchospasmolysis test in the past 6 months.5)FEF and to have been 70\% or more of normal val- \\
ue. \\
Exclusion: none
\end{tabular}

Interventions

For 9 months period, patients were assigned to 3 months on each of the following treatments in random order:BDP + B2 as needed,DNCG-either as capsule with spinhaler, or as an inhaled solution +B2 as needed, placebo-capsule $+\mathrm{B} 2$ as needed

Duration:12 weeks

Dose: $200 \mathrm{mcg}$ (ICS): $20 \mathrm{mg}$ (SCG)

Daily dose: $600 \mathrm{mcg}$ (ICS) Medium dose; 60mg(SCG)

Dose/day:3

Cumulative dose: $50400 \mathrm{mg}$ (ICS);5040mg

(SCG)

Delivery device:MDI(ICS);

DPI(SCG)

\section{Outcomes}

FEV1, peak flow variation,FVC,FEF50,FEF25,PC20,B-agonist use,symptoms (assessed by parents)

\begin{tabular}{ll}
\hline Notes & Jadad Quality \\
& Score: 2 \\
& Possible bias:none \\
\hline
\end{tabular}

\section{Risk of bias}

\begin{tabular}{lll}
\hline Bias & Authors' judgement & Support for judgement \\
\hline Allocation concealment? & Unclear risk & B - Unclear \\
\hline
\end{tabular}

\section{Shapiro 1991}

\begin{tabular}{ll}
\hline Methods & RCT: parallel group. \\
& Blinding: double.
\end{tabular}


SCG: 17 at entry, 15 completion (88\% completed).

Mean age: 11.4

Age range: 8-18

Gender: $71 \%$ male

Race/ethnicity: not reported.

Setting: Seattle, Washington; clinical setting not reported.

Asthma severity: moderate persistent.

Inclusion: 1) FEV1<80\% pred; 2) reversibility $>15 \%$ after isoproterenol; 3) daily tx with at least 2 drugs

for asthma management; 4) PD20 $<10 \mathrm{mg} / \mathrm{ml}$ after run-in.

Exclusion: none

$\begin{array}{ll}\text { Interventions } & \text { After } 2 \text { wk washout period with only b-agonist } \\ \text { ized to } 12 \text { weeks of triamcinolone acetonide } \\ \text { rescue medication. } \\ \text { Duration: } 12 \text { weeks. } \\ \text { Dose: Unclear (ICS); } 20 \mathrm{mg} \text { (SCG). } \\ \text { Daily dose: Unclear (ICS); } 60 \mathrm{mg} \text { Low (SCG). } \\ \text { Doses/day: } 3 \\ \text { Cumulative dose: Unclear (ICS); } 5040 \text { (SCG). } \\ \text { Delivery device: MDI (ICS); nebulizer (SCG). }\end{array}$

Outcomes

FEV1, (change in) mean weekly PEFR, methacholine sensitivity, FEF25-75, wheezing, albuterol use, theophylline use, cough, chest tightness, withdrawals

$\begin{array}{ll}\text { Notes } & \text { Jadad Quality Score: 5EMPHOLIDAY } \\ \text { Possible bias: none }\end{array}$

Possible bias: none

\section{Risk of bias}

\begin{tabular}{lll}
\hline Bias & Authors' judgement & Support for judgement \\
\hline Allocation concealment? & Unclear risk & B - Unclear \\
\hline
\end{tabular}

\section{Svendsen 1987}

$\begin{array}{ll}\text { Methods } & \text { RCT: cross-over design. } \\ & \text { Blinding: double. }\end{array}$

Participants

ICS/SCG:38 at entry, 38 at completion (100\% completed).

Mean age: 29.4

Age range: not reported

Gender: $50 \%$ male

Setting: Copenhagen, Denmark; patients were referred from other hospitals or general practitioners to the outpatient department of allergy.

Asthma severity: not reported

Inclusion: 1) FEV1 >65 \%pred; 2) PC20 $<2.0 \mathrm{mg} / \mathrm{ml}$; 3) skin prick test and/or RAST positive to 1 or more common allergens; 4) need for additional antiasthmatic medication besides bronchodilators and/or theophyllines.

Exclusion: 1) inhaled steroids or SCG within 4 weeks; 2) oral steroids within 3 mos; 3 ) seasonal allergies; 4) major medical disease.

\footnotetext{
Interventions

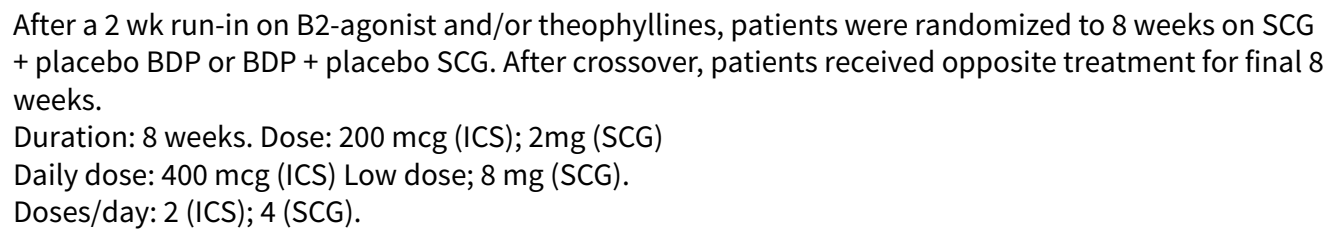


Svendsen 1987 (Continued)

Cumulative dose: $22400 \mathrm{mg}$ (ICS); $448 \mathrm{mg}$ (SCG).

Delivery device: MDI

\begin{tabular}{|c|c|c|}
\hline Outcomes & \multicolumn{2}{|c|}{ FEV1, PEF, FVC, PC20, reduced activity, sleep disturbance, wheezing, salbutamol use, cough. } \\
\hline Notes & \multicolumn{2}{|l|}{$\begin{array}{l}\text { Jadad Quality Score: } 4 . \\
\text { Possible bias:none }\end{array}$} \\
\hline \multicolumn{3}{|l|}{ Risk of bias } \\
\hline Bias & Authors' judgement & Support for judgement \\
\hline Allocation concealment? & Unclear risk & B - Unclear \\
\hline
\end{tabular}

* imputed SD; †change score; 1)Additional 16(ICS) and 23(SCG) drop out from the study

Characteristics of excluded studies [ordered by study ID]

\begin{tabular}{|c|c|}
\hline Study & Reason for exclusion \\
\hline Adelroth 1998 & Not an RCT but a review article. \\
\hline Agertoft 1994 & $\begin{array}{l}\text { Not RCT (CCT) of } 278 \text { children with asthma. Intervention group with budesonide but control group } \\
\text { consisted of SCG, theophylline, or B2-agonists. }\end{array}$ \\
\hline Anonymous 1975 & Not an RCT but a case presentation. \\
\hline Anonymous 1996 & Not an RCT but a review paper. \\
\hline Anonymous 1997 & Review paper, not RCT. \\
\hline Arner 1971 & $\begin{array}{l}\text { RCT - asthmatic adults already on corticosteroids were randomized to SCG or placebo and then } \\
\text { crossed over. }\end{array}$ \\
\hline Balzano 2002 & Not an RCT \\
\hline Baxter Jones 2000 & Comparison involved ssA2 agonist versus inhaled steroids. \\
\hline Bisgaard 2004 & may enroll patients without asthma \\
\hline Brown 1973 & Not an RCT. 31 children with asthma were placed on ICS. \\
\hline Capristo 1994 & Comparison involved nedocromil vs ICS rather than SCG vs ICS. \\
\hline Carlsen 1996 & Not an RCT but a review. \\
\hline Carter 2002 & Not an RCT \\
\hline Chuchalin 2002 & Comparison not ICS or SCG \\
\hline Cockcroft 1987 & $\begin{array}{l}\text { Intervention too short. RCT involving } 10 \text { adults with asthma who received BDP, SCG, or salbutamol } \\
\text { alone for } 6 \text { days and had assessment of FEV1. }\end{array}$ \\
\hline Comis 1993 & $\begin{array}{l}\text { Comparison involved SCG vs. nedocromil rather than ICS, and outcomes related to exercise-in- } \\
\text { duced asthma (not an outcome of interest). }\end{array}$ \\
\hline
\end{tabular}




\section{Study}

Del Bufalo 1993

\section{Donahue 1997}

Dubus 2003

Friday 1973

Gordon 2003

Higgs 1996

Holgate 1997

Kannisto S 2000

\section{Reason for exclusion}

Comparison involved nedocromil vs placebo rather than ICS vS SCG in patients with COPD and not asthma.

Not an RCT (a cohort study).

Not an RCT

Comparison involved SCG vs placebo in steroid-dependent asthmatics.

Comparison not ICS vs. SCG

Intervention length of 2 weeks was too short.

Not an RCT but an editorial.

Not RCT (CCT involving 75 children with asthma. 60 were randomized to BUD or FP and remaining 15 were placed on SCG or nedocromil).

\begin{tabular}{|c|c|}
\hline Kanter 1997 & Not RCT(This should be listed as review paper.) \\
\hline Khurana 1977 & Not RCT. Cohort study of 70 children treated with cromolyn and followed prospectively for 5 years. \\
\hline Kidner 1968 & Not direct comparison (RCT of 28 asthmatic patients randomized to SCG or placebo). \\
\hline Kurokawa 1970 & Comparison of Intal (SCG) vs placebo rather than SCG vs ICS. \\
\hline Lindquist 2001 & Not RCT \\
\hline Mapp 1987 & Short washout period (1 week), short intervention (1 week), outcome not pertinent. \\
\hline Martinati 1996 & Not RCT (CCT) of 64 children with asthma ages 5-10. \\
\hline Martinati 1998 & Not RCT (cohort study) of 49 children with asthma. \\
\hline Mathison 1971 & RCT of cromolyn vs placebo in 30 adults with asthma. Inhaled steroids in both groups. \\
\hline Meyer 2003 & Comparison not of SCG or ICS \\
\hline Muijsers 2002 & not an RCT \\
\hline Nikander 2003 & Comparison not of SCG or ICS \\
\hline Pauwels 2003 & Comparison not of SCG vs. ICS \\
\hline Pelikan 1988a & No outcomes of interest (bronchial provocation tests); too short intervention (1 day). \\
\hline Pelikan 1988b & $\begin{array}{l}\text { Not an RCT, no outcomes of interest. } 61 \text { patients with asthma were pretreated with DSCG or BDP } \\
\text { and measured late asthmatic responses. }\end{array}$ \\
\hline Pepys 1974 & $\begin{array}{l}\text { Not RCT ( } 8 \text { adults with asthma were given SCG and BDP on successive days), no outcome of interest } \\
\text { (immediate and late asthma reactions), too short intervention ( } 1 \text { day). }\end{array}$ \\
\hline Petersen 1996 & $\begin{array}{l}\text { Not a direct comparison of SCG vs ICS. Children on ICS were randomized to SCG or placebo and } \\
\text { outcomes were measured. }\end{array}$ \\
\hline
\end{tabular}




\begin{tabular}{|c|c|}
\hline Study & Reason for exclusion \\
\hline Pichaipat 1995 & $\begin{array}{l}\text { Not RCT ( } 14 \text { children with asthma were given placebo, terbutaline, SCG, or budesonide on succes- } \\
\text { sive weeks); no outcomes of interest (exercise induced fall in FEV1). }\end{array}$ \\
\hline Reijonen 1996 & No subjects with asthma (children 1 to 23 months old with bronchiolitis). \\
\hline Reijonen 1998 & No subjects with asthma (children 1 to 23 months old with bronchiolitis were enrolled). \\
\hline Rubinfeld 1985 & An RCT, but comparison was nedocromil vs. placebo. \\
\hline Ruffin 1987 & An RCT, but comparison was nedocromil vs. placebo. \\
\hline Sarsfield 1977 & Not RCT \\
\hline Shore 1971 & Not an RCT (all 90 children with asthma were given SCG); no controls; no inhaled steroid arm. \\
\hline Sidelnikov 1985 & Not an RCT. \\
\hline Sin Hyung 1998 & $\begin{array}{l}\text { Involved children with exercise-induced asthma rather than chronic asthma. Intervention was only } \\
1 \text { day rather than minimum of } 4 \text { weeks. }\end{array}$ \\
\hline Toogood 1981 & Comparison of ICS +/- SCG \\
\hline Volovitz 2003 & Comparison not SCG or ICS \\
\hline Von Berg 2002 & comparison not of SCG or ICS \\
\hline Wuthrich 1982 & $\begin{array}{l}\text { Too short intervention ( } 10 \text { days) and washout ( } 4 \text { days). Cross-over RCT of } 36 \text { asthmatics comparing } \\
\text { SCG with FCB. }\end{array}$ \\
\hline Zeiger 1991 & not an RCT \\
\hline
\end{tabular}

\section{DATA AND ANALYSES}

\section{Comparison 1. Inhaled Corticosteroids vs Cromolyn for Children}

\begin{tabular}{lllll}
\hline Outcome or subgroup title & $\begin{array}{l}\text { No. of } \\
\text { studies }\end{array}$ & $\begin{array}{l}\text { No. of } \\
\text { partici- } \\
\text { pants }\end{array}$ & Statistical method & Effect size \\
\hline $\begin{array}{l}1 \text { Exacerbations (mean number per pa- } \\
\text { tient per year) }\end{array}$ & 1 & 337 & $\begin{array}{l}\text { Mean Difference (IV, Fixed, 95\% } \\
\text { Cl) }\end{array}$ & $-1.18[-2.15,-0.21]$ \\
\hline $\begin{array}{l}1.1 \text { Parallel } \\
2 \text { Exacerbations (\%) }\end{array}$ & 1 & 337 & $\begin{array}{l}\text { Mean Difference (IV, Fixed, 95\% } \\
\text { Cl) }\end{array}$ & $-1.18[-2.15,-0.21]$ \\
\hline 2.1 Parallel & 2 & 193 & Risk Ratio (M-H, Fixed, 95\% Cl) & $0.99[0.67,1.48]$ \\
\hline 3 FEV1(GIV) & 2 & 193 & Risk Ratio (M-H, Fixed, 95\% Cl) & $0.99[0.67,1.48]$ \\
\hline
\end{tabular}




\begin{tabular}{|c|c|c|c|c|}
\hline Outcome or subgroup title & $\begin{array}{l}\text { No. of } \\
\text { studies }\end{array}$ & $\begin{array}{l}\text { No. of } \\
\text { partici- } \\
\text { pants }\end{array}$ & Statistical method & Effect size \\
\hline 3.1 Parallel & 7 & & $\begin{array}{l}\text { mean difference }(\mathrm{L}) \text { (Fixed, } \\
95 \% \mathrm{Cl} \text { ) }\end{array}$ & $0.08[0.03,0.13]$ \\
\hline 3.2 Cross over & 3 & & $\begin{array}{l}\text { mean difference }(\mathrm{L}) \text { (Fixed, } \\
95 \% \mathrm{Cl} \text { ) }\end{array}$ & $0.04[-0.04,0.12]$ \\
\hline 4 PEF(GIV) & 10 & & $\begin{array}{l}\text { mean diff (L/min) (Fixed, 95\% } \\
\mathrm{Cl})\end{array}$ & $17.29[11.33,23.25]$ \\
\hline 4.1 Parallel & 6 & & $\begin{array}{l}\text { mean diff (L/min) (Fixed, 95\% } \\
\mathrm{Cl})\end{array}$ & $19.52[10.67,28.36]$ \\
\hline 4.2 Cross-Over & 4 & & $\begin{array}{l}\text { mean diff (L/min) (Fixed, 95\% } \\
\mathrm{Cl})\end{array}$ & $15.44[7.36,23.51]$ \\
\hline $\begin{array}{l}5 \text { School Absence (mean days per pa- } \\
\text { tient per year) }\end{array}$ & 1 & 137 & $\begin{array}{l}\text { Mean Difference (IV, Fixed, 95\% } \\
\mathrm{CI})\end{array}$ & $0.27[-3.33,3.87]$ \\
\hline 5.1 Parallel & 1 & 137 & $\begin{array}{l}\text { Mean Difference (IV, Fixed, 95\% } \\
\mathrm{CI})\end{array}$ & $0.27[-3.33,3.87]$ \\
\hline $\begin{array}{l}6 \text { Nights Disturbed by Asthma (mean } \\
\text { nights per patient per year) }\end{array}$ & 1 & 137 & $\begin{array}{l}\text { Mean Difference (IV, Fixed, 95\% } \\
\mathrm{CI})\end{array}$ & $-2.56[-8.81,3.69]$ \\
\hline 6.1 Parallel & 1 & 137 & $\begin{array}{l}\text { Mean Difference (IV, Fixed, 95\% } \\
\mathrm{CI})\end{array}$ & $-2.56[-8.81,3.69]$ \\
\hline 7 Asthma Symtom Score(GIV) & 9 & & $\begin{array}{l}\text { mean difference (Fixed, 95\% } \\
\mathrm{CI})\end{array}$ & Subtotals only \\
\hline 7.1 Parallel & 6 & & $\begin{array}{l}\text { mean difference (Fixed, 95\% } \\
\mathrm{CI})\end{array}$ & $-0.39[-0.54,-0.24]$ \\
\hline 7.2 Cross Over & 3 & & $\begin{array}{l}\text { mean difference (Fixed, 95\% } \\
\mathrm{Cl} \text { ) }\end{array}$ & $-0.38[-0.71,-0.05]$ \\
\hline $\begin{array}{l}8 \text { Asthma Free Days (mean days per pa- } \\
\text { tient) }\end{array}$ & 2 & 332 & $\begin{array}{l}\text { Mean Difference (IV, Fixed, 95\% } \\
\mathrm{CI} \text { ) }\end{array}$ & $0.69[-0.33,1.71]$ \\
\hline 8.1 Parallel & 2 & 332 & $\begin{array}{l}\text { Mean Difference (IV, Fixed, 95\% } \\
\mathrm{CI})\end{array}$ & $0.69[-0.33,1.71]$ \\
\hline 9 Rescue Bronchodilator Use(GIV) & 6 & & $\begin{array}{l}\text { mean difference (Fixed, 95\% } \\
\mathrm{Cl} \text { ) }\end{array}$ & Subtotals only \\
\hline 9.1 Parallel & 5 & & $\begin{array}{l}\text { mean difference (Fixed, 95\% } \\
\mathrm{Cl} \text { ) }\end{array}$ & $-0.24[-0.42,-0.07]$ \\
\hline 9.2 Cross Over & 1 & & $\begin{array}{l}\text { mean difference (Fixed, 95\% } \\
\mathrm{Cl} \text { ) }\end{array}$ & $-0.64[-1.28,-0.00]$ \\
\hline 10 Rescue Bronchodilator Use(\%) & 2 & 69 & Risk Ratio (M-H, Fixed, 95\% Cl) & $0.21[0.09,0.49]$ \\
\hline 10.1 Parallel & 1 & 29 & Risk Ratio (M-H, Fixed, 95\% Cl) & $0.27[0.07,1.05]$ \\
\hline
\end{tabular}




\begin{tabular}{|c|c|c|c|c|}
\hline Outcome or subgroup title & $\begin{array}{l}\text { No. of } \\
\text { studies }\end{array}$ & $\begin{array}{l}\text { No. of } \\
\text { partici- } \\
\text { pants }\end{array}$ & Statistical method & Effect size \\
\hline 10.2 Cross Over & 1 & 40 & Risk Ratio (M-H, Fixed, 95\% Cl) & $0.19[0.06,0.54]$ \\
\hline $\begin{array}{l}11 \text { General Practitioner Visits (mean vis- } \\
\text { its per patient per year) }\end{array}$ & 2 & 467 & $\begin{array}{l}\text { Mean Difference (IV, Fixed, 95\% } \\
\mathrm{Cl} \text { ) }\end{array}$ & $-0.36[-0.91,0.19]$ \\
\hline 11.1 Parallel & 2 & 467 & $\begin{array}{l}\text { Mean Difference (IV, Fixed, 95\% } \\
\mathrm{Cl})\end{array}$ & $-0.36[-0.91,0.19]$ \\
\hline $\begin{array}{l}12 \text { Emergency Department Visits (mean } \\
\text { visits per patient per year) }\end{array}$ & 2 & 467 & $\begin{array}{l}\text { Mean Difference (IV, Fixed, 95\% } \\
\mathrm{Cl} \text { ) }\end{array}$ & $-0.03[-0.13,0.06]$ \\
\hline 12.1 Parallel & 2 & 467 & $\begin{array}{l}\text { Mean Difference (IV, Fixed, 95\% } \\
\mathrm{Cl})\end{array}$ & $-0.03[-0.13,0.06]$ \\
\hline $\begin{array}{l}13 \text { Hospitalizations (mean hospitaliza- } \\
\text { tions per patient per year) }\end{array}$ & 1 & 330 & $\begin{array}{l}\text { Mean Difference (IV, Fixed, 95\% } \\
\mathrm{Cl})\end{array}$ & $0.02[-0.05,0.09]$ \\
\hline 13.1 Parallel & 1 & 330 & $\begin{array}{l}\text { Mean Difference (IV, Fixed, 95\% } \\
\mathrm{Cl} \text { ) }\end{array}$ & $0.02[-0.05,0.09]$ \\
\hline 14 Hospitalizations (\%) & 1 & 132 & Risk Ratio (M-H, Fixed, 95\% Cl) & $1.0[0.06,15.65]$ \\
\hline 14.1 Parallel & 1 & 132 & Risk Ratio (M-H, Fixed, 95\% Cl) & $1.0[0.06,15.65]$ \\
\hline $\begin{array}{l}15 \text { Growth (mean } \mathrm{cm} \text { per patient per } \\
\text { year) }\end{array}$ & 1 & 60 & $\begin{array}{l}\text { Mean Difference (IV, Fixed, 95\% } \\
\mathrm{Cl})\end{array}$ & $-0.5[-1.03,0.03]$ \\
\hline 15.1 Parallel & 1 & 60 & $\begin{array}{l}\text { Mean Difference (IV, Fixed, 95\% } \\
\mathrm{Cl})\end{array}$ & $-0.5[-1.03,0.03]$ \\
\hline 16 Oropharyngeal Side Effects (\%) & 2 & 289 & Risk Ratio (M-H, Fixed, 95\% Cl) & $1.26[0.25,6.48]$ \\
\hline 16.1 Parallel & 2 & 289 & Risk Ratio (M-H, Fixed, 95\% Cl) & $1.26[0.25,6.48]$ \\
\hline $\begin{array}{l}17 \text { Adrenal Suppession (mean nmol uri- } \\
\text { nary cortisol per patient per day) }\end{array}$ & 1 & 48 & $\begin{array}{l}\text { Mean Difference (IV, Fixed, 95\% } \\
\mathrm{CI})\end{array}$ & $-5.40[-41.14,30.34]$ \\
\hline 17.1 Parallel & 1 & 48 & $\begin{array}{l}\text { Mean Difference (IV, Fixed, 95\% } \\
\mathrm{Cl})\end{array}$ & $-5.40[-41.14,30.34]$ \\
\hline 18 Total Adverse Events (\%) & 6 & 1018 & Risk Ratio (M-H, Fixed, 95\% Cl) & $1.02[0.72,1.45]$ \\
\hline 18.1 Parallel & 6 & 1018 & Risk Ratio (M-H, Fixed, 95\% Cl) & $1.02[0.72,1.45]$ \\
\hline $\begin{array}{l}19 \text { Quality of life (mean score per patient } \\
\text { per year) }\end{array}$ & 1 & 335 & $\begin{array}{l}\text { Mean Difference (IV, Fixed, 95\% } \\
\mathrm{Cl})\end{array}$ & $0.30[-1.87,2.47]$ \\
\hline 19.1 Parallel & 1 & 335 & $\begin{array}{l}\text { Mean Difference (IV, Fixed, 95\% } \\
\mathrm{CI} \text { ) }\end{array}$ & $0.30[-1.87,2.47]$ \\
\hline
\end{tabular}


Analysis 1.1. Comparison 1 Inhaled Corticosteroids vs Cromolyn for Children, Outcome 1 Exacerbations (mean number per patient per year).

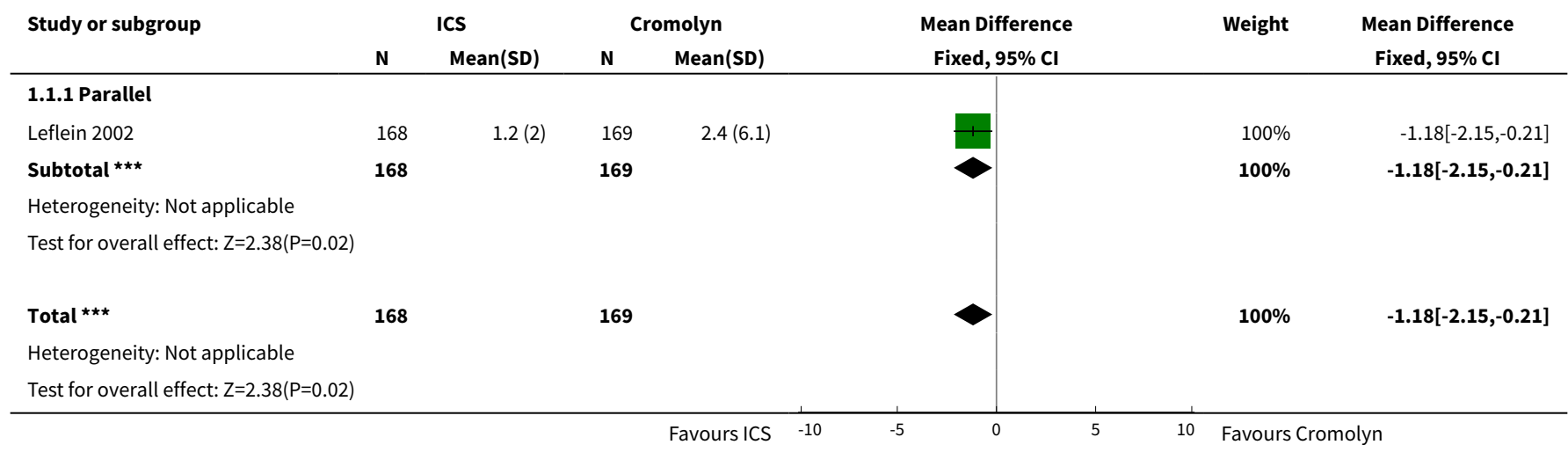

Analysis 1.2. Comparison 1 Inhaled Corticosteroids vs Cromolyn for Children, Outcome 2 Exacerbations (\%).

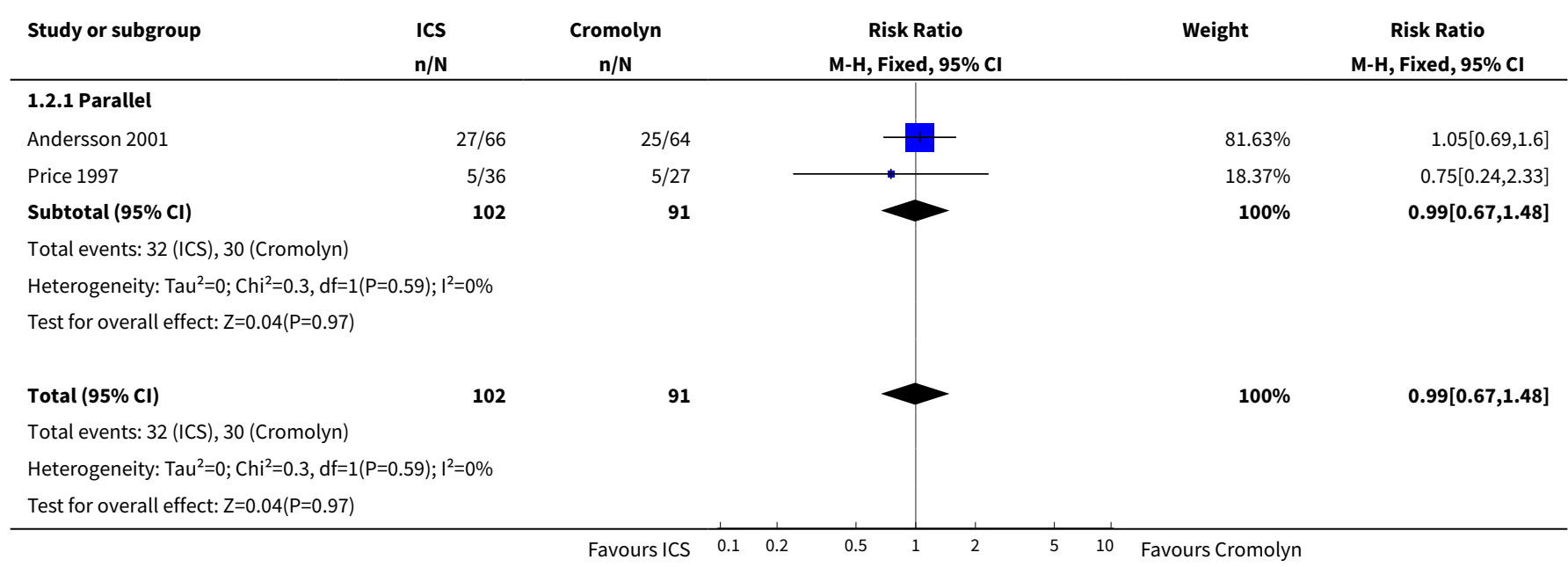

Analysis 1.3. Comparison 1 Inhaled Corticosteroids vs Cromolyn for Children, Outcome 3 FEV1(GIV).

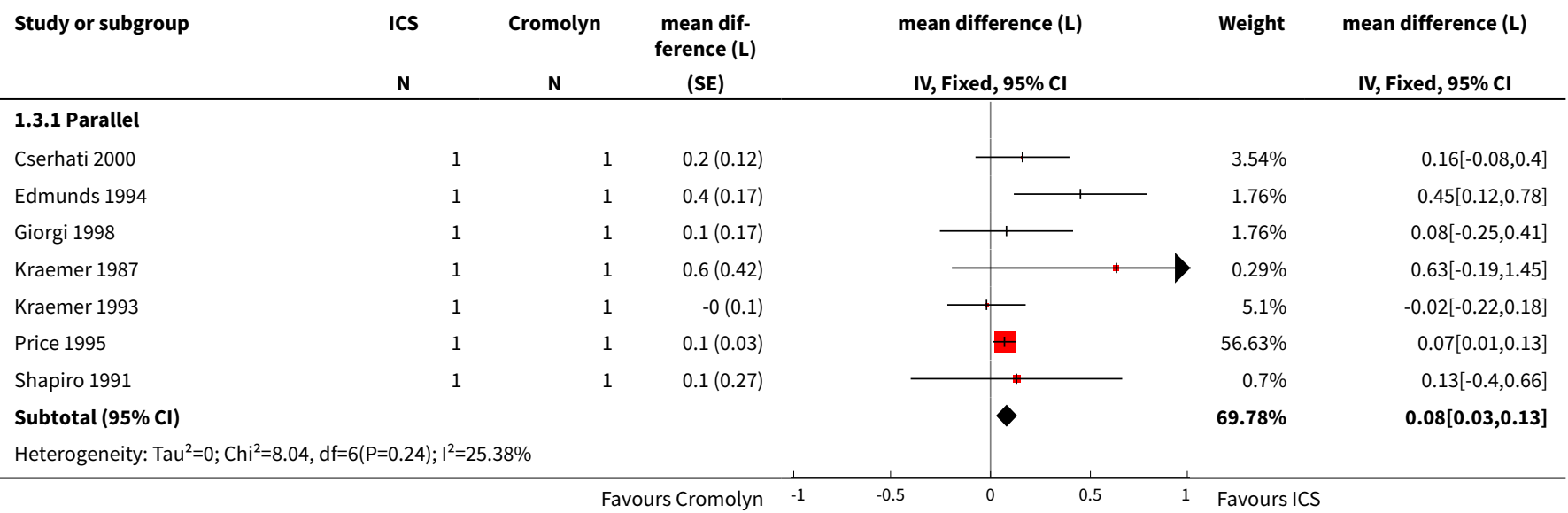




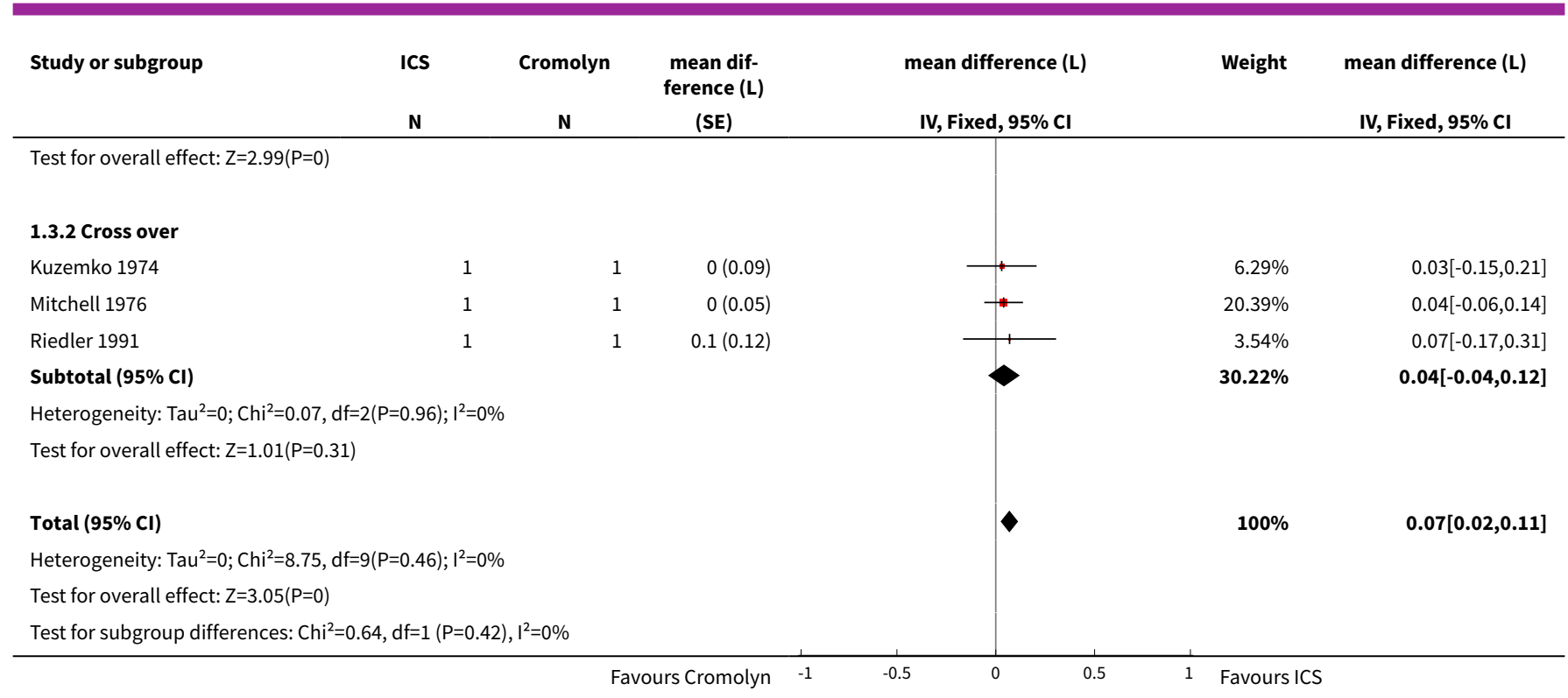

Analysis 1.4. Comparison 1 Inhaled Corticosteroids vs Cromolyn for Children, Outcome 4 PEF(GIV).

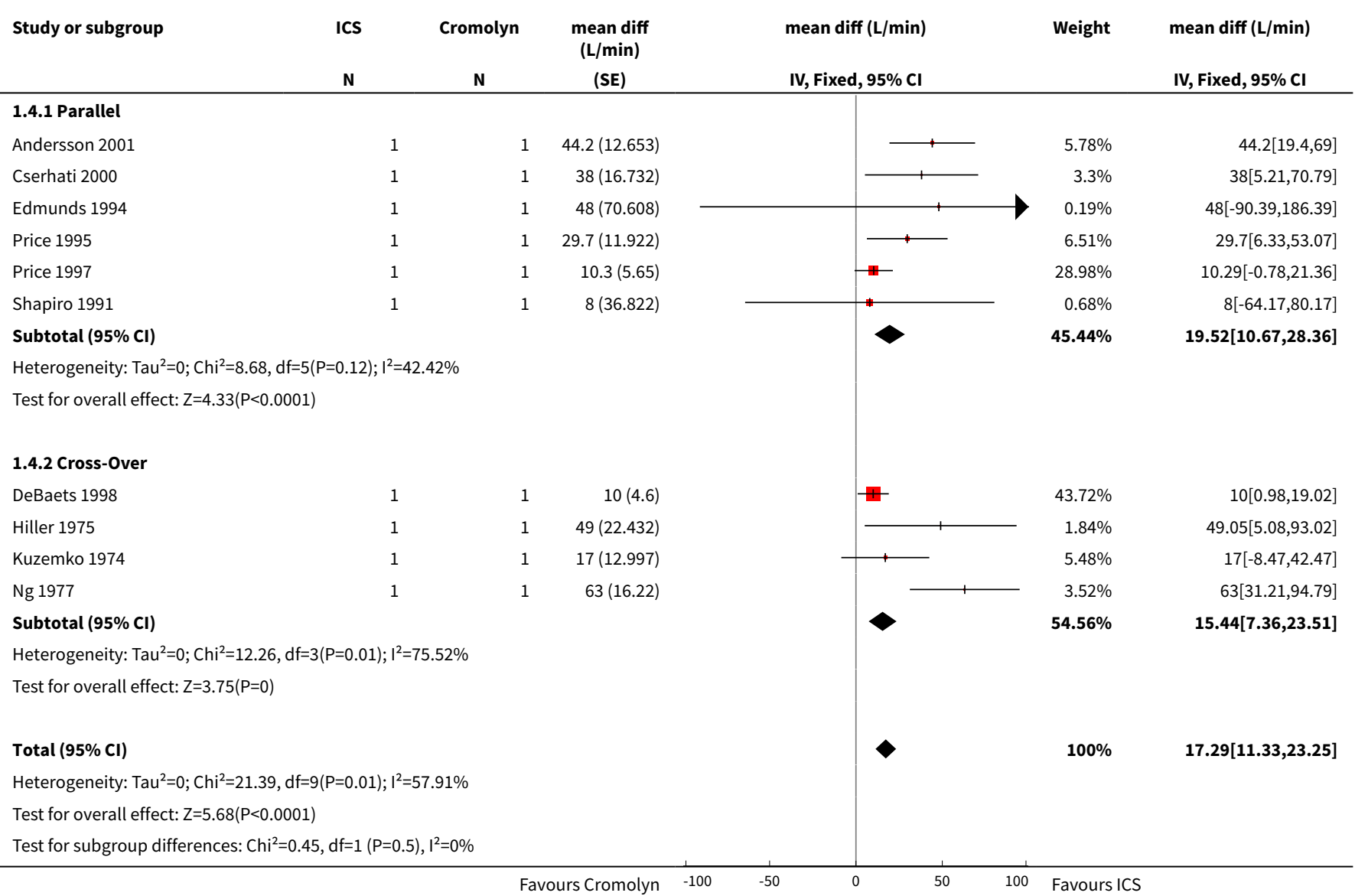


Analysis 1.5. Comparison 1 Inhaled Corticosteroids vs Cromolyn for Children, Outcome 5 School Absence (mean days per patient per year).

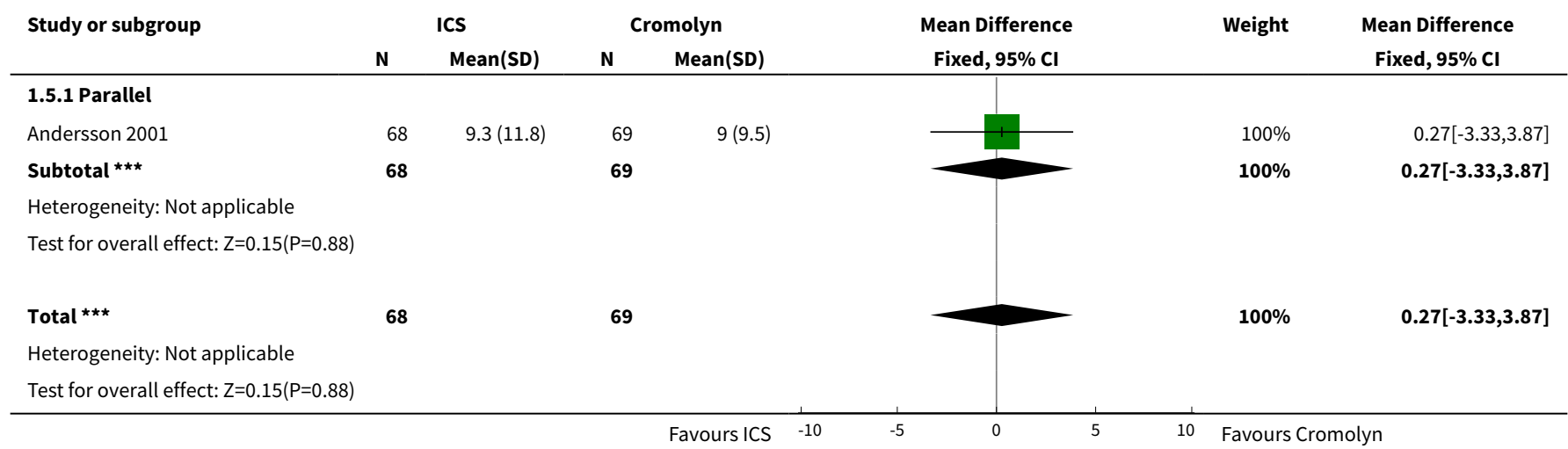

Analysis 1.6. Comparison 1 Inhaled Corticosteroids vs Cromolyn for Children, Outcome 6 Nights Disturbed by Asthma (mean nights per patient per year).

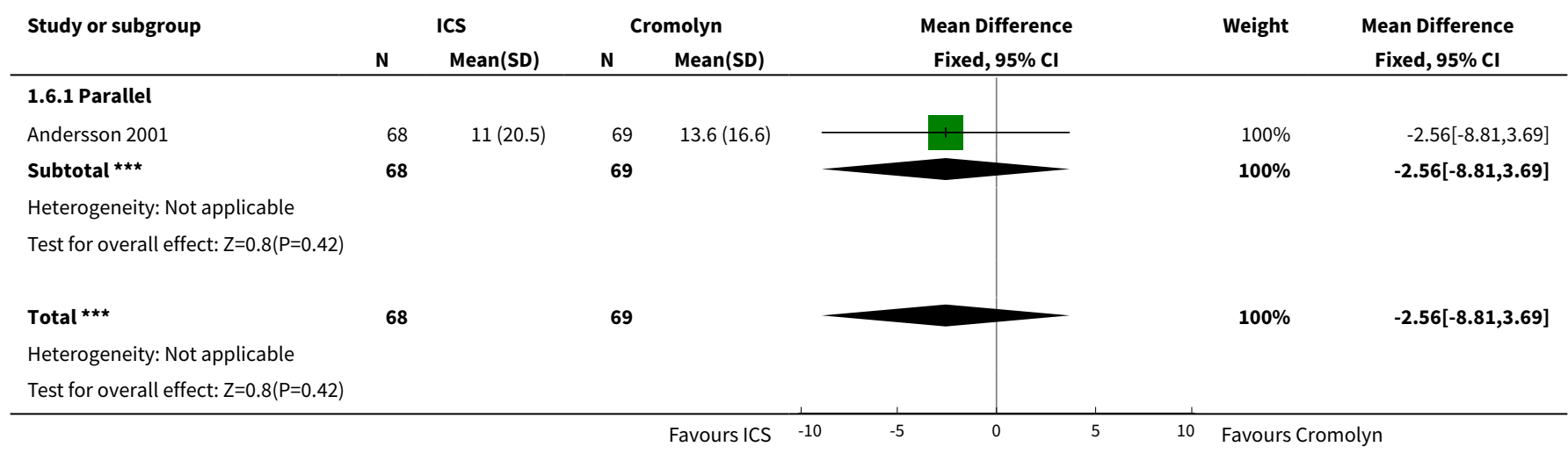

Analysis 1.7. Comparison 1 Inhaled Corticosteroids vs Cromolyn for Children, Outcome 7 Asthma Symtom Score(GIV).

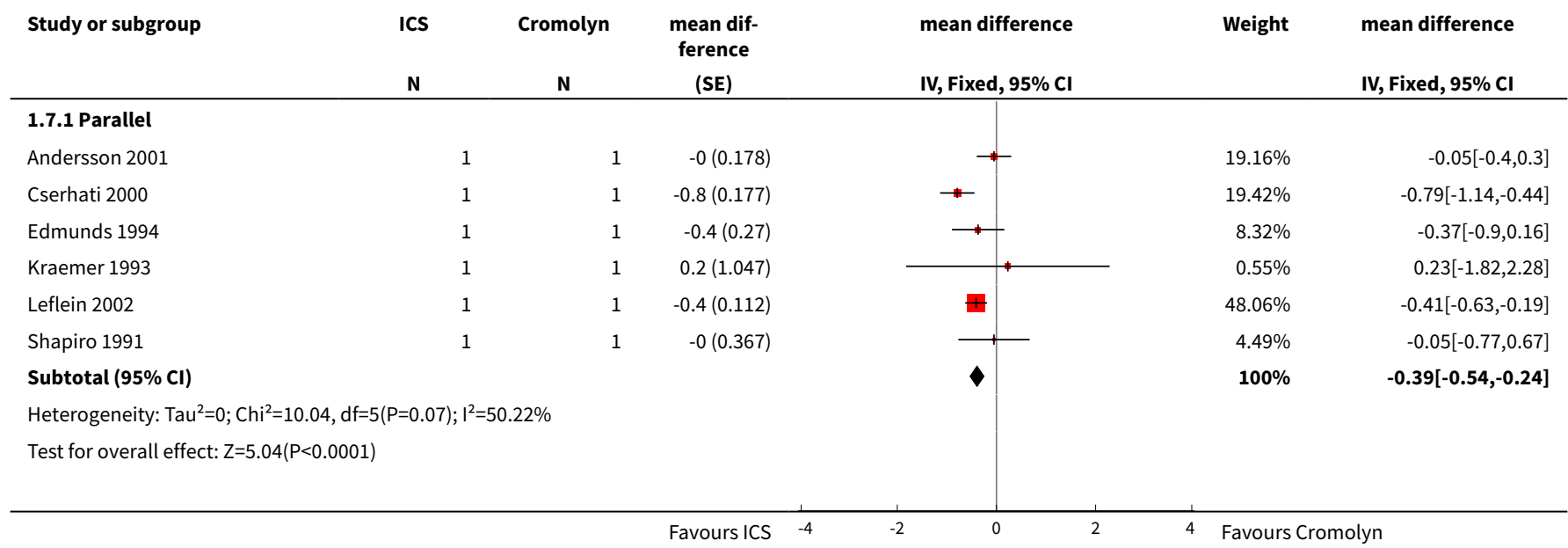




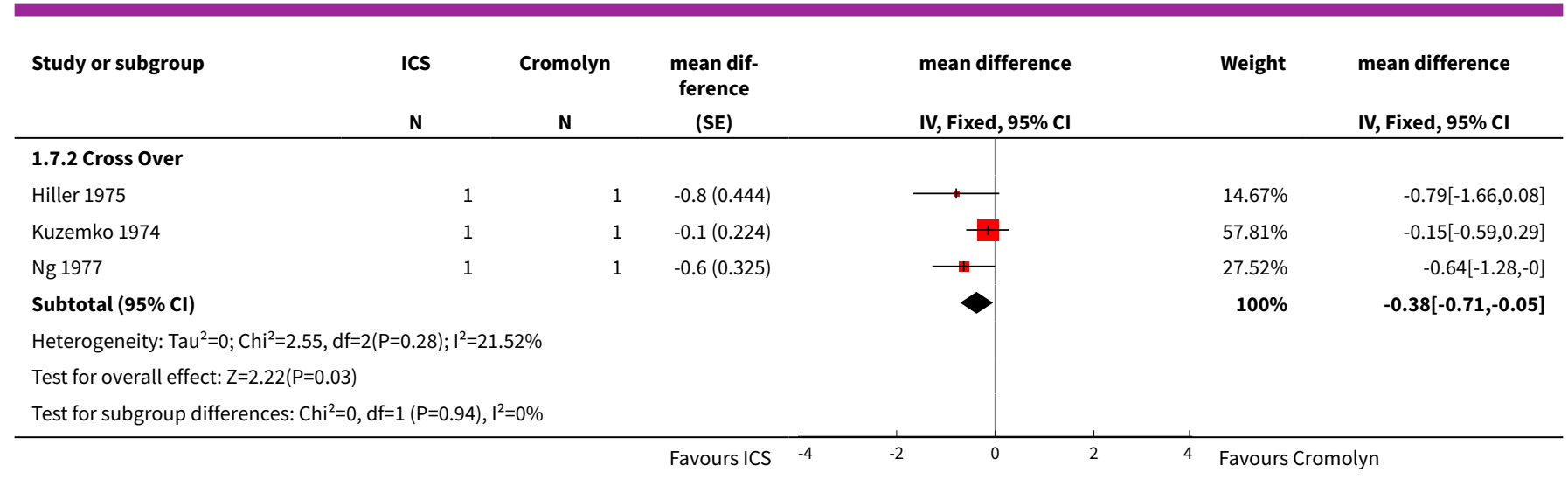

Analysis 1.8. Comparison 1 Inhaled Corticosteroids vs Cromolyn for Children, Outcome 8 Asthma Free Days (mean days per patient).

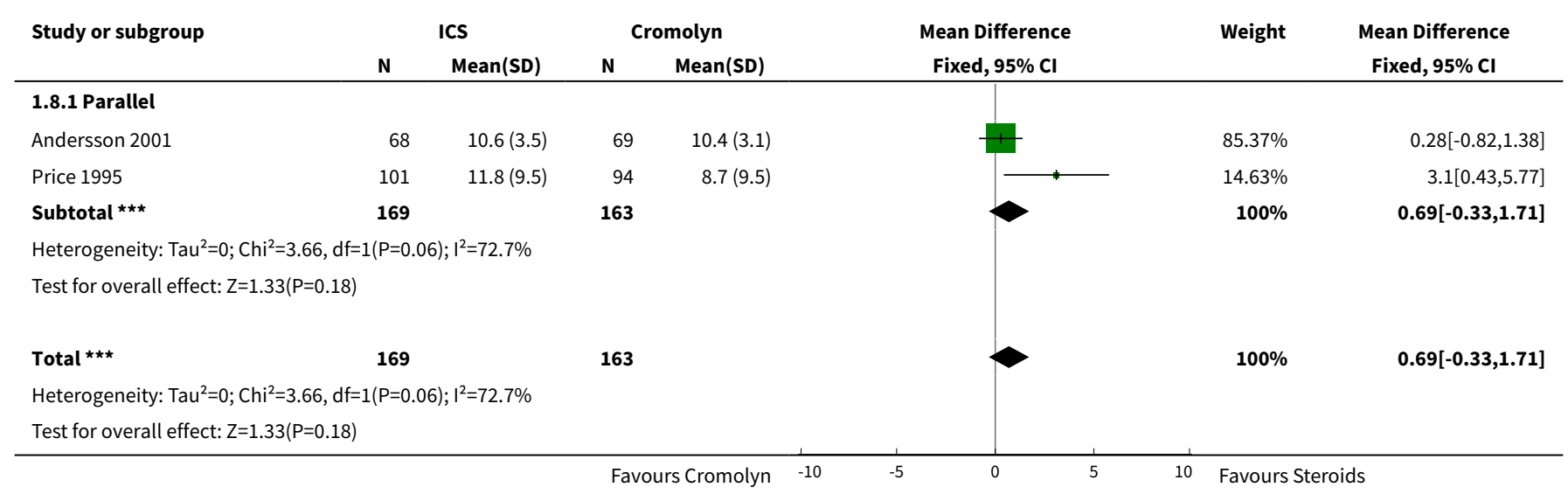

Analysis 1.9. Comparison 1 Inhaled Corticosteroids vs Cromolyn for Children, Outcome 9 Rescue Bronchodilator Use(GIV).

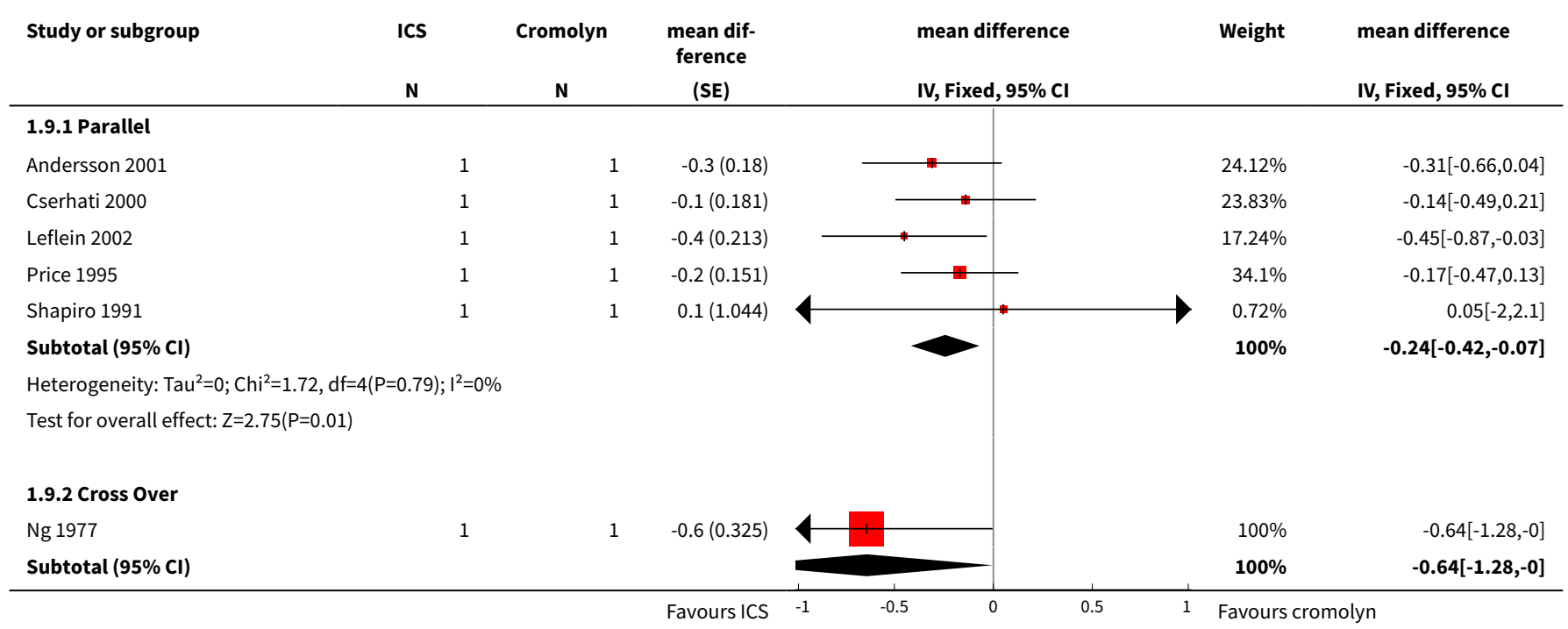




\begin{tabular}{|c|c|c|c|c|c|c|c|}
\hline Study or subgroup & ICS & Cromolyn & $\begin{array}{l}\text { mean dif- } \\
\text { ference }\end{array}$ & \multicolumn{2}{|c|}{ mean difference } & Weight & $\begin{array}{l}\text { mean difference } \\
\text { IV, Fixed, } 95 \% \mathrm{CI}\end{array}$ \\
\hline \multicolumn{8}{|c|}{ Test for overall effect: $Z=1.97(P=0.05)$} \\
\hline \multicolumn{8}{|c|}{ Test for subgroup differences: $\mathrm{Chi}^{2}=1.39, \mathrm{df}=1(\mathrm{P}=0.24), \mathrm{I}^{2}=28.08 \%$} \\
\hline
\end{tabular}

Analysis 1.10. Comparison 1 Inhaled Corticosteroids vs Cromolyn for Children, Outcome 10 Rescue Bronchodilator Use(\%).

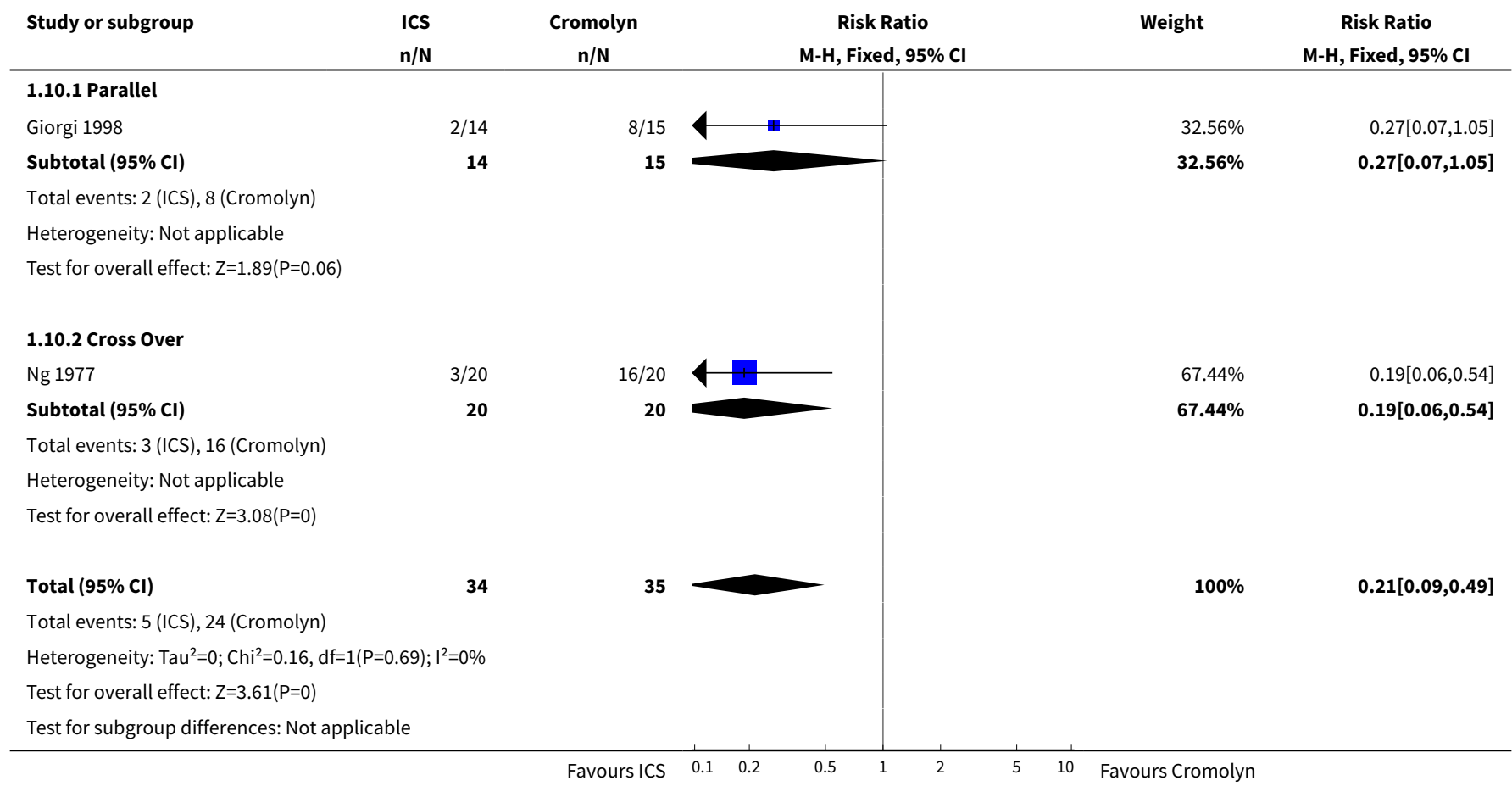

\section{Analysis 1.11. Comparison 1 Inhaled Corticosteroids vs Cromolyn for Children, Outcome 11 General Practitioner Visits (mean visits per patient per year).}

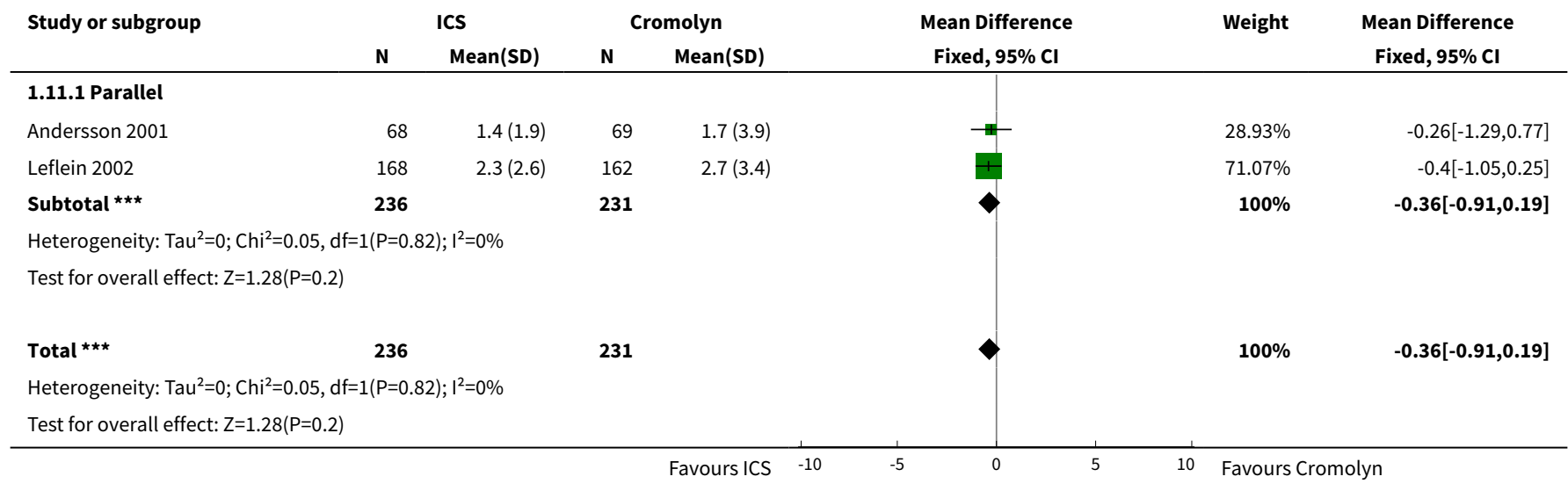


Analysis 1.12. Comparison 1 Inhaled Corticosteroids vs Cromolyn for Children, Outcome 12 Emergency Department Visits (mean visits per patient per year).

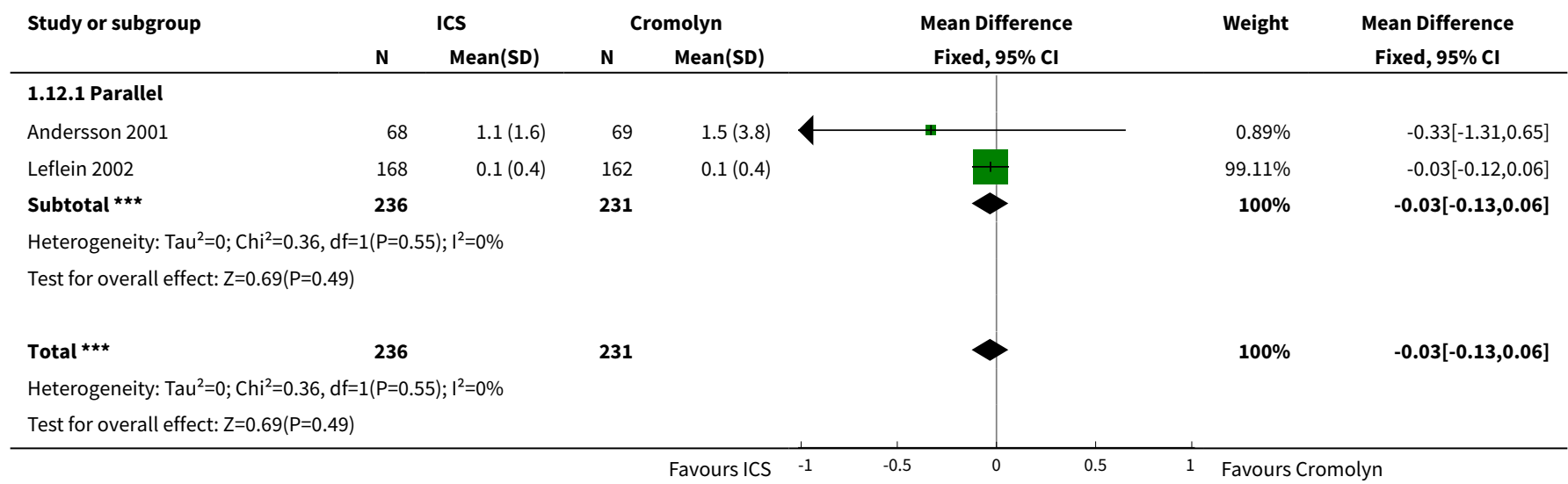

Analysis 1.13. Comparison 1 Inhaled Corticosteroids vs Cromolyn for Children, Outcome 13 Hospitalizations (mean hospitalizations per patient per year).

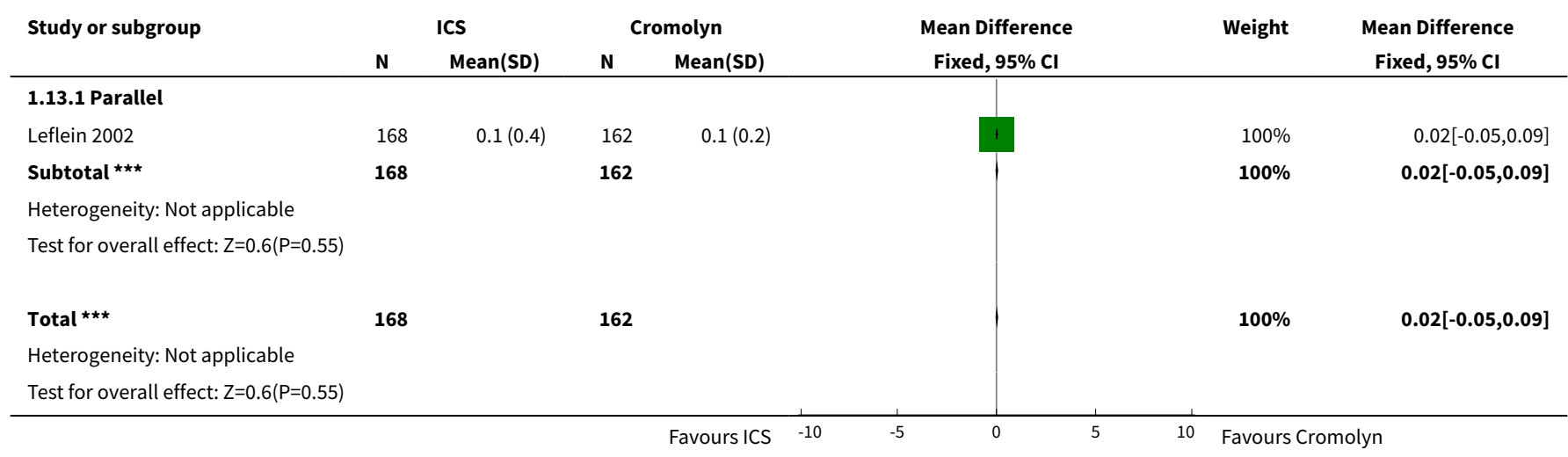

Analysis 1.14. Comparison 1 Inhaled Corticosteroids vs Cromolyn for Children, Outcome 14 Hospitalizations (\%).

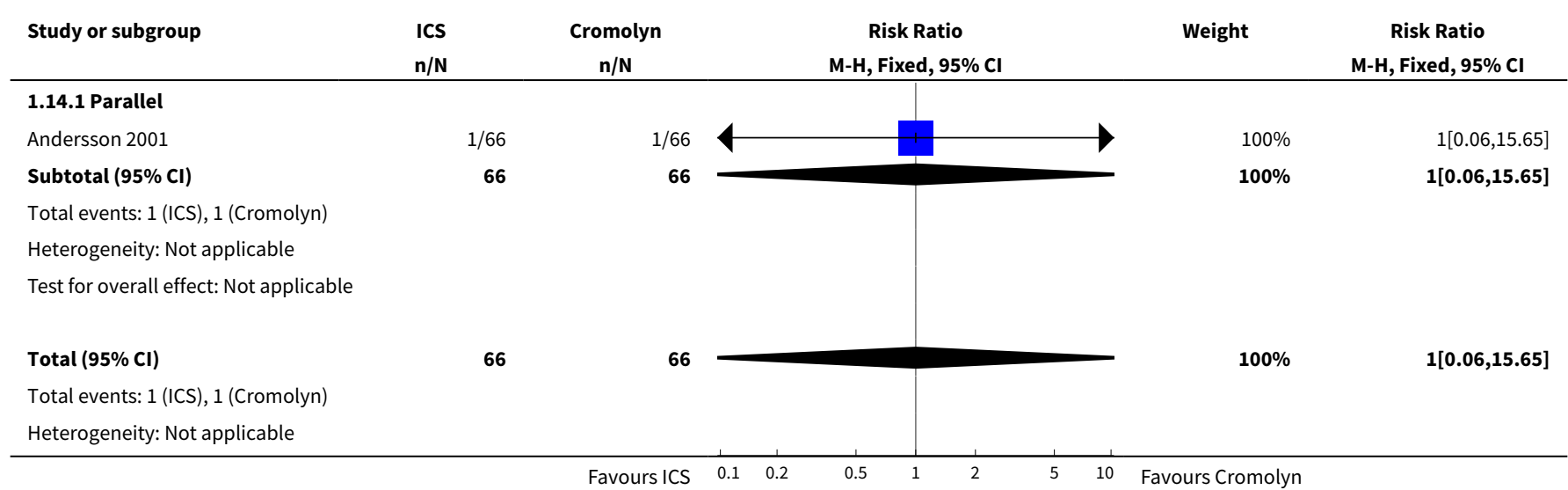




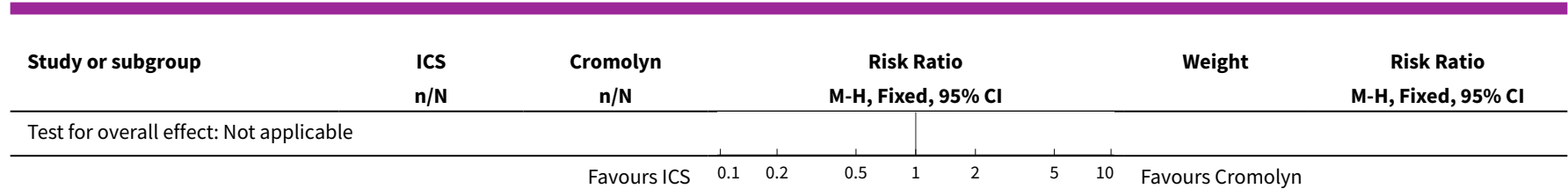

Analysis 1.15. Comparison 1 Inhaled Corticosteroids vs Cromolyn for Children, Outcome 15 Growth (mean $\mathrm{cm}$ per patient per year).

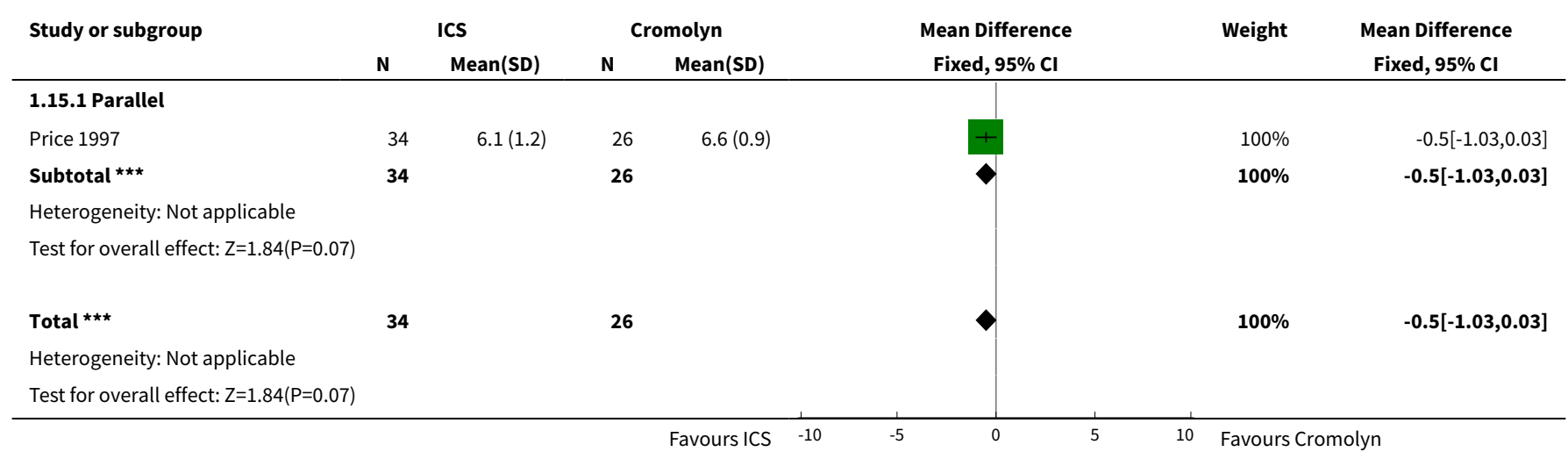

Analysis 1.16. Comparison 1 Inhaled Corticosteroids vs Cromolyn for Children, Outcome 16 Oropharyngeal Side Effects (\%).

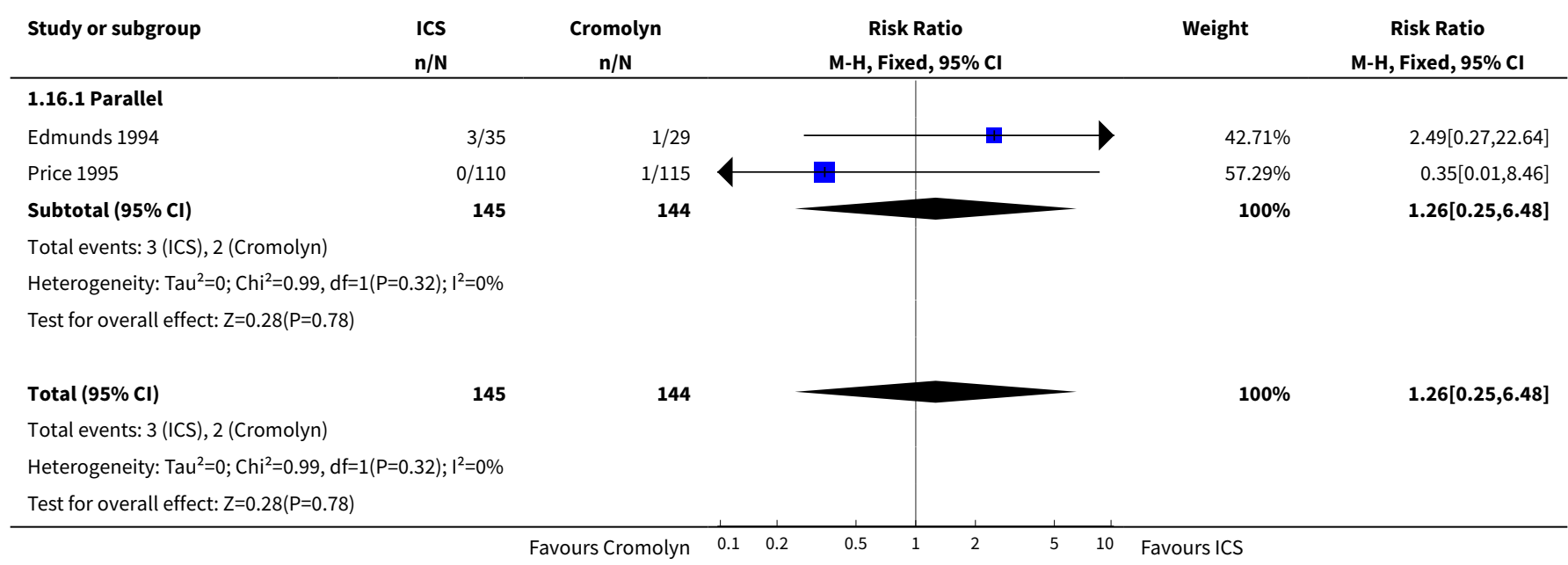

Analysis 1.17. Comparison 1 Inhaled Corticosteroids vs Cromolyn for Children, Outcome 17 Adrenal Suppession (mean nmol urinary cortisol per patient per day).

\begin{tabular}{|c|c|c|c|c|c|c|c|c|c|}
\hline \multirow[t]{2}{*}{ Study or subgroup } & \multicolumn{2}{|c|}{ ICS } & \multicolumn{2}{|c|}{ Cromolyn } & & \multirow{2}{*}{\multicolumn{2}{|c|}{$\begin{array}{c}\text { Mean Difference } \\
\text { Fixed, } 95 \% \mathrm{Cl}\end{array}$}} & \multirow[t]{2}{*}{ Weight } & \multirow{2}{*}{$\begin{array}{c}\text { Mean Difference } \\
\text { Fixed, } 95 \% \mathrm{Cl}\end{array}$} \\
\hline & $\mathbf{N}$ & Mean(SD) & $\mathbf{N}$ & Mean(SD) & & & & & \\
\hline \multicolumn{10}{|l|}{ 1.17.1 Parallel } \\
\hline
\end{tabular}




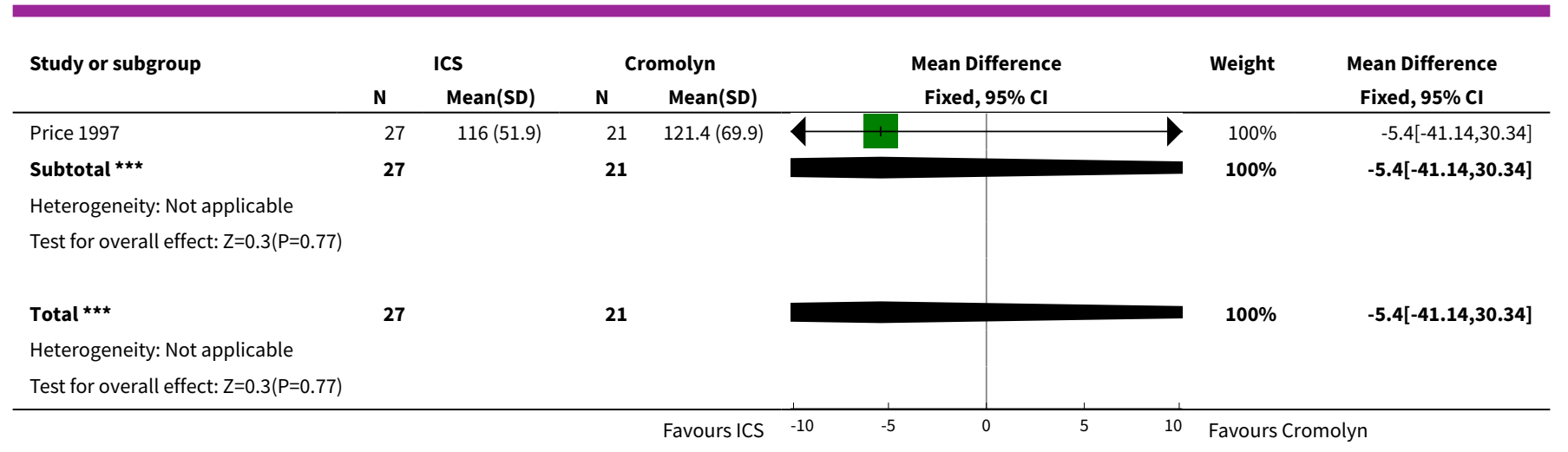

Analysis 1.18. Comparison 1 Inhaled Corticosteroids vs Cromolyn for Children, Outcome 18 Total Adverse Events (\%).

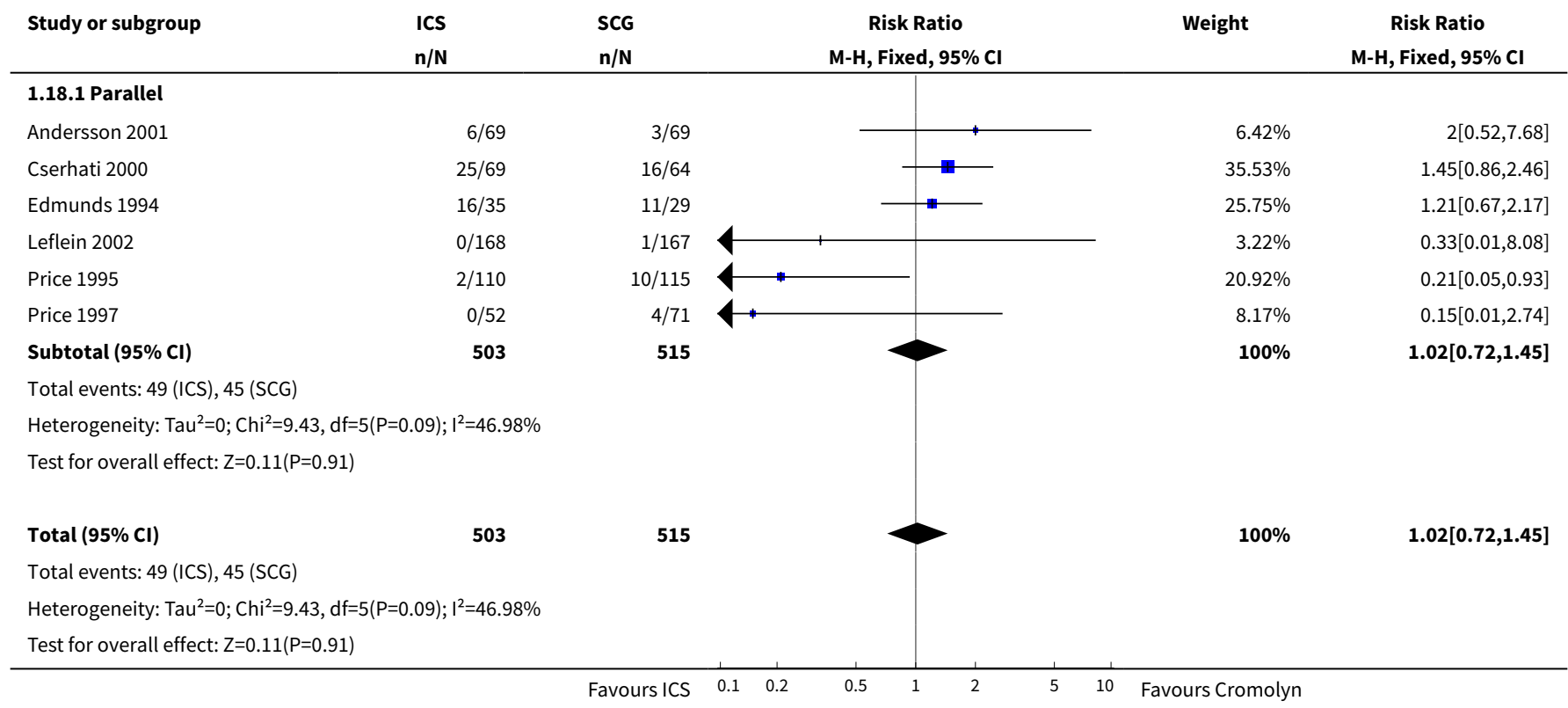

Analysis 1.19. Comparison 1 Inhaled Corticosteroids vs Cromolyn for Children, Outcome 19 Quality of life (mean score per patient per year).

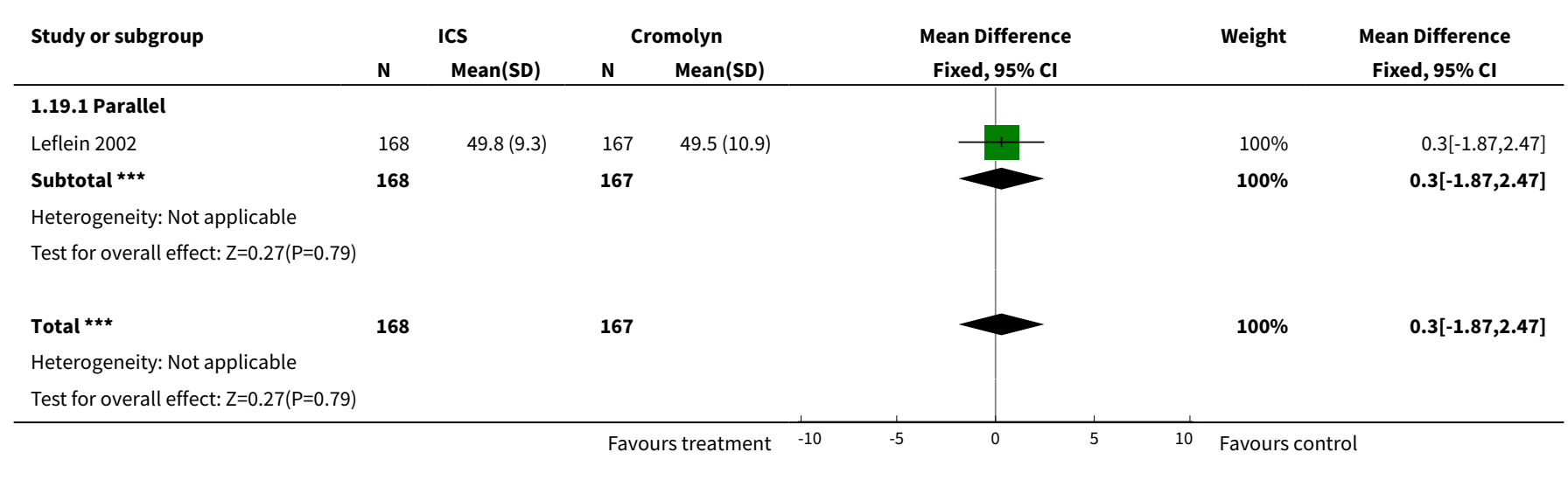


Comparison 2. Inhaled Corticosteroids vs Cromolyn for Children by Asthma Severity

\begin{tabular}{lllll}
\hline $\begin{array}{l}\text { Outcome or subgroup ti- } \\
\text { tle }\end{array}$ & $\begin{array}{l}\text { No. of } \\
\text { studies }\end{array}$ & $\begin{array}{l}\text { No. of } \\
\text { partici- } \\
\text { pants }\end{array}$ & Statistical method & Effect size \\
\hline 1 FEV1(GIV) & 10 & mean difference (Fixed, 95\% Cl) & Subtotals only \\
\hline 1.1 Mild-Moderate & 9 & mean difference (Fixed, 95\% Cl) & $0.07[0.03,0.12]$ \\
\hline 1.2 Unclear & 1 & mean difference (Fixed, 95\% Cl) & $0.03[-0.15,0.21]$ \\
\hline 2 PEF(GIV) & 10 & mean diff (L/min) (Fixed, 95\% Cl) & Subtotals only \\
\hline 2.1 Mild-Moderate & 6 & mean diff (L/min) (Fixed, 95\% Cl) & $19.52[10.67,28.36]$ \\
\hline 2.2 Moderate-Severe & 2 & mean diff (L/min) (Fixed, 95\% Cl) & $58.21[32.45,83.97]$ \\
\hline 2.3 Unclear & 2 & mean diff (L/min) (Fixed, 95\% Cl) & $10.78[2.28,19.28]$ \\
\hline
\end{tabular}

\section{Analysis 2.1. Comparison 2 Inhaled Corticosteroids vs Cromolyn} for Children by Asthma Severity, Outcome 1 FEV1(GIV).

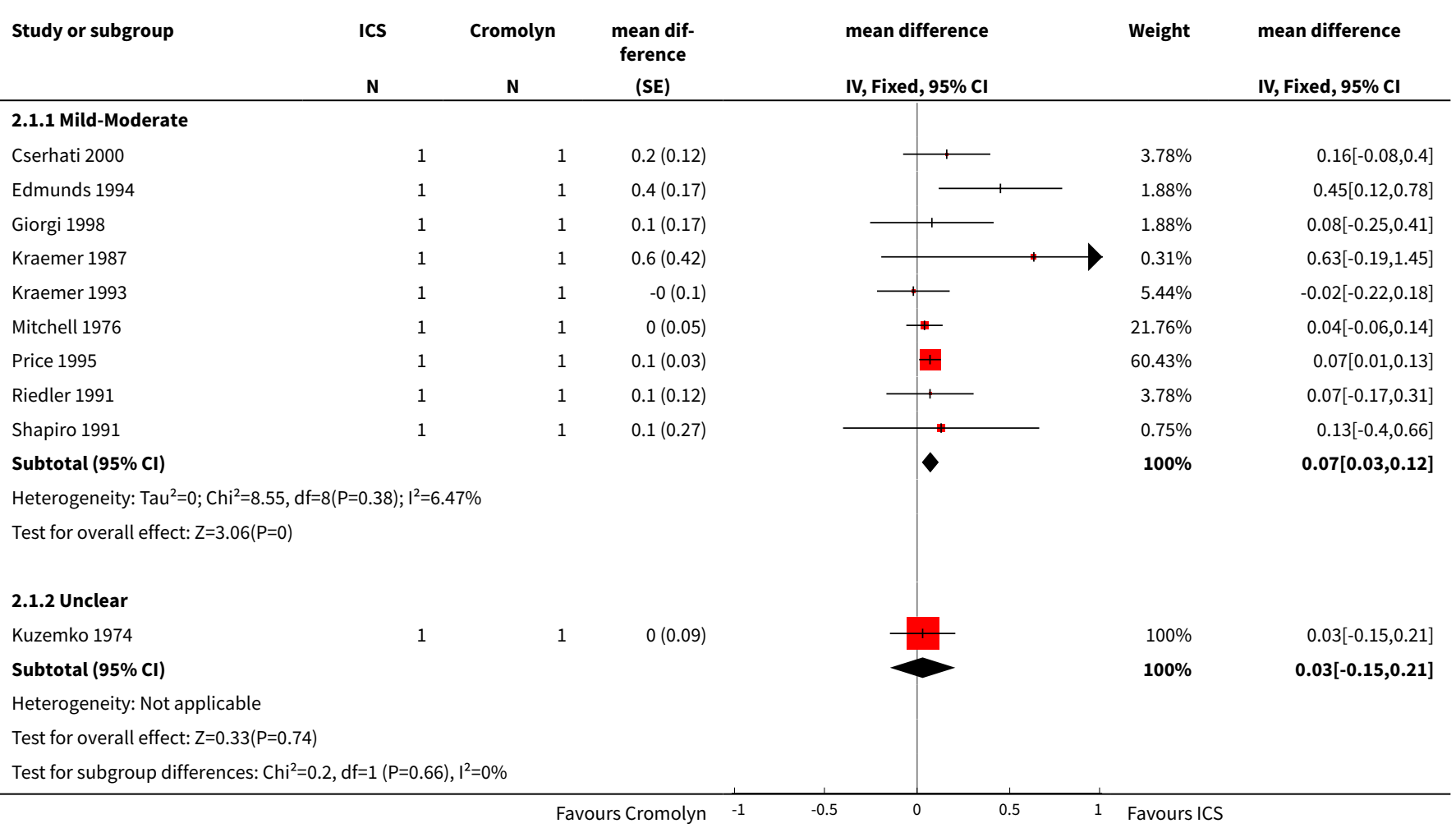


Analysis 2.2. Comparison 2 Inhaled Corticosteroids vs Cromolyn for Children by Asthma Severity, Outcome 2 PEF(GIV).

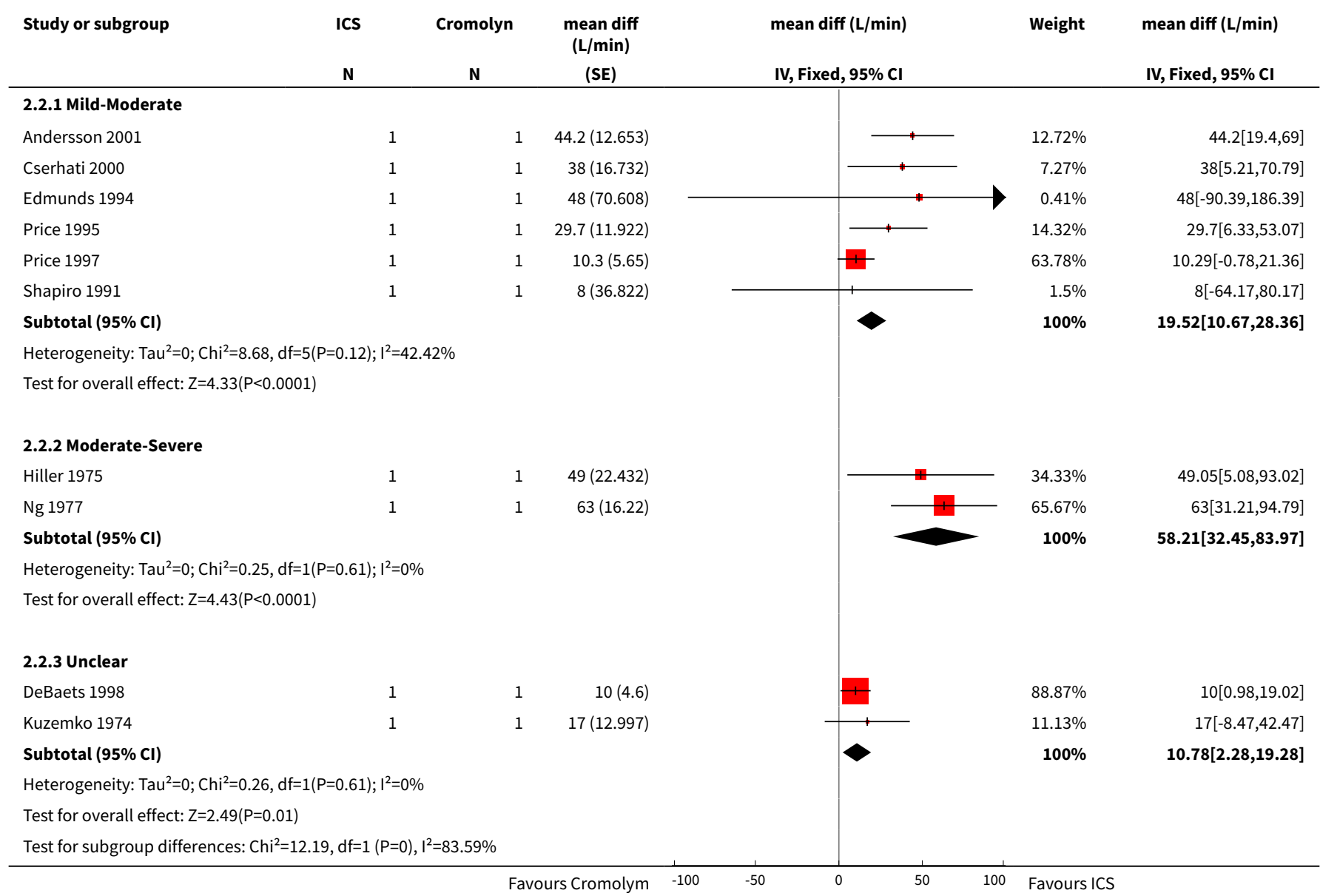

\section{Comparison 3. Inhalded Corticosteroids vs Cromolyn for Children by BDP-equivalent Steroid Dosage}

\begin{tabular}{lllll}
\hline $\begin{array}{l}\text { Outcome or subgroup ti- } \\
\text { tle }\end{array}$ & $\begin{array}{l}\text { No. of } \\
\text { studies }\end{array}$ & $\begin{array}{l}\text { No. of } \\
\text { partici- } \\
\text { pants }\end{array}$ & Statistical method & Effect size \\
\hline 1 FEV1 (GIV) & 10 & mean difference (Fixed, 95\% Cl) & Subtotals only \\
\hline 1.1 Low Dose & 5 & mean difference (Fixed, 95\% Cl) & $0.06[0.01,0.10]$ \\
\hline 1.2 Medium Dose & 5 & mean difference (Fixed, $95 \% \mathrm{Cl})$ & $0.18[0.04,0.31]$ \\
\hline 2 PEF(GIV) & 10 & mean diff (L/min) (Fixed, 95\% Cl) & Subtotals only \\
\hline 2.1 Low Dose & 5 & mean diff (L/min) (Fixed, 95\% Cl) & $12.03[5.58,18.49]$ \\
\hline 2.2 Medium Dose & 5 & mean diff (L/min) (Fixed, $95 \% \mathrm{Cl})$ & $47.98[32.39,63.57]$ \\
\hline
\end{tabular}


Analysis 3.1. Comparison 3 Inhalded Corticosteroids vs Cromolyn for Children by BDP-equivalent Steroid Dosage, Outcome 1 FEV1 (GIV).

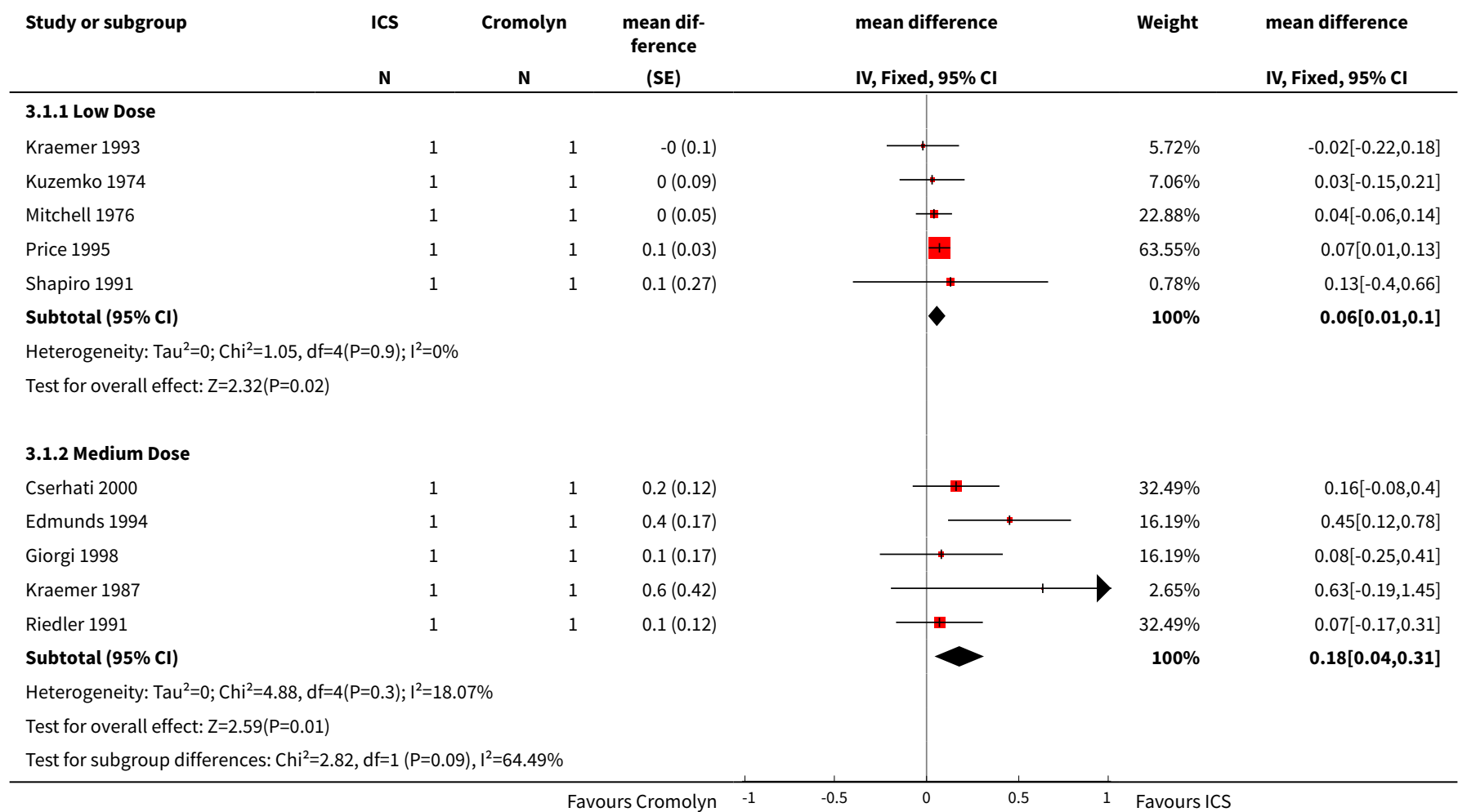

Analysis 3.2. Comparison 3 Inhalded Corticosteroids vs Cromolyn for Children by BDP-equivalent Steroid Dosage, Outcome 2 PEF(GIV).

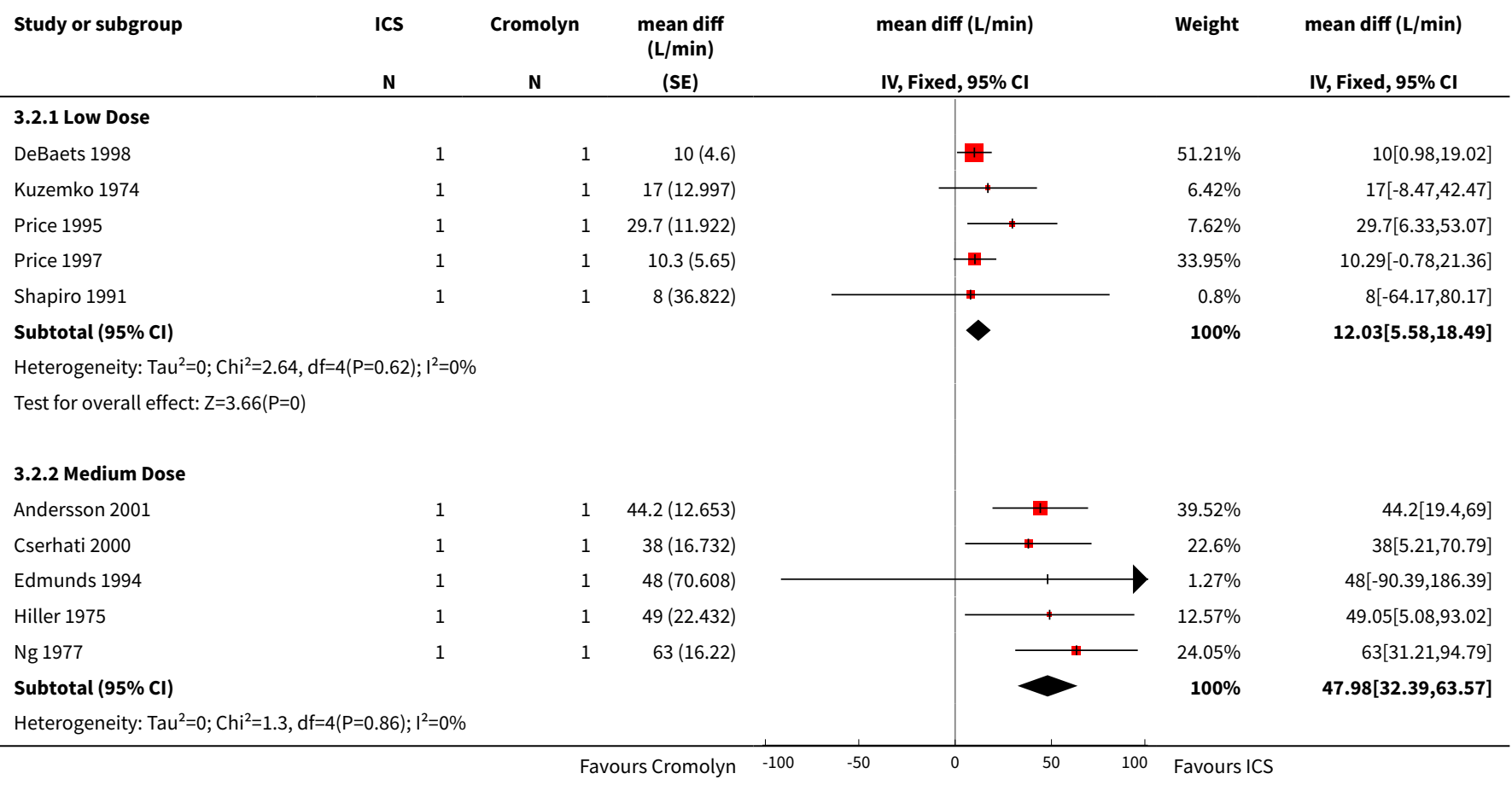




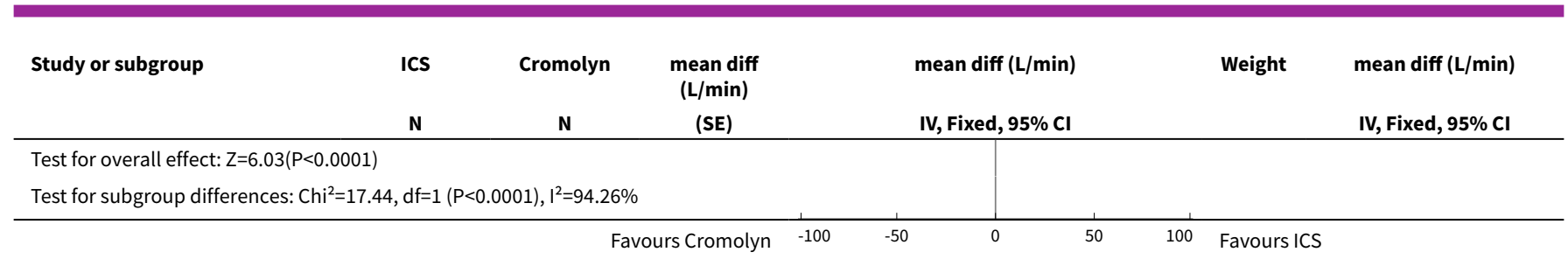

Comparison 4. Inhaled Corticosteroids vs Cromolyn for Children by Study Quality

\begin{tabular}{lllll}
\hline Outcome or subgroup title & $\begin{array}{l}\text { No. of } \\
\text { studies }\end{array}$ & $\begin{array}{l}\text { No. of } \\
\text { partici- } \\
\text { pants }\end{array}$ & Statistical method & Effect size \\
\hline 1 FEV1(GIV) & 10 & mean difference (Fixed, 95\% Cl) & Subtotals only \\
\hline 1.1 With Quality Score 1 or 2 & 4 & mean difference (Fixed, 95\% Cl) & $0.09[-0.04,0.22]$ \\
\hline 1.2 With Quality Score3, 4 or 5 & 6 & mean difference (Fixed, 95\% Cl) & $0.07[0.02,0.11]$ \\
\hline 2 PEF(GIV) & 10 & mean diff (L/min) (Fixed, 95\% Cl) & Subtotals only \\
\hline 2.1 With Quality Score 1 or 2 & 1 & mean diff (L/min) (Fixed, 95\% Cl) & $48.0[-90.39,186.39]$ \\
\hline 2.2 With Quality Score 3, 4 or 5 & 9 & mean diff (L/min) (Fixed, 95\% Cl) & $17.23[11.27,23.20]$ \\
\hline
\end{tabular}

Analysis 4.1. Comparison 4 Inhaled Corticosteroids vs Cromolyn for Children by Study Quality, Outcome 1 FEV1(GIV).

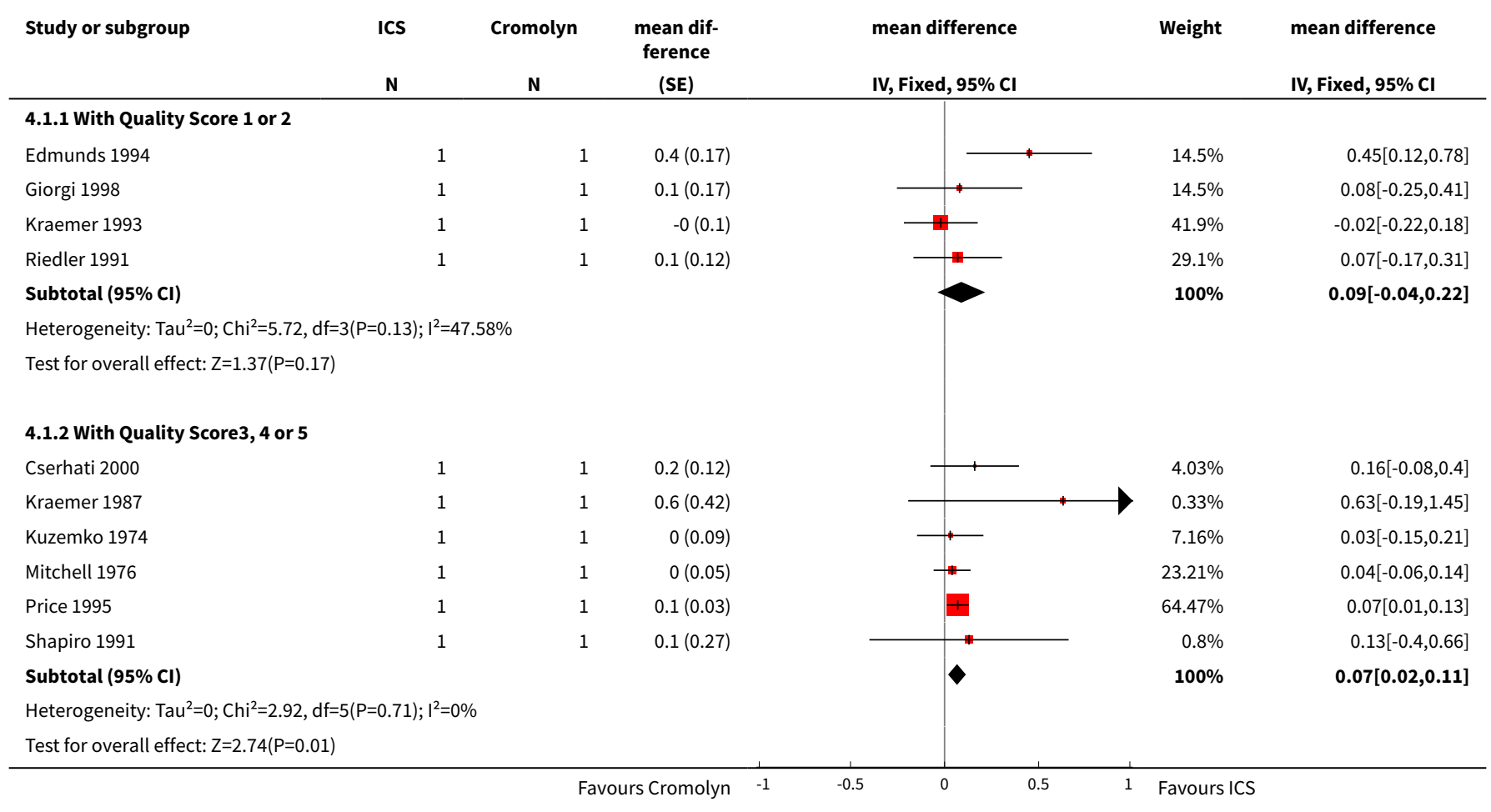




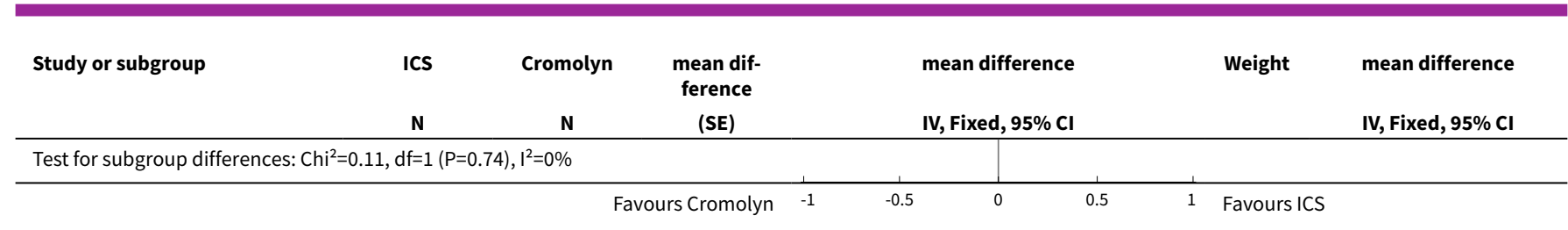

Analysis 4.2. Comparison 4 Inhaled Corticosteroids vs Cromolyn for Children by Study Quality, Outcome 2 PEF(GIV).

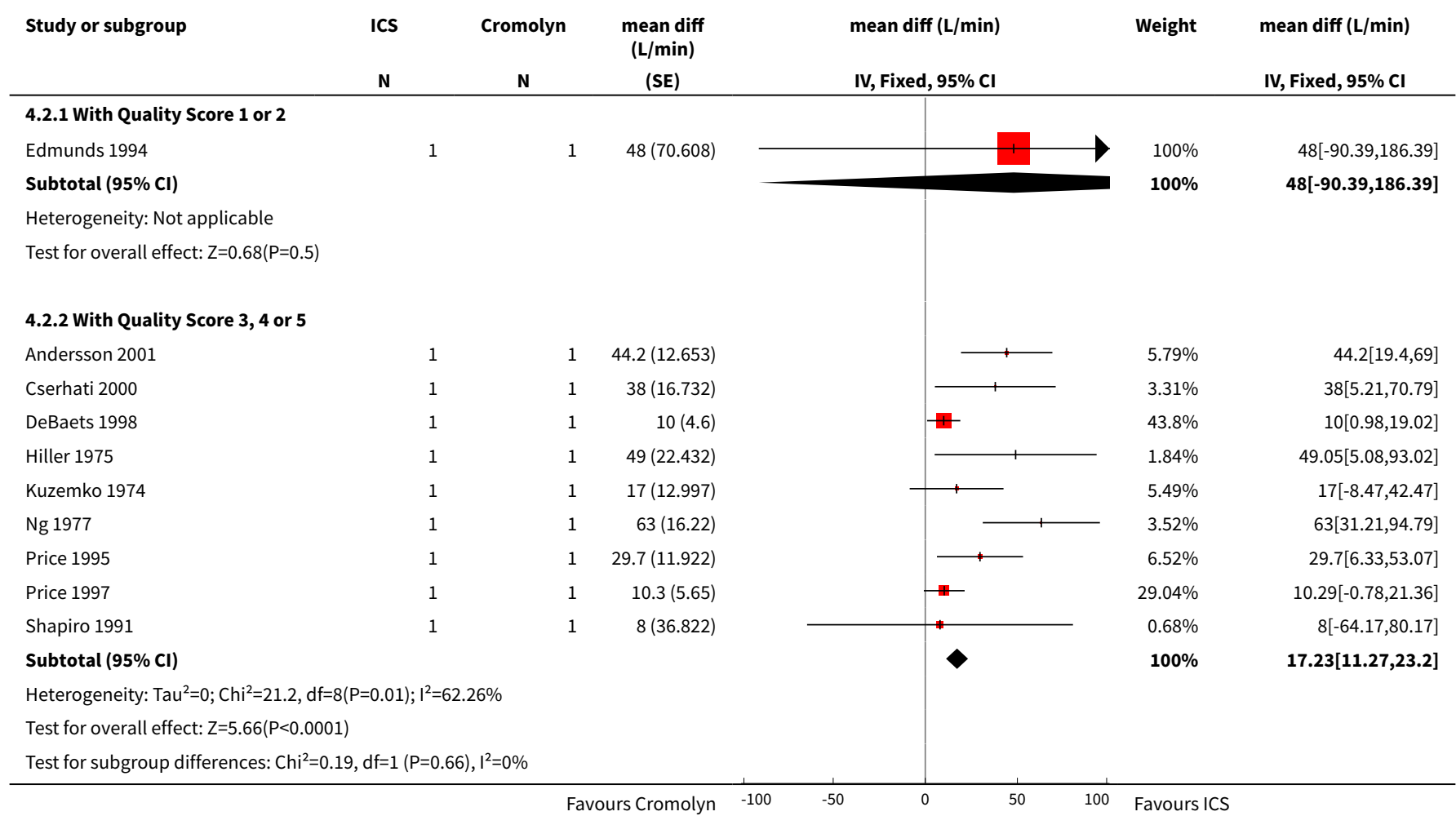

\section{Comparison 5. Inhaled Corticosteroids vs Cromolyn for Children by Cromolyn Dosage}

\begin{tabular}{lllll}
\hline $\begin{array}{l}\text { Outcome or subgroup } \\
\text { title }\end{array}$ & $\begin{array}{l}\text { No. of } \\
\text { studies }\end{array}$ & $\begin{array}{l}\text { No. of } \\
\text { partici- } \\
\text { pants }\end{array}$ & Statistical method & Effect size \\
\hline 1 FEV1(GIV) & 10 & mean difference (L) (Fixed, 95\% Cl) & Subtotals only \\
\hline 1.1 Optimal & 4 & mean difference (L) (Fixed, 95\% Cl) & $0.07[0.03,0.12]$ \\
\hline 1.2 Sub-optimal & 6 & mean difference (L) (Fixed, 95\% Cl) & $0.04[-0.06,0.15]$ \\
\hline 2 PEF(GIV) & 10 & mean diff (L/min) (Fixed, 95\% Cl) & Subtotals only \\
\hline 2.1 Optimal & 7 & mean diff (L/min) (Fixed, 95\% Cl) & $23.81[15.39,32.23]$ \\
\hline 2.2 Sub-optimal & 3 & mean diff (L/min) (Fixed, 95\% Cl) & $10.74[2.30,19.18]$ \\
\hline
\end{tabular}




\section{Analysis 5.1. Comparison 5 Inhaled Corticosteroids vs Cromolyn for Children by Cromolyn Dosage, Outcome 1 FEV1(GIV).}

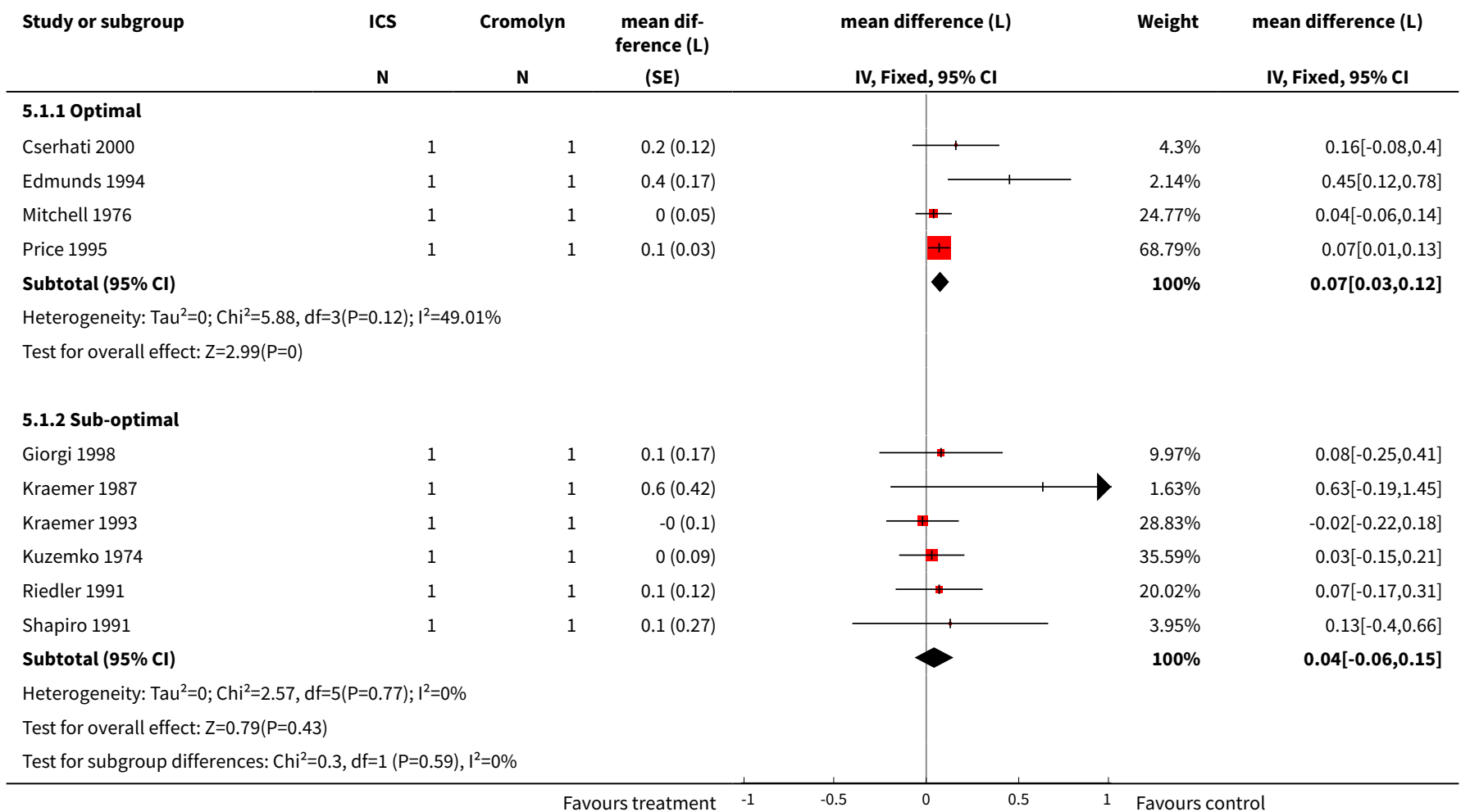

\section{Analysis 5.2. Comparison 5 Inhaled Corticosteroids vs Cromolyn for Children by Cromolyn Dosage, Outcome 2 PEF(GIV).}

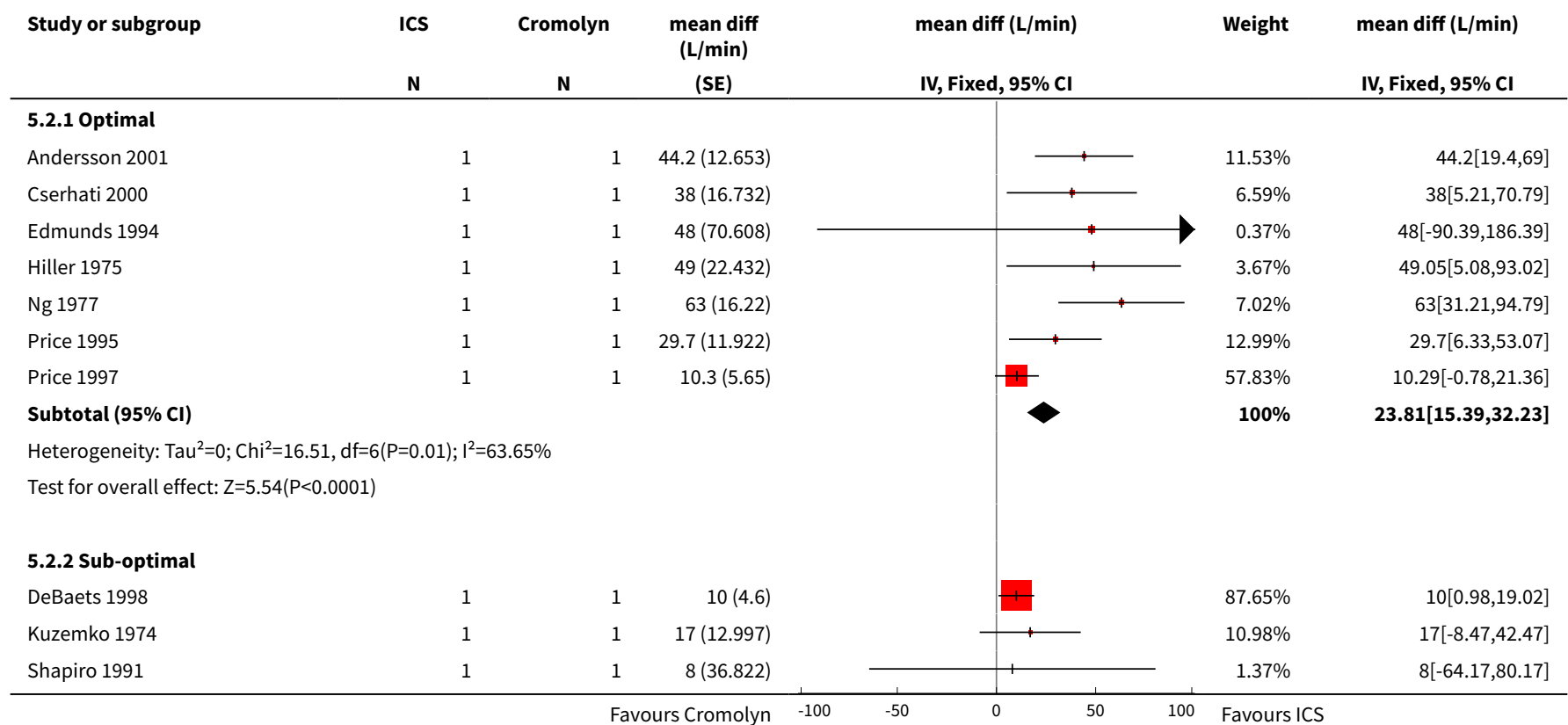




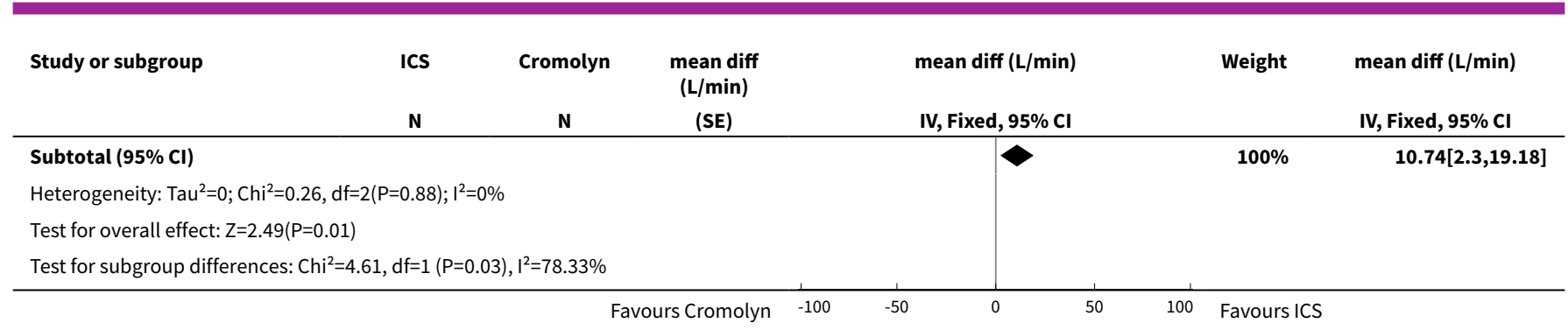

\section{Comparison 6. Inhaled Corticosteroids vs Cromolyn for Adults}

\begin{tabular}{|c|c|c|c|c|}
\hline Outcome or subgroup title & $\begin{array}{l}\text { No. of } \\
\text { studies }\end{array}$ & $\begin{array}{l}\text { No. of } \\
\text { partici- } \\
\text { pants }\end{array}$ & Statistical method & Effect size \\
\hline $\begin{array}{l}1 \text { Exacerbations (mean number } \\
\text { per patient per } 6 \text { months) }\end{array}$ & 1 & 24 & Mean Difference (IV, Fixed, 95\% Cl) & $-3.30[-5.62,-0.98]$ \\
\hline 1.1 Cross Over & 1 & 24 & Mean Difference (IV, Fixed, 95\% CI) & $-3.30[-5.62,-0.98]$ \\
\hline 2 Exacerbations (\%) & 1 & 24 & Risk Ratio (M-H, Fixed, 95\% Cl) & $0.22[0.06,0.82]$ \\
\hline 2.1 Cross Over & 1 & 24 & Risk Ratio (M-H, Fixed, 95\% Cl) & $0.22[0.06,0.82]$ \\
\hline 3 FEV(GIV) & 7 & & mean difference (L) (Fixed, 95\% Cl) & $0.21[0.13,0.28]$ \\
\hline 3.1 Parallel & 3 & & mean difference $(\mathrm{L})$ (Fixed, 95\% Cl) & $-0.05[-0.23,0.14]$ \\
\hline 3.2 Cross Over & 4 & & mean difference $(\mathrm{L})$ (Fixed, 95\% Cl) & $0.25[0.17,0.33]$ \\
\hline 4 PEF(GIV) & 5 & & mean diff (L/min) (Fixed, 95\% Cl) & $28.16[18.73,37.59]$ \\
\hline 4.1 Parallel & 1 & & mean diff (L/min) (Fixed, 95\% Cl) & $-17.2[-98.95,64.55]$ \\
\hline 4.2 Cross Over & 4 & & mean diff (L/min) (Fixed, 95\% Cl) & $28.77[19.28,38.26]$ \\
\hline 5 Asthma Symptom Score(GIV) & 4 & & mean difference (Fixed, 95\% Cl) & Subtotals only \\
\hline 5.1 Parallel & 1 & & mean difference (Fixed, 95\% Cl) & $0.32[-0.91,1.55]$ \\
\hline 5.2 Cross Over & 3 & & mean difference (Fixed, 95\% Cl) & $-0.58[-0.96,-0.20]$ \\
\hline $\begin{array}{l}6 \text { Rescue Bronchodilator Use } \\
\text { (GIV) }\end{array}$ & 3 & & mean difference (Fixed, 95\% Cl) & Subtotals only \\
\hline 6.1 Cross Over & 3 & & mean difference (Fixed, 95\% Cl) & $-0.52[-0.90,-0.14]$ \\
\hline $\begin{array}{l}7 \text { Oropharyngeal Side Effects } \\
\text { (\%) }\end{array}$ & 1 & 62 & Risk Ratio (M-H, Fixed, 95\% Cl) & $2.0[0.39,10.13]$ \\
\hline 7.1 Cross Over & 1 & 62 & Risk Ratio (M-H, Fixed, 95\% Cl) & $2.0[0.39,10.13]$ \\
\hline 8 Total Adverse Events (\%) & 2 & 99 & Risk Ratio (M-H, Fixed, 95\% Cl) & $1.04[0.37,2.91]$ \\
\hline
\end{tabular}




\begin{tabular}{lllll}
\hline Outcome or subgroup title & $\begin{array}{l}\text { No. of } \\
\text { studies }\end{array}$ & $\begin{array}{l}\text { No. of } \\
\text { partici- } \\
\text { pants }\end{array}$ & Statistical method & Effect size \\
\hline 8.1 Parallel & 1 & 37 & Risk Ratio $(\mathrm{M}-\mathrm{H}$, Fixed, $95 \% \mathrm{Cl})$ & $1.06[0.31,3.60]$ \\
\hline 8.2 Cross Over & 1 & 62 & Risk Ratio $(\mathrm{M}-\mathrm{H}$, Fixed, $95 \% \mathrm{Cl})$ & $1.0[0.15,6.66]$ \\
\hline
\end{tabular}

Analysis 6.1. Comparison 6 Inhaled Corticosteroids vs Cromolyn for Adults, Outcome 1 Exacerbations (mean number per patient per 6 months).

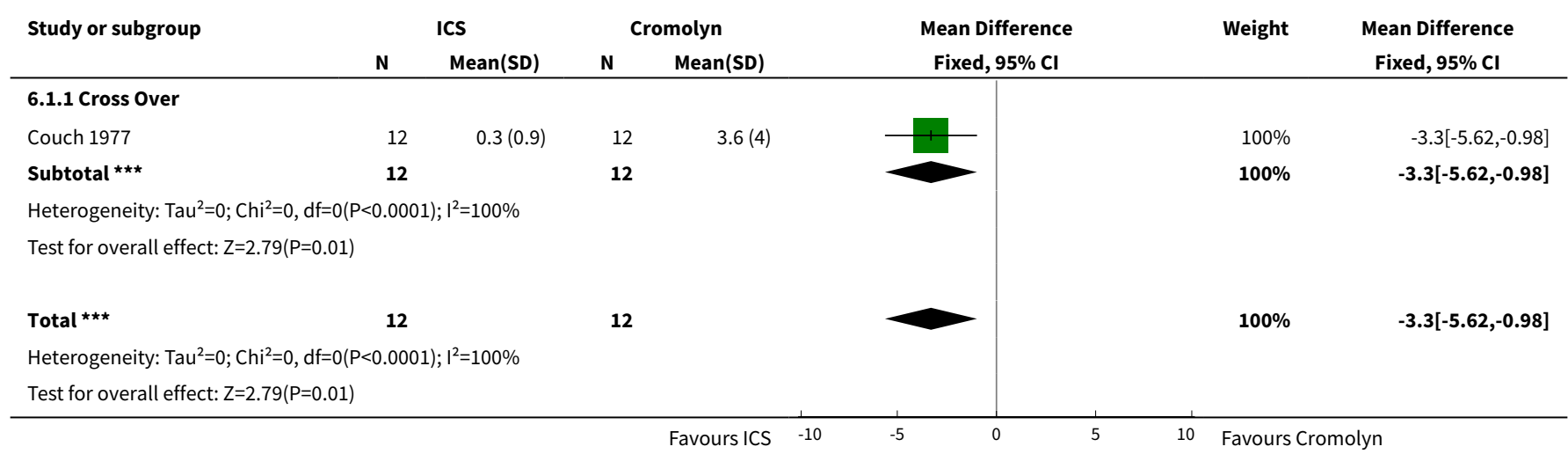

Analysis 6.2. Comparison 6 Inhaled Corticosteroids vs Cromolyn for Adults, Outcome 2 Exacerbations (\%).

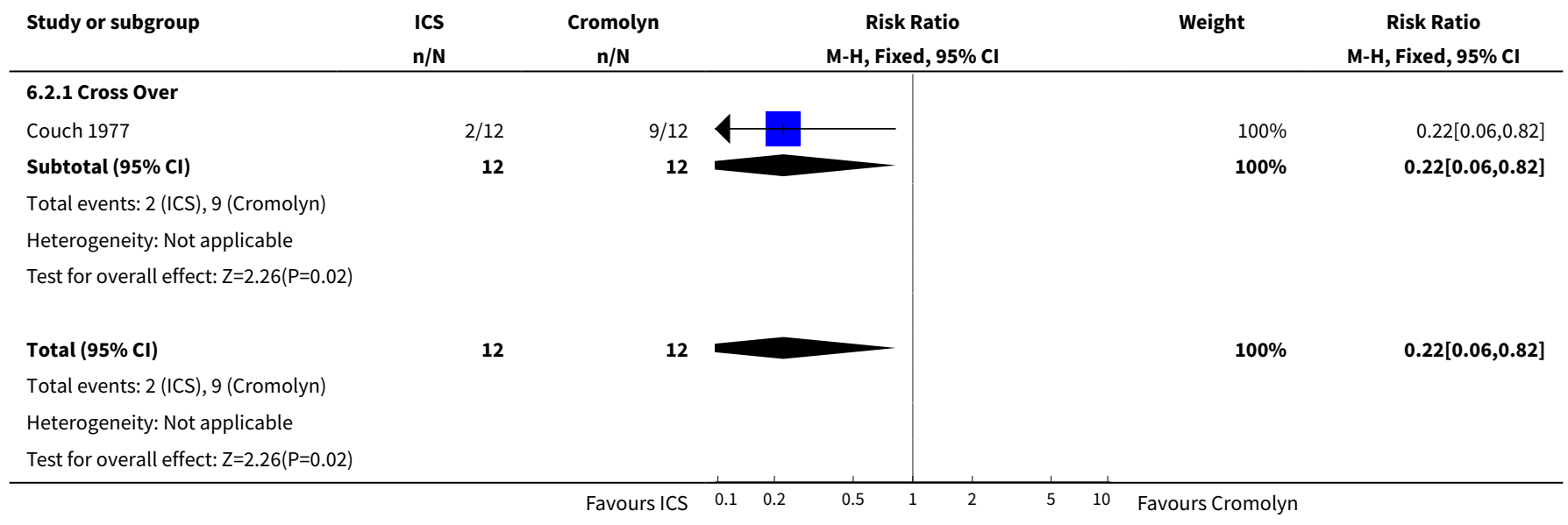

Analysis 6.3. Comparison 6 Inhaled Corticosteroids vs Cromolyn for Adults, Outcome 3 FEV(GIV).

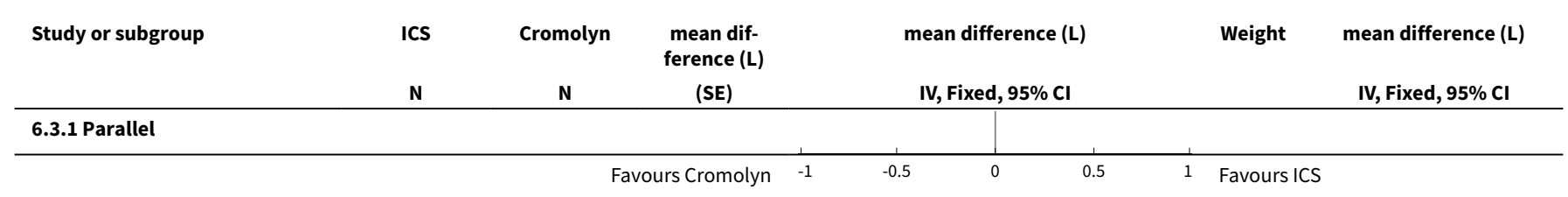




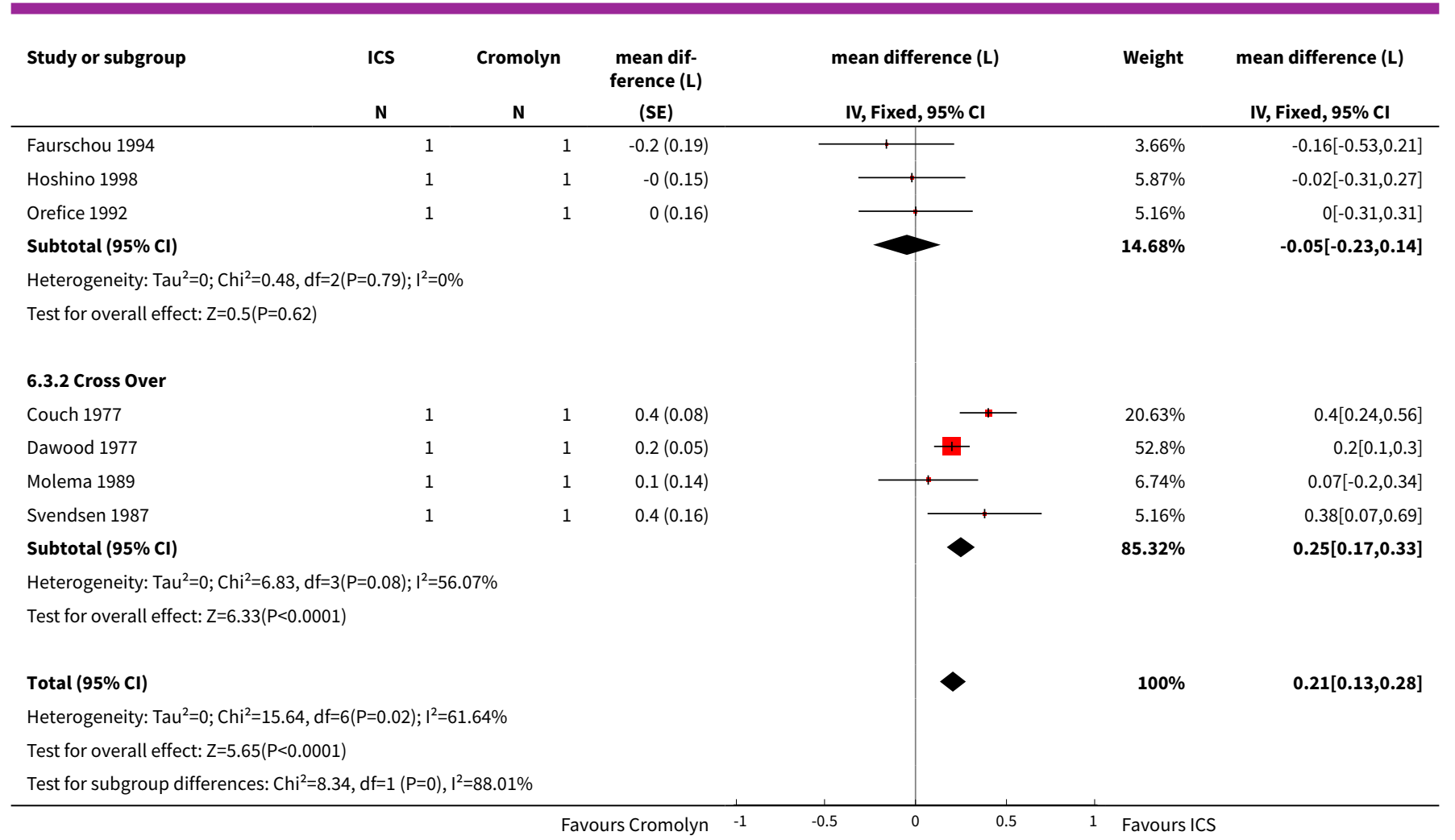

Analysis 6.4. Comparison 6 Inhaled Corticosteroids vs Cromolyn for Adults, Outcome 4 PEF(GIV).

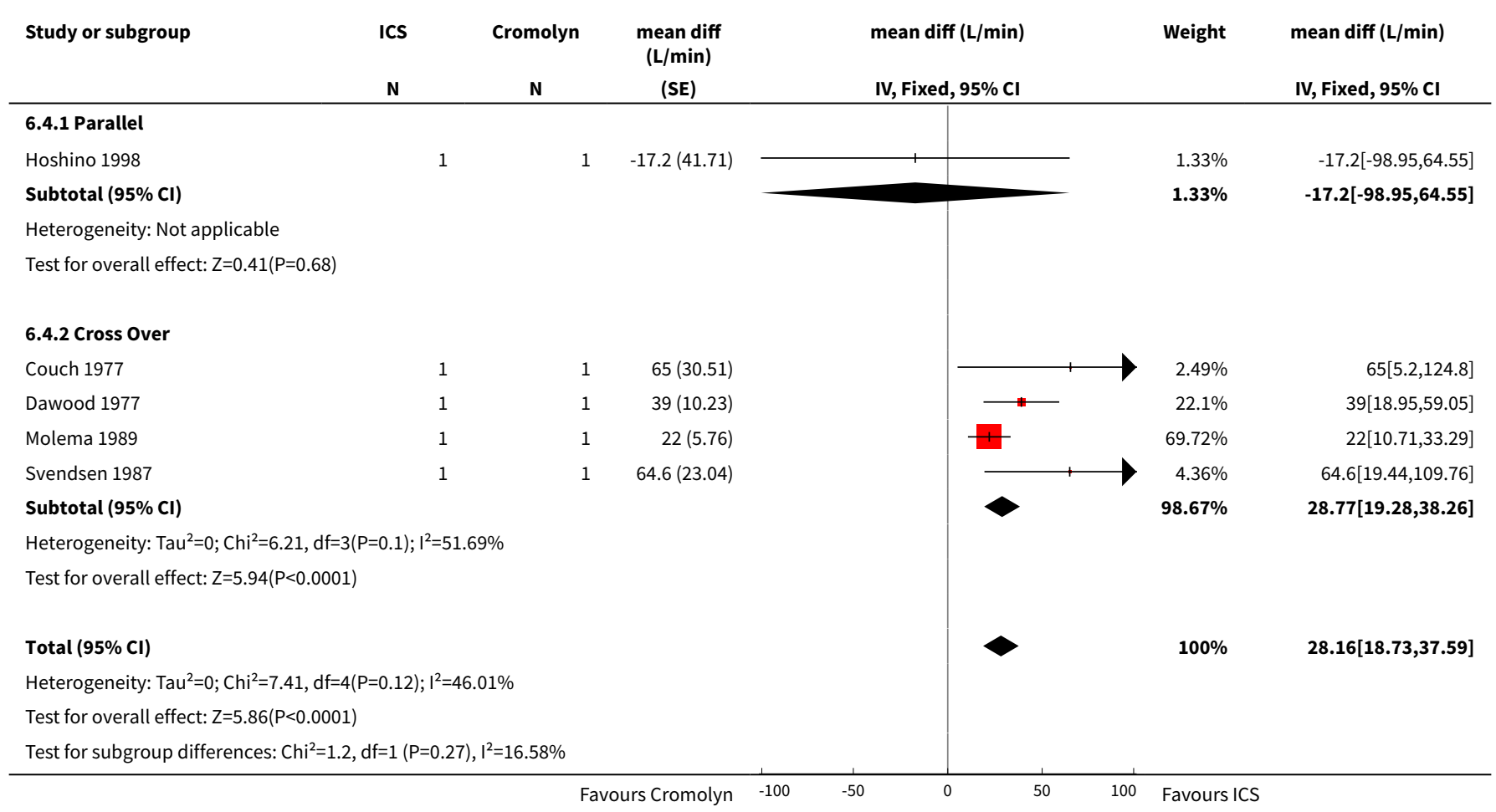


Analysis 6.5. Comparison 6 Inhaled Corticosteroids vs Cromolyn for Adults, Outcome 5 Asthma Symptom Score(GIV).

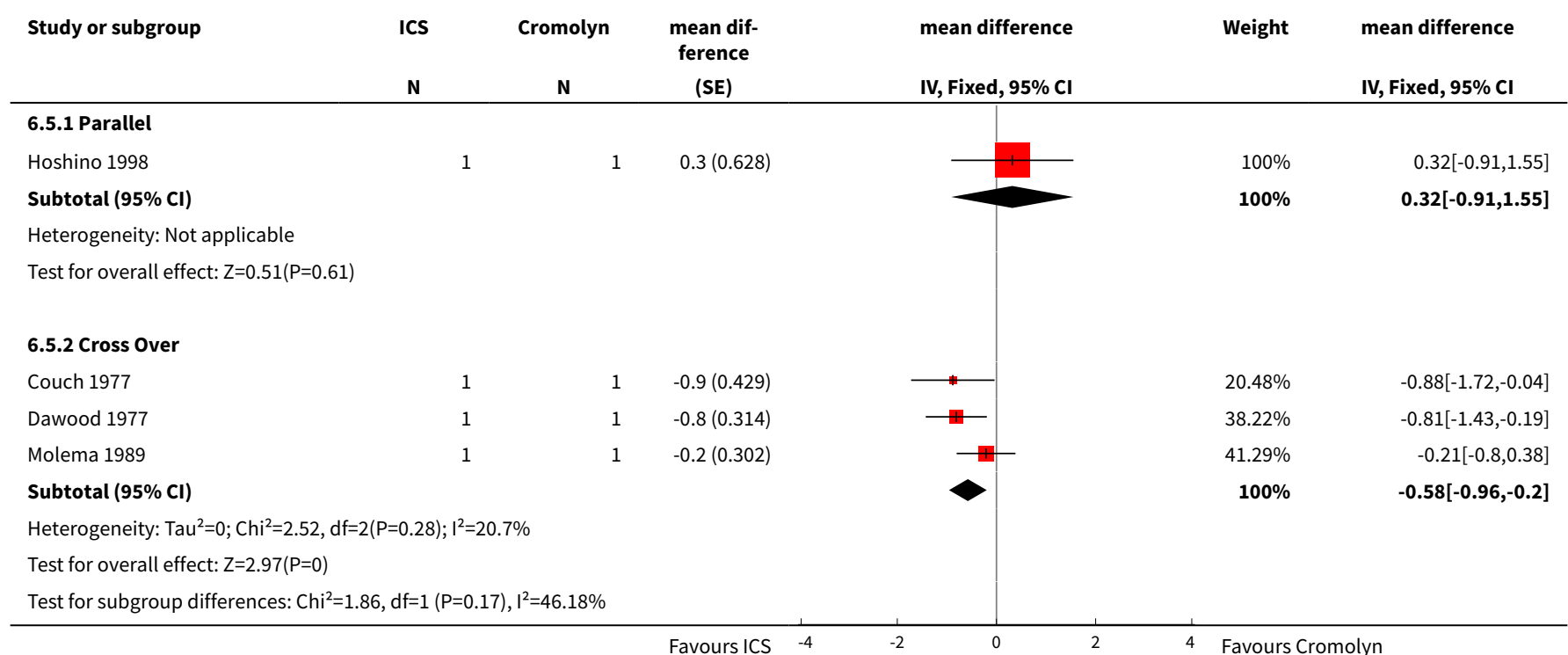

Analysis 6.6. Comparison 6 Inhaled Corticosteroids vs Cromolyn for Adults, Outcome 6 Rescue Bronchodilator Use (GIV).

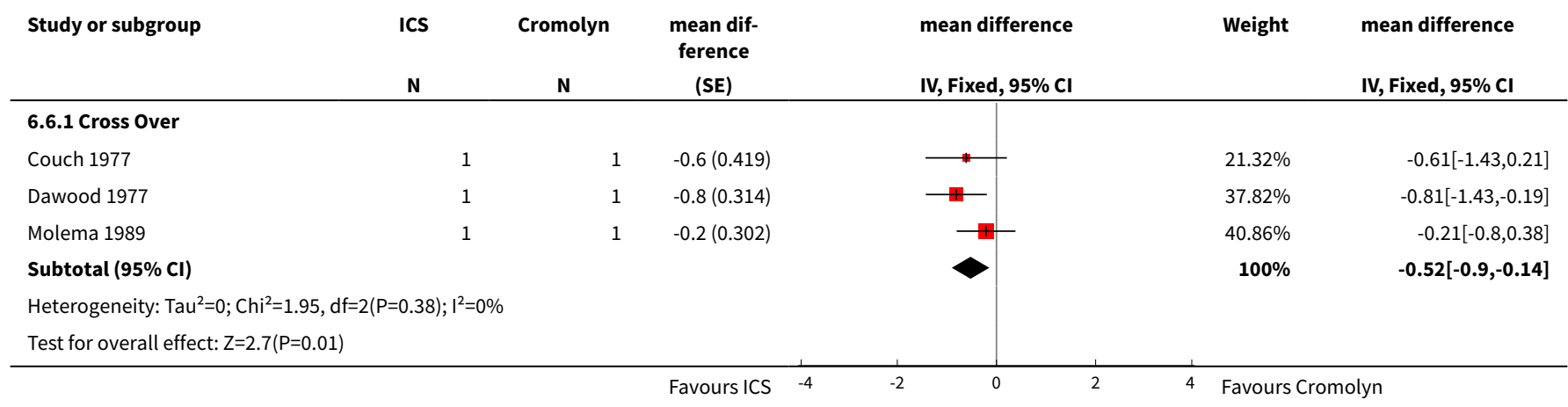

Analysis 6.7. Comparison 6 Inhaled Corticosteroids vs Cromolyn for Adults, Outcome 7 Oropharyngeal Side Effects (\%).

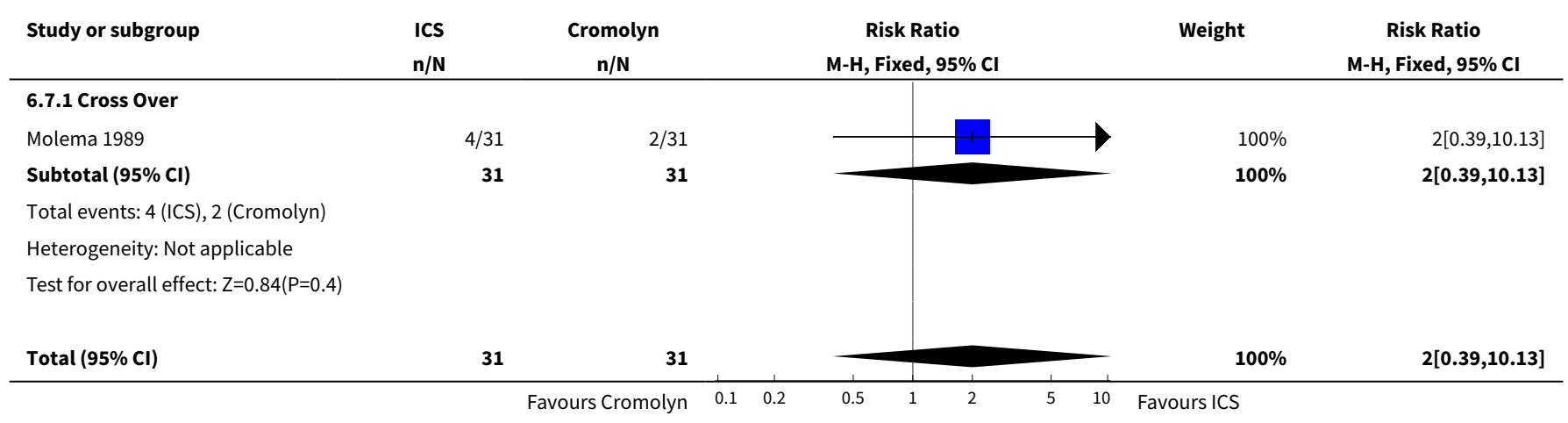




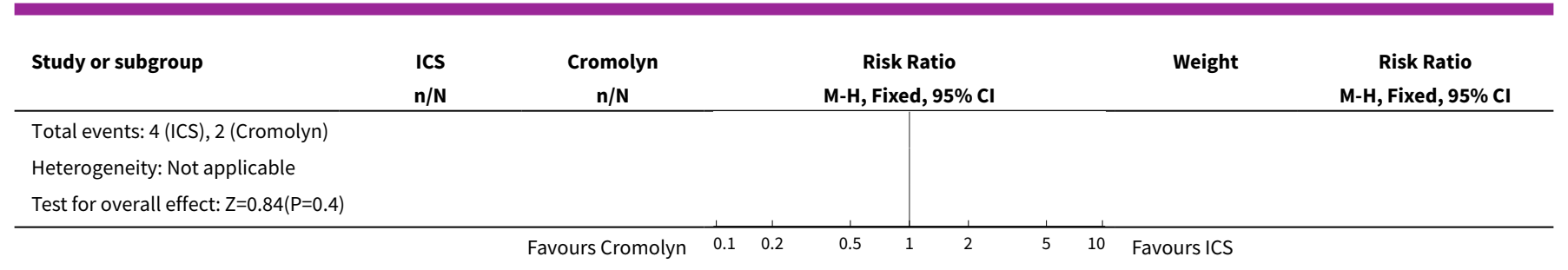

Analysis 6.8. Comparison 6 Inhaled Corticosteroids vs Cromolyn for Adults, Outcome 8 Total Adverse Events (\%).

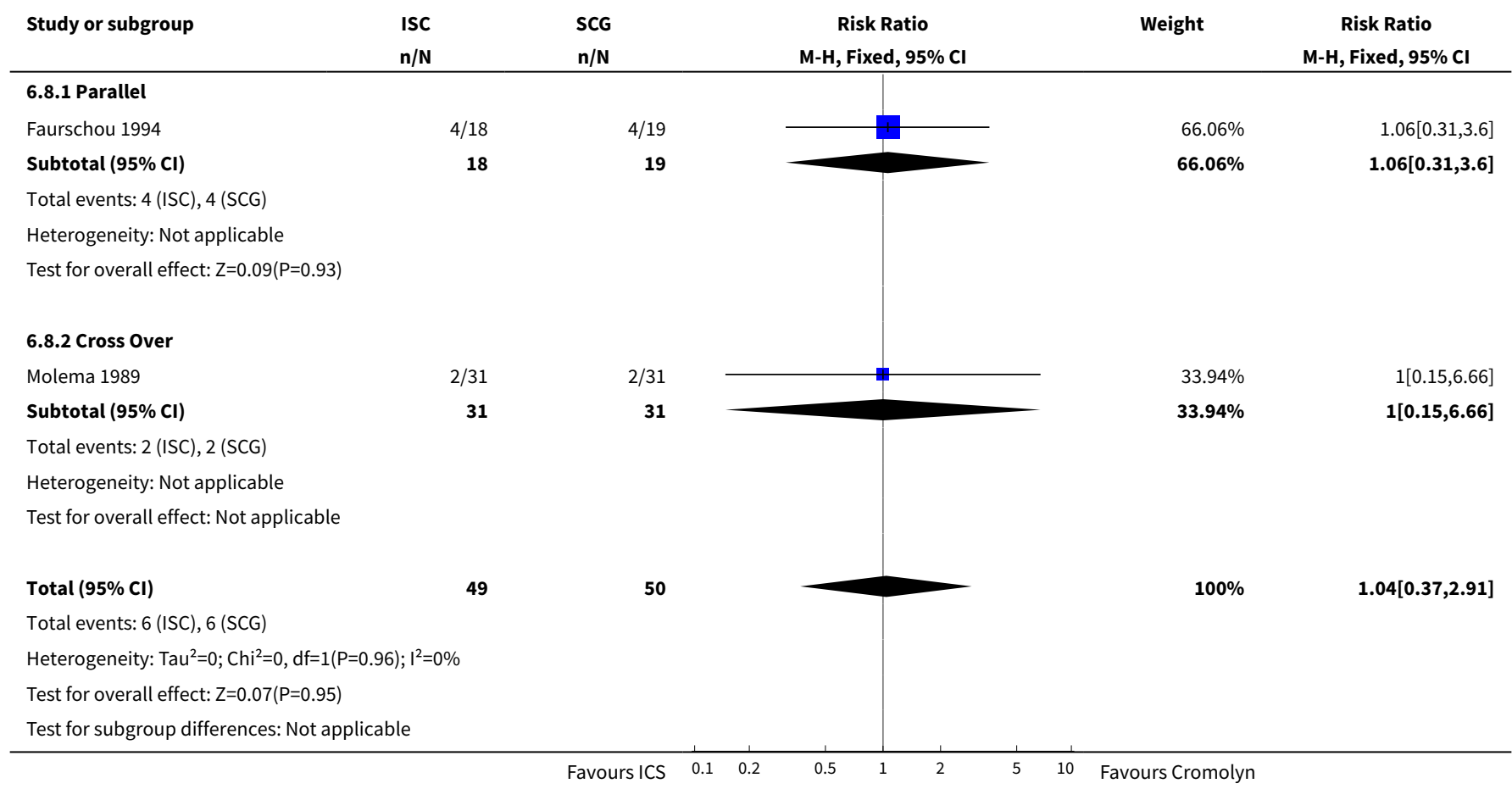

\section{Comparison 7. Inhaled Corticosteroids vs Cromolyn for Adults by Asthma Severity}

\begin{tabular}{lllll}
\hline Outcome or subgroup title & $\begin{array}{l}\text { No. of } \\
\text { studies }\end{array}$ & $\begin{array}{l}\text { No. of } \\
\text { partici- } \\
\text { pants }\end{array}$ & Statistical method & Effect size \\
\hline 1 FEV1(GIV) & 7 & mean difference (L) (Fixed, 95\% Cl) & Subtotals only \\
\hline 1.1 Mild-Moderate & 4 & mean difference (L) (Fixed, 95\% Cl) & $0.15[0.06,0.23]$ \\
\hline 1.2 Moderete-Severe & 2 & mean difference (L) (Fixed, 95\% Cl) & $0.32[0.18,0.45]$ \\
\hline 1.3 Not Reported & 1 & mean difference (L) (Fixed, 95\% Cl) & $0.38[0.07,0.69]$ \\
\hline 2 PEF(GIV) & 5 & mean diff (L/min) (Fixed, 95\% Cl) & Subtotals only \\
\hline 2.1 Mild-Moderate & 2 & mean diff (L/min) (Fixed, 95\% Cl) & $35.81[16.34,55.28]$ \\
\hline
\end{tabular}




\begin{tabular}{lllll}
\hline Outcome or subgroup title & $\begin{array}{l}\text { No. of } \\
\text { studies }\end{array}$ & $\begin{array}{l}\text { No. of } \\
\text { partici- } \\
\text { pants }\end{array}$ & Statistical method & Effect size \\
\hline 2.2 Moderate-Severe & 2 & & mean diff $(\mathrm{L} / \mathrm{min})($ Fixed, 95\% Cl) & $23.48[12.39,34.57]$ \\
\hline 2.3 Not Reported & 1 & mean diff $(\mathrm{L} / \mathrm{min})($ Fixed, 95\% Cl) & $64.6[19.44,109.76]$ \\
\hline
\end{tabular}

Analysis 7.1. Comparison 7 Inhaled Corticosteroids vs Cromolyn for Adults by Asthma Severity, Outcome 1 FEV1(GIV).

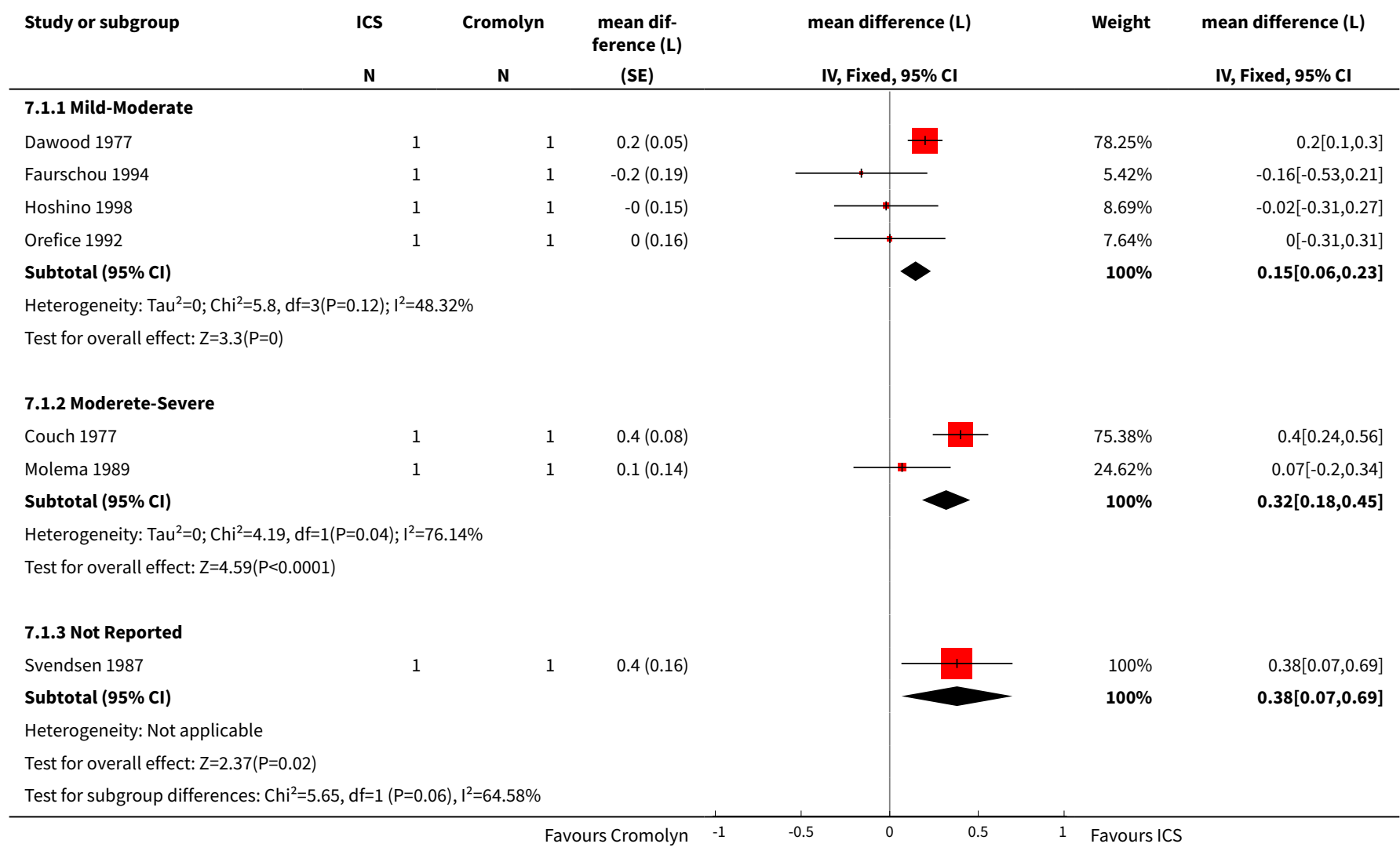

Analysis 7.2. Comparison 7 Inhaled Corticosteroids vs Cromolyn for Adults by Asthma Severity, Outcome 2 PEF(GIV).

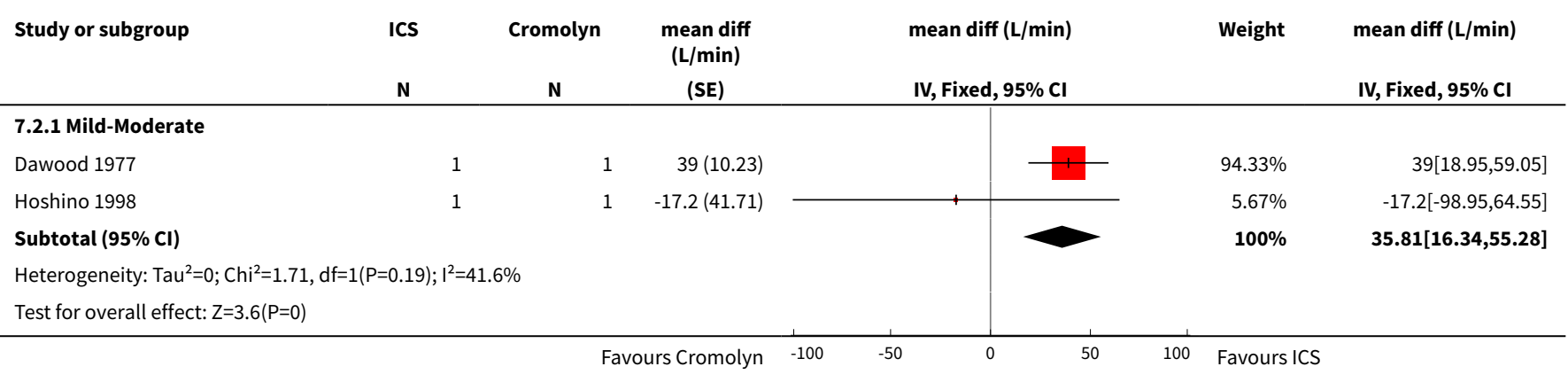




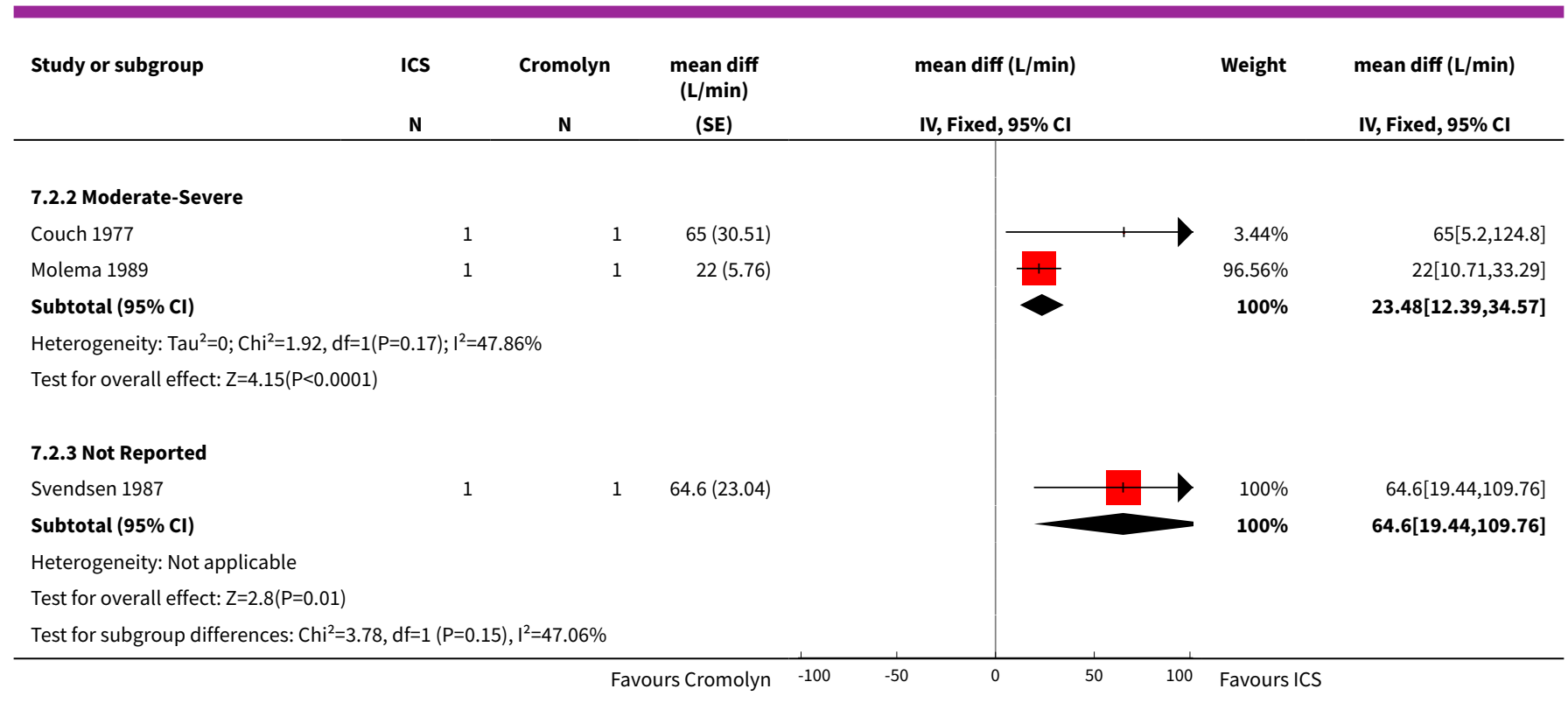

\section{Comparison 8. Inhaled Corticosteroids vs Cromolyn for Adults by Study Quality}

\begin{tabular}{lllll}
\hline Outcome or subgroup title & $\begin{array}{l}\text { No. of } \\
\text { studies }\end{array}$ & $\begin{array}{l}\text { No. of } \\
\text { partici- } \\
\text { pants }\end{array}$ & Statistical method & Effect size \\
\hline 1 FEV1(GIV) & 7 & mean difference (L) (Fixed, 95\% Cl) & Subtotals only \\
\hline 1.1 With Quality Score 1 or 2 & 2 & mean difference (L) (Fixed, 95\% Cl) & $-0.01[-0.22,0.20]$ \\
\hline 1.2 With Quality Score 3, 4 or 5 & 5 & mean difference (L) (Fixed, 95\% Cl) & $0.23[0.16,0.31]$ \\
\hline 2 PEF(GIV) & 5 & mean diff (L/min) (Fixed, 95\% Cl) & Subtotals only \\
\hline 2.1 With Quality Score 1 or 2 & 1 & mean diff (L/min) (Fixed, 95\% Cl) & $-17.2[-98.95,64.55]$ \\
\hline 2.2 With Quality Score 3, 4 or 5 & 4 & mean diff (L/min) (Fixed, 95\% Cl) & $28.77[19.28,38.26]$ \\
\hline
\end{tabular}

Analysis 8.1. Comparison 8 Inhaled Corticosteroids vs Cromolyn for Adults by Study Quality, Outcome 1 FEV1(GIV).

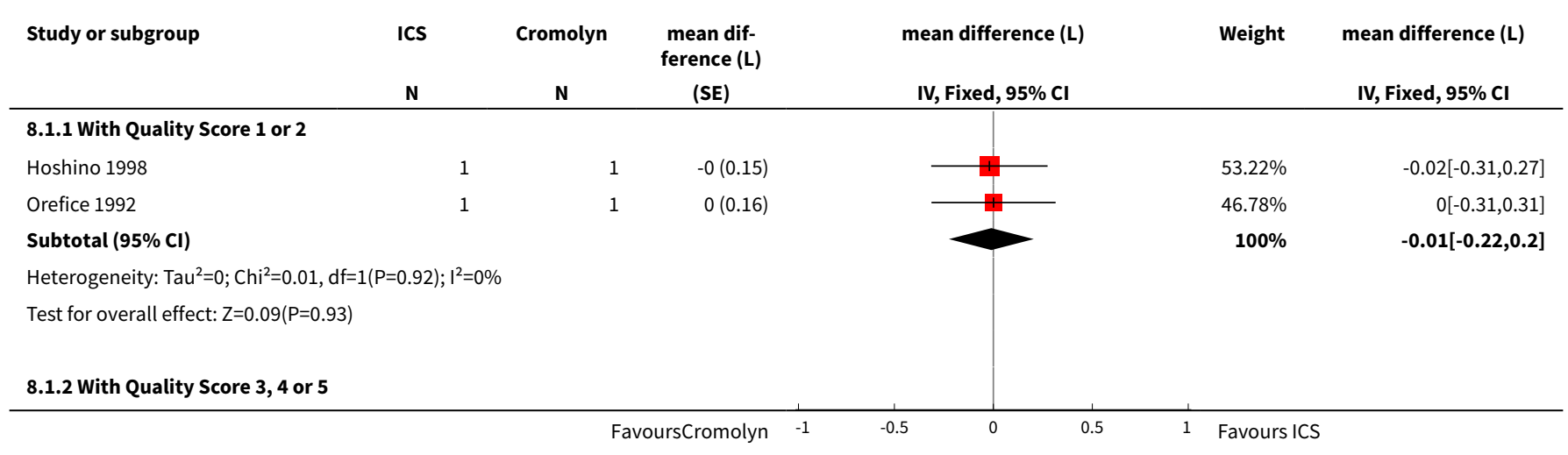




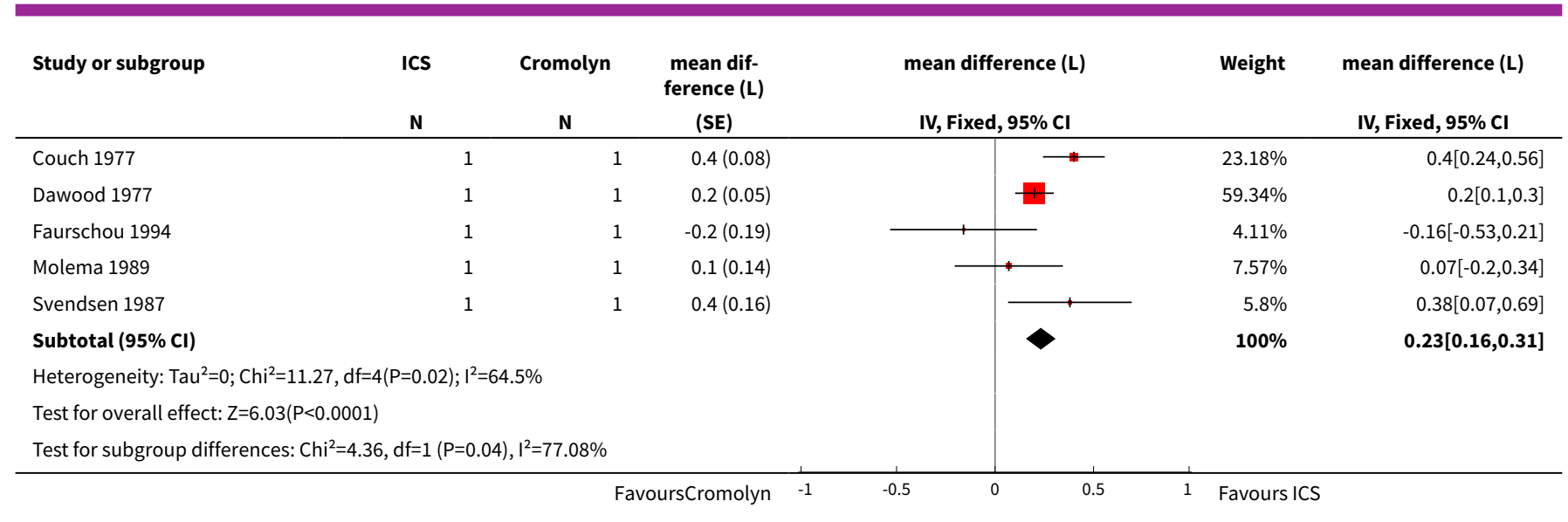

Analysis 8.2. Comparison 8 Inhaled Corticosteroids vs Cromolyn for Adults by Study Quality, Outcome 2 PEF(GIV).

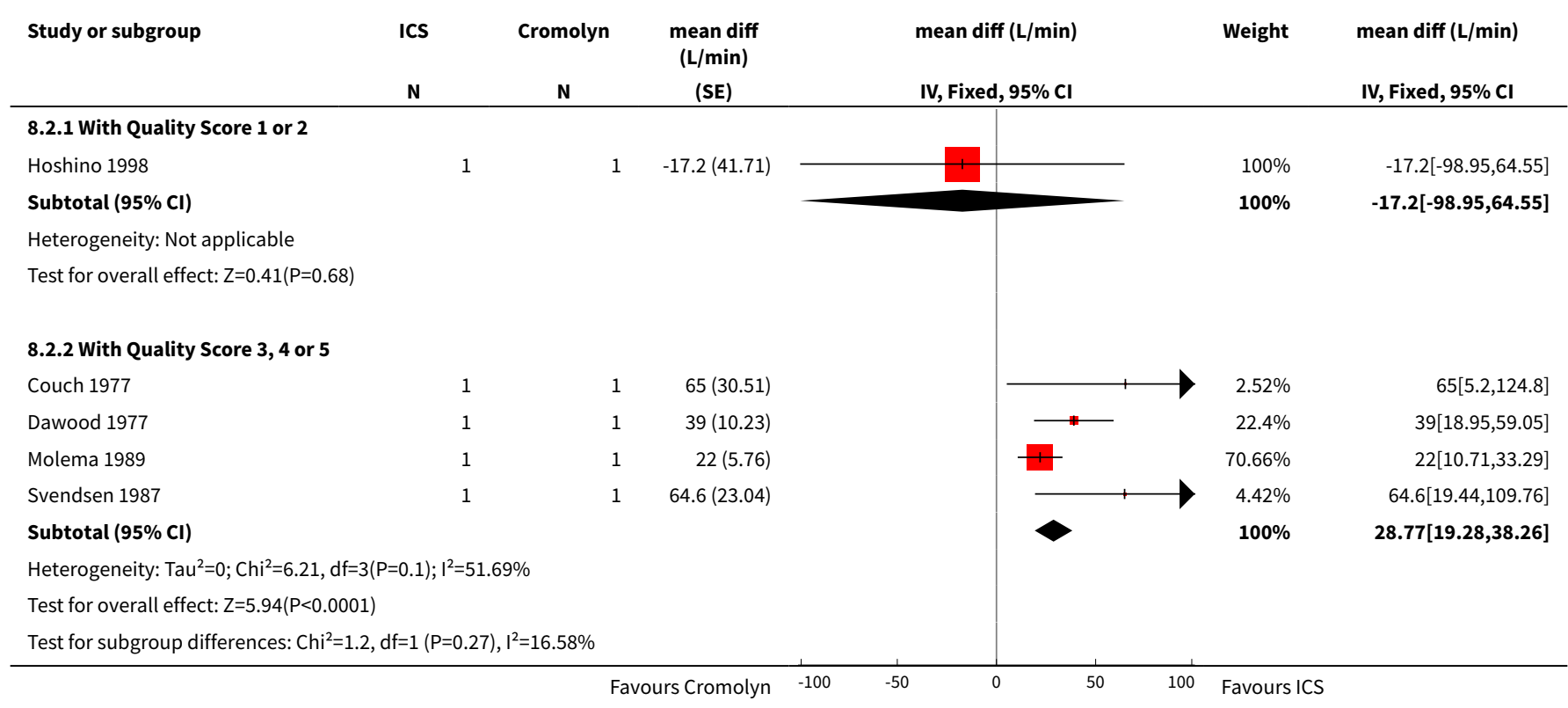

\section{Comparison 9. Inhaled Corticosteroids vs Cromolyn for Adults by Cromolyn Dosage}

\begin{tabular}{lllll}
\hline $\begin{array}{l}\text { Outcome or subgroup } \\
\text { title }\end{array}$ & $\begin{array}{l}\text { No. of } \\
\text { studies }\end{array}$ & $\begin{array}{l}\text { No. of } \\
\text { partici- } \\
\text { pants }\end{array}$ & Statistical method & Effect size \\
\hline 1 FEV1(GIV) & 7 & mean difference (L) (Fixed, 95\% Cl) & Subtotals only \\
\hline 1.1 Optimal & 2 & mean difference (L) (Fixed, 95\% Cl) & $0.26[0.17,0.34]$ \\
\hline 1.2 Sub-optimal & 5 & mean difference (L) (Fixed, 95\% Cl) & $0.07[-0.07,0.20]$ \\
\hline 2 PEF(GIV) & 5 & mean diff (L/min) (Fixed, 95\% Cl) & Subtotals only \\
\hline 2.1 Optimal & 2 & mean diff (L/min) (Fixed, 95\% Cl) & $41.63[22.62,60.64]$ \\
\hline \hline
\end{tabular}




\begin{tabular}{lllll}
\hline $\begin{array}{l}\text { Outcome or subgroup } \\
\text { title }\end{array}$ & $\begin{array}{l}\text { No. of } \\
\text { studies }\end{array}$ & $\begin{array}{l}\text { No. of } \\
\text { partici- } \\
\text { pants }\end{array}$ & Statistical method & Effect size \\
\hline 2.2 Sub-optimal & 3 & & mean diff $(\mathrm{L} / \mathrm{min})($ Fixed, $95 \% \mathrm{Cl})$ & $23.77[12.92,34.63]$ \\
\hline
\end{tabular}

Analysis 9.1. Comparison 9 Inhaled Corticosteroids vs Cromolyn for Adults by Cromolyn Dosage, Outcome 1 FEV1(GIV).

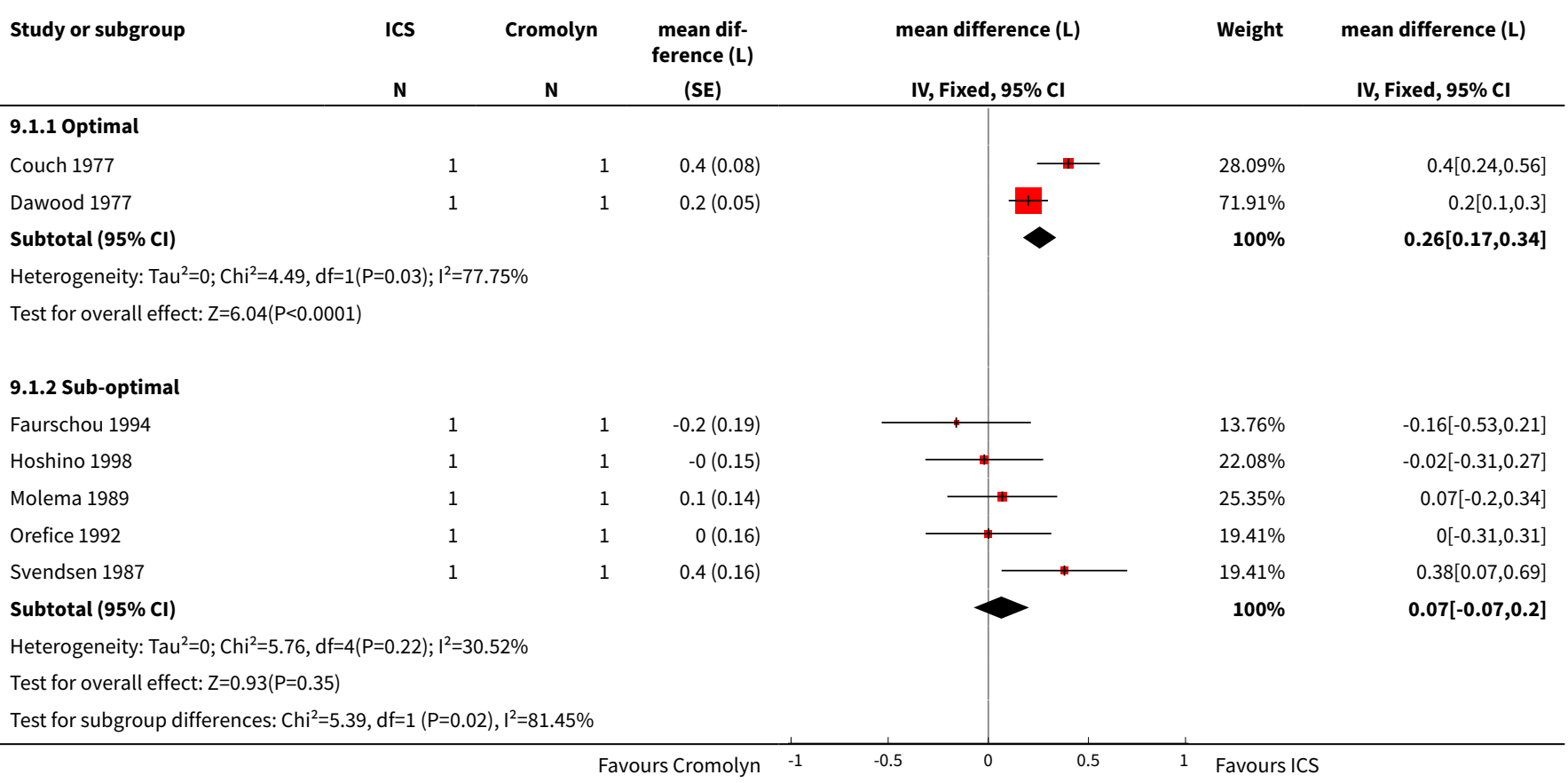

Analysis 9.2. Comparison 9 Inhaled Corticosteroids vs Cromolyn for Adults by Cromolyn Dosage, Outcome 2 PEF(GIV).

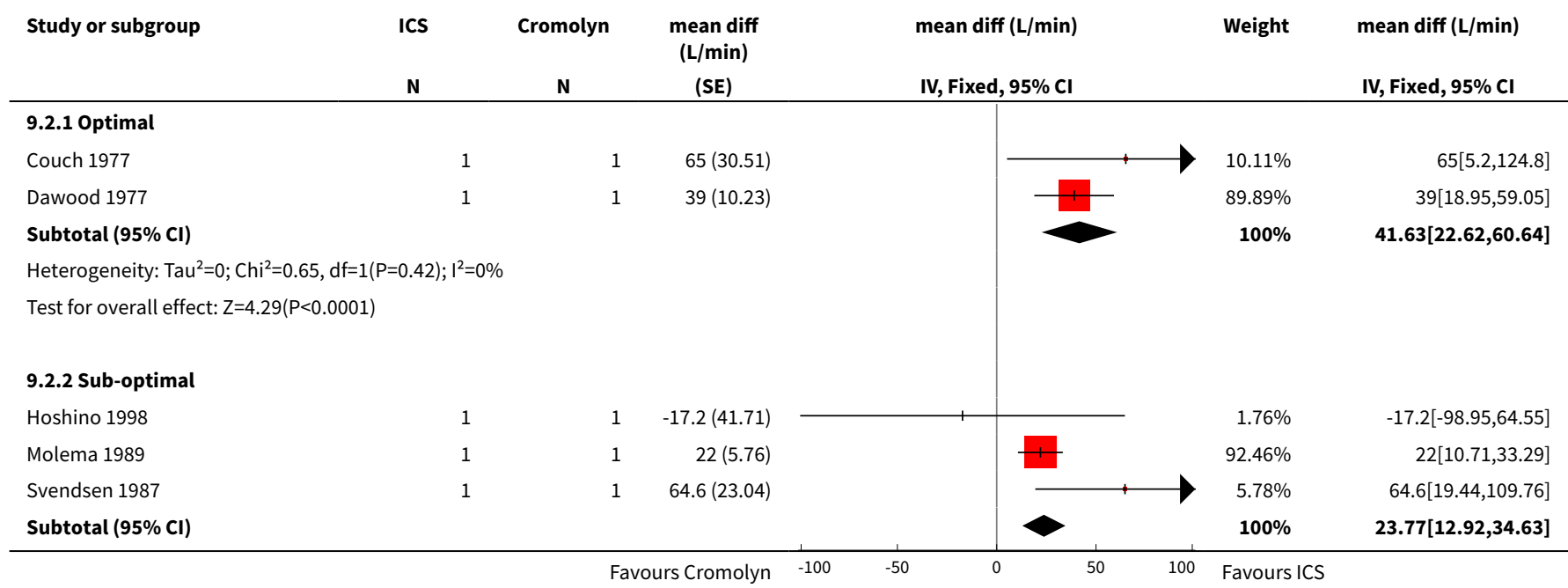




\begin{tabular}{lccccc} 
Study or subgroup & ICS & Cromolyn & $\begin{array}{c}\text { mean diff } \\
(\mathrm{L} / \mathrm{min})\end{array}$ & mean diff (L/min) \\
& $\mathrm{N}$ & $\mathrm{N}$ & (SE) & IV, Fixed, $95 \% \mathrm{Cl}$ & IVean diff (L/min) \\
\hline
\end{tabular}

Heterogeneity: $\mathrm{Tau}^{2}=0 ; \mathrm{Chi}^{2}=4.2, \mathrm{df}=2(\mathrm{P}=0.12) ; \mathrm{I}^{2}=52.38 \%$

Test for overall effect: $Z=4.29(P<0.0001)$

Test for subgroup differences: $\mathrm{Chi}^{2}=2.56, \mathrm{df}=1(\mathrm{P}=0.11), \mathrm{I}^{2}=60.88 \%$

$\begin{array}{lllllll}\text { Favours Cromolyn } & -100 & -50 & 0 & 50 & 100 & \text { Favours ICS }\end{array}$

\section{ADDITIONAL TABLES}

Table 1. Meta-Regression Module for FEV1(children)

\begin{tabular}{lll}
\hline & Coefficient & $\mathbf{9 5 \%} \mathbf{C l}$ \\
\hline ICS dose & 0.16 & $-0.01,0.34$ \\
\hline Jadad Score & 0.06 & $-0.10,0.23$ \\
\hline Constant & -0.00 & $-0.16,0.16$ \\
\hline Asthma Severity & Dropped & \\
\hline
\end{tabular}

Table 2. Meta-Regression Module for PEF(children)

\begin{tabular}{lll}
\hline & Coefficient & $\mathbf{9 5 \%} \mathbf{C l}$ \\
\hline Asthma Severity & 16.26 & $-16.22,48.75$ \\
\hline ICS dose & 28.20 & $6.07,50.33$ \\
\hline Jadad Score & -6.06 & $-145.85,133.74$ \\
\hline Constant & 19.80 & $-120.35,159.94$ \\
\hline
\end{tabular}

Table 3. Meta-Regression Module for FEV1 (adults)

\begin{tabular}{lll} 
& Coefficient & $\mathbf{9 5 \%} \mathbf{C l}$ \\
\hline Asthma Severity & 0.16 & $-0.01,0.32$ \\
\hline Jadad Score & 0.19 & $-0.05,0.42$ \\
\hline Constant & -0.01 & $-0.22,0.20$ \\
\hline
\end{tabular}

Table 4. Meta-Regression Module for PEF(adults) 
Table 4. Meta-Regression Module for PEF(adults) (Continued)

\begin{tabular}{lcc} 
Asthma Severity & -15.52 & $-38.44,7.40$ \\
\hline Jadad Score & 56.20 & $-27.97,140.37$ \\
\hline Constant & -17.20 & $-98.94,64.54$ \\
\hline
\end{tabular}

WHAT'S NEW

\begin{tabular}{lll}
\hline Date & Event & Description \\
\hline 28 July 2008 & Amended & Converted to new review format. \\
\hline
\end{tabular}

\section{HISTORY}

Protocol first published: Issue 3, 2002

Review first published: Issue 2, 2006

\begin{tabular}{lll}
\hline Date & Event & Description \\
\hline 14 February 2006 & $\begin{array}{l}\text { New citation required and conclusions } \\
\text { have changed }\end{array}$ & Substantive amendment \\
\hline
\end{tabular}

\section{CONTRIBUTIONS OF AUTHORS}

JG designed the protocol, participated in the review of eligible papers, participated in and oversaw the abstraction of data, participated in and oversaw the analysis, and wrote the review.

RK participated in the protocol design, participated in the review of eligible papers, and assisted in writing the review.

SN participated in the review of eligible papers, participated in the abstraction and analysis of data, and assisted in writing the review. JZ participated in the protocol design, participated in the review of eligible papers, and assisted in writing the review.

\section{DECLARATIONS OF INTEREST}

None known.

\section{INDEX TERMS}

\section{Medical Subject Headings (MeSH)}

Administration, Inhalation; Adrenal Cortex Hormones [ ${ }^{*}$ therapeutic use]; Anti-Asthmatic Agents [ ${ }^{*}$ therapeutic use]; Asthma [ ${ }^{*}$ drug therapy]; Cromolyn Sodium [ ${ }^{\star}$ therapeutic use]; Glucocorticoids [therapeutic use]; Randomized Controlled Trials as Topic

\section{MeSH check words}

Adolescent; Adult; Child; Humans 